\title{
CLASSICAL EPIC IN THE WORKS OF J.R.R. TOLKIEN
}

\author{
By
}

Hannah Parry

A thesis submitted to Victoria University of Wellington in fulfilment of the requirement for the degree of Master of Arts in English

Victoria University of Wellington

February 2012 


\begin{abstract}
$\underline{\text { Abstract }}$
The Lord of the Rings has often been described as an 'epic', and although Tolkien drew most famously on Northern mythology in his creation of Middle-earth much of his work also bears similarities to classical epic, both with regard to particular characters and archetypes and to more general themes and motifs. This thesis examines the connections between The Lord of the Rings and the epics of Homer and Virgil, investigating the manner in which these allusions function in Tolkien and how they contribute to our understanding of Middleearth as at least partially an epic world with epic ideals of heroism. At the same time, however, it identifies the ways in which Tolkien changes or subverts such classical ideals and archetypes as they combine with other cultural influences.
\end{abstract}

Following the model established in The Hobbit, The Lord of the Rings begins with the folk-tale heroes and setting of the Shire before gradually moving into an epic world. Not only heroes such as Aragorn, but less obviously epic heroes such as Gandalf, Frodo and Sam, draw frequently on the iconography and motifs associated with specific and general classical figures, while women such as Arwen, Eowyn and Galadriel can similarly be read as part of classical tradition. Moreover, despite the purely fictional nature of Middle-earth in contrast to the historical (if mythologised) cultures of classical epic, The Lord of the Rings contains many examples of epic type-scenes that in classical epic illustrate the correct manner in which a hero should behave both in peace and in battle. The Lord of the Rings' relationship to epic is complex, however, not only employing these heroic and epic conventions but also subverting or superseding them as Tolkien engages with the problems of classical motifs within a very different universe. The heroes and heroines of The Lord of the Rings must navigate codes of behaviour both classical and non-classical, and willingly relinquish those out of place in the new age being born around them.

This tension between old and new codes of behaviour is made more explicit during the book's twin 'returns', that of Aragorn to Minas Tirith and the hobbits to the Shire. Although these continue to draw extensively on classical predecessors, most notably Aeneas' prophesised arrival in Latium and Odysseus' famous homecoming, these predecessors are also superseded as Middle-earth moves into the Fourth Age. While The Hobbit moves from folk tale to epic and back again, The Lord of the Rings moves from folk-tale to epic to somewhere "beyond the epic" (Flieger 145), and as the book draws to its elegiac conclusion pure classical values become increasingly supplanted by the book's own heroic code, influenced by many heroic traditions and overwhelmingly by Tolkien's Catholic beliefs. In the end, The Lord of the Rings can perhaps be read as an epic about the passing of epic, and thus an epic for the modern world. 


\section{$\underline{\text { Acknowledgements }}$}

Thanks to Geoff Miles for his supervision of this thesis. 


\section{Table of Contents}

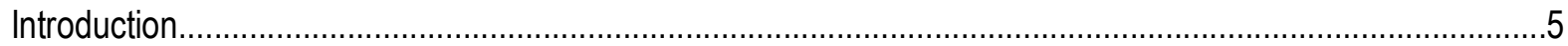

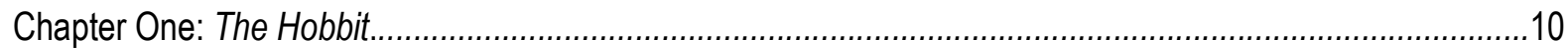

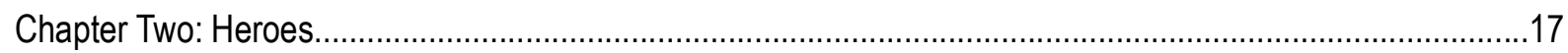

"Unlike They Were, Yet Also Much Akin": Boromir, Faramir and Epic Heroism..................................17

"Strider and Dunadan Too": Aragorn, Odysseus and Aeneas.........................................................23

"As an Old Man Hooded and Cloaked": Gandalf, Saruman and Odysseus.......................................28

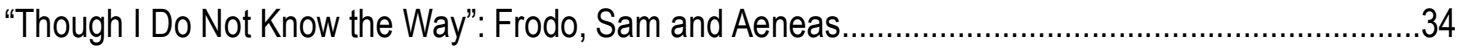

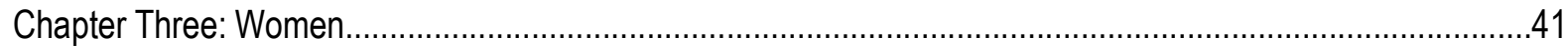

Evenstar of Her People and Morning of Pale Spring: Arwen and Eowyn............................................41

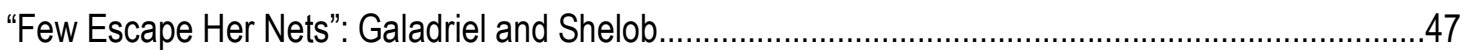

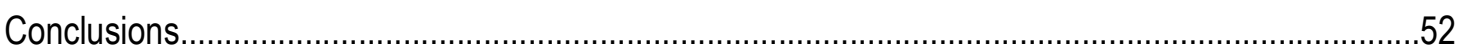

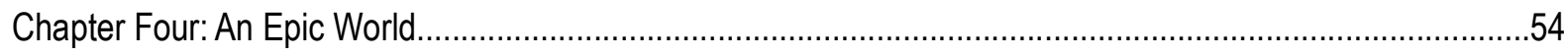

Meeting Your Match in Courtesy: Hospitality in Middle-earth.....................................................54

"The Glory You Reap Shall Be Yours Forever": Warfare...........................................................61

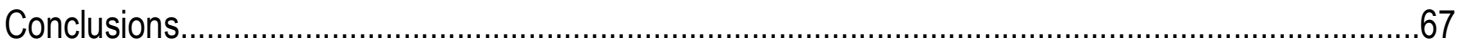

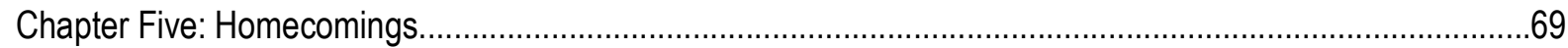

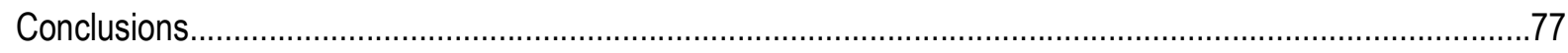

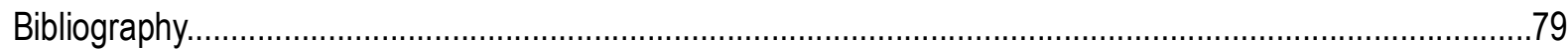




\section{INTRODUCTION}

In his book The Epic, Paul Merchant refers to Tolkien's "conscious use of epic" (76), wherein his narrative "take[s] the form of a massive journey and employ[s] a host of characters, some heroic, some darker and more monstrous" (76). Merchant is not alone in equating Tolkien with epic, and many Tolkien scholars have done the same either by implication (Kocher's essay "Middle-earth: An Imaginary World?" refers to The Lord of the Rings as an "epic" throughout, while Isaacs and others comment in passing on the book's "epic structure" (7)) or in more detail (Jane Chance's "The Lord of the Rings: Tolkien's Epic", for example, examines the ideals of Christian and Germanic epic as a source for the moral system of Tolkien's "epic novel" (197)). In the former cases, the application of the term to The Lord of the Rings is often symptomatic of what seems to be a common problem in assigning a genre to the book rather than a serious argument for the book as epic: a single collection of Tolkien criticism sees it referred to not only as an epic but as a romance (Lewis; Zimbardo), a fairy tale (Fuller, Reilly), a "Quest Tale" (Auden), and, perhaps most accurately but least neatly, a derivation from fairy tale, epic, and romance (Flieger). Most of those who, like Chance, have examined The Lord of the Rings' connection to the epic genre have naturally tended to do so in terms of the Germanic, Christian and Icelandic heroic traditions that were Tolkien's area of scholarship. There have also been attempts to link The Lord of the Rings to individual classical epics, particularly Virgil's Aeneid. Among the most sustained of these are Morse's book Evocation of Virgil in Tolkien's Art: Geritol for the Classics, which draws parallels between the characters, themes and specific images found in both The Lord of the Rings and Virgil's Aeneid, Obertino's "Moria and Hades: Underworld Journeys in Virgil and Tolkien", which offers a psycho-analytical reading comparing Frodo's journey through Moria with Aeneas' through Hades, and Reckford's "Some Trees in Virgil and Tolkien", which examines the similarities between Tolkien's and Virgil's world-views. Few, however, have examined the book explicitly in terms of the traditions and archetypes of classical epic.

Although Tolkien himself did not use the term 'epic' to refer to any of his published works - in fact, it seems a term of which he was wary, preferring to describe Anglo-Saxon epic Beowulf as an "heroic-elegiac poem" ("Beowulf" 31) - he was certainly familiar with the genre in the form of Homer and Virgil, citing Homer in particular as his first discovery of "the sensation of literary pleasure" (Letters 172), and in many ways The Lord of the Rings can be seen as part of the epic tradition, classical and otherwise. While not always adhering to epic form in conventional ways, the book none-the-less engages with several key features of the genre, most notably in terms of subject matter; "high seriousness and elevated style" (Griffin 21); scope and episodic structure; an "awareness of historical perspective" (Merchant 2) and the use of song and poetry to "gloriffy] the deeds and destinies of great heroes" (Griffin 13) within this history.

At many points, of course, the style and subject matter of The Lord of the Rings is not - even in the modern 
sense of the word - "epic" at all. While Tolkien was specifically drawing on his background knowledge of ancient texts and mythologies, he was not drawing wholly on any one particular form but aimed to include in The Lord of the Rings a combination of "the colloquialism and vulgarity of Hobbits, poetry and the highest style of prose" (Letters 160), and the world of the hobbits in particular bears little resemblance to the world of "the glorious deeds of men of old and the blessed gods who inhabit Olympus" that Griffin cites (paraphrasing Hesiod's Theogony) as the subject for Greek epic (16). The language in the early sections of the book, as with many of the passages dealing with hobbit-kind, is indeed "colloquial": the opening sentence, "When Mr Bilbo Baggins of Bag End announced he would shortly be celebrating his eleventy-first birthday with a party of special magnificence, there was much talk and excitement in Hobbiton" (21), is hardly an Homeric proem, and its subject is hardly the rage or sufferings of an Homeric hero. Similarly, the hobbits themselves, though undeniably heroic, are far from Homeric heroes: Flieger identifies Frodo in particular as a "fairy-tale hero... a little man both literally and figuratively" (124), and the perils suffered early in the quest, including an enchanted forest, are suited to his stature as such. While such folk-tale or fairy-tale elements are not necessarily excluded from the epic genre (the Cyclops episode from the Odyssey, as Peretti and others have pointed out, is an archetypal folk-tale), the overall effect is very different from that of classical epic.

However, though the four arguably most important major characters of The Lord of the Rings are far more similar to the archetypes of a folk-tale or fairy-story than to those of classical epic, the wider world in which they find themselves in increasingly begins to resemble that of Achilles or Aeneas. Several of the features Martin identifies as typical of conventional definitions of ancient epic - most notably cosmic scale, serious purpose, a setting in the distant past, the presence of heroic and supernatural characters and plots pivoting on wars or quests (10) - could almost be written to describe the unfolding plot of The Lord of the Rings. Described by Tolkien's Foreword as "a history of the Great War of the Ring" (xv), the scale of the work encompasses not only a war spanning an entire invented world but also "glimpses of the yet more ancient history that preceded it" (xv), and includes many instances of "praise of the serious" (Martin 10) in its depiction of epic-style battles and heroic deeds. Like Greek epic, The Lord of the Rings is set in and nostalgic for an "heroic past" (Griffin 16) where men are closer to supernatural beings (in this case Elves, Ents and Wizards rather than gods), and as with Virgil's Aeneid we witness the transition into an era closer to our own as the end of the text sees Aragorn establish a "new age [that] preserve[s] the memory and the glory of the years that were gone" (947). Heroic and supernatural characters, whose "deeds and destinies" are "glorified" in the manner Griffin allies with Greek epic (13), are evident throughout the text - Aragorn in particular is "a traditional epic/romance hero, larger than life, a leader, fighter, lover, healer" (Flieger 124) - while the labyrinthine plot centres around a war and a quest, both aimed at the destruction of a supernatural threat. If The Lord of the Rings is often, as Tolkien said of The Hobbit, the story of "simple ordinary man, neither artistic or noble or heroic... against a high setting" (Letters 159), that "high setting" is one that contains a striking number of 
archetypal epic features.

Although the presence of such features does not, as Martin points out, automatically constitute an epic, the treatment of this epic subject matter often evokes that of Homer or Virgil (as well as Anglo-Saxon and Norse mythological texts). Tolkien's use of the phrase "the highest style of prose" is interesting, mirroring as it does the "high seriousness and elevated style" (Griffin 21) identified as a feature of the epic genre by both Tillyard and Griffin, and indeed the language used in Tolkien's treatment of the "high" elements of The Lord of the Rings would not be out of place in classical or Anglo-Saxon epic. Moreover, perhaps due largely to Tolkien's desire to blend "all the elements and motives of what has preceded it" (Letters 160) within the book, The Lord of the Rings also has the "amplitude, breadth [and] inclusiveness" (6) Tillyard identifies as a requirement of true epic. Drawing on Aristotle's definition of epic in opposition to tragedy, which focusses on a single event befalling a small group of people, Tillyard claims epic possesses a "greater amplitude" (6) and scope, and The Lord of the Rings features multiple heroes and plot-lines within a story-line that encompasses at least six major cultures. Its combination of folk-tale hobbits and great heroes exemplifies what Tillyard saw as the ideal trait of an epic writer, the ability to "range from the simple sensualities to a susceptibility to the numinous" (8): where Homer demonstratates this ability through comparisons of great, even "numinous", subjects with homelier ones through simile, Tolkien incorporates both within the narrative. As a result, the book also utilises an episodic structure compared by Rosebury to that of Homer's Odyssey (26), as the narrative follows numerous characters across the varied cultures of Middle-earth much as the narrative of that epic follows Odysseus across the ancient Mediterranean seas.

Where The Lord of the Rings seems to deviate most from conventional epic is in its wholly imaginary setting. Although Merchant describes Middle-earth as a "world not far distant from that of the Nibelungenlied" (76), it in fact differs from the settings of traditional ancient epic in that it is lacking, as Griffin defines it, a dimension of established history to blend with invention (17). Despite existing in a world plagued with monsters, divinities and the supernatural, the heroes of classical epic none-the-less exist explicitly in the world of ancient Greece and Rome before the time of the poets, and were pre-existing mythological figures glorified as the listeners' "predecessors and, as they often believed, their ancestors" (Griffin 13). This sense of epic as part historical or even, as in the case of Virgil's Aeneid, etiological in that it provides an origin story for their civilisation, was crucial to the social and imaginative function of the form: Ezra Pound defines the entire epic genre simply as "a poem including history" (Merchant 1). By contrast, while there are hints that The Lord of the Rings' Middleearth is in fact our own world in a mythic past (hobbits are described in the prologue, as Kocher points out, as "relatives of ours" that "still linger [in] the North-West of the Old World, East of the Sea" now that the Third Age of Middle-earth is "long past, and the shape of all the lands has been changed" (2)), there is certainly no attempt to place the Third Age within the context of English history and Middle-earth possesses its own unique 
cosmogony and mythology. The heroes, cultures and events of The Lord of the Rings are Tolkien's own invention, with no basis in existing actual or even mythic history.

Despite this, however, the idea of the narrative taking place against the backdrop of history is at the heart of The Lord of the Rings. Tolkien himself refers to The Lord of the Rings and his other Middle-earth texts quite matter-of-factly as "history" throughout his writings and the Prologue and Appendixes cite invented ancient texts from which his information is compiled and translated, a characteristic Kocher identifies as a "standard literary pose ... that he did not himself invent the subject matter of his epic but is only a modern scholar who is compiling, editing and eventually translating copies of very ancient records of Middle-earth that have come into his hands" (148). Unlike many other instances of this literary pose, however, the "history" of Middle-earth long predates the writing of the book itself (Tolkien saw himself as writing in the tradition of texts "founded on an earlier matter which is put to new uses - like Homer, or Beowulf, or Virgil, or Greek and Shakespearean tragedy" (Letters 201)) and is not only meticulously developed but made a presence throughout the entire text. References are made throughout to "historical" figures and events, whether as background information, in fragments of poems and songs, or even worked into the texture of the story through formulaic simile (Théoden, for example, rides out "like a god of old, even as Orome the Great in the battle of the Valar when the world was young" (820)). Moreover, within the context of the invented world, the events of The Lord of the Rings can even be seen as performing the same historical function as those of Virgil's Aeneid. Where that epic depicts the origins of the Roman Empire with the defeat of Turnus and the prophesised installation of Aeneas and his descendents in Latium, The Lord of the Rings depicts the origins of the Fourth Age of Middle-earth with the defeat of Sauron and the prophesised installation of Aragorn and his descendents in Minas Tirith. Tolkien echoes Virgil's sense of the backdrop of history behind the events of epic, but gives the weight Virgil bestows on the origins of his own city to the history of a wholly imaginary world; a tactic perhaps entirely appropriate for an audience that no longer holds the same belief in a mythic past as did that of the ancient authors.

Moreover, the characters of the book echo the classical heroic attitude toward the glorification of history through epic (somewhat tempered by Tolkien's Christian sensibilities). Not only does epic entail an "awareness of historical perspective" (Merchant 2), but its heroes themselves possess an awareness of and respect for this oral history and actively seek a place within it. The social practice of "singing of men's fame" (II. 9.189) often occurs within epic narrative, taking the form of epic digressions in which the action of the epic is interrupted as tales sung by bards or told by other characters are summarised at length. Moreover, particularly in Homer, the heroes themselves actively seek immortalisation in heroic epic, motivated in battle by the gaining of kleos (fame requiring heroic deeds to be seen and made public) and the desire to "win excellent glory" (II. 18.121). As Merchant points out, both the Odyssey and the Aeneid see heroes witness their lives passing into legend within their own lifetimes: Odysseus hears the bard Demodocus "sing the famous actions / 
of.../ the quarrel between Odysseus and Peleus' son Achilles" (Od. 7.73-74) at the palace of King Alcinous, while Aeneas not only tells his own story before a court as Odysseus later does but upon his arrival in Carthage marvels at the depictions of the Trojan war - including "himself in combat / with the Achaean chiefs" (Aen. 1.690-691) - inscribed upon a temple to Juno. The narrative of The Lord of the Rings is similarly permeated with epic digressions, as minstrels and major characters alike chant tales of heroes from Middleearth's "history" such as Beren (187-189) and Earendil (227-230). Though, crucially, Tolkien's heroes are largely not motivated by a desire to "win excellent glory" (II. 18.121) (with the possible exception of the Rohirrim), they are aware of the potential for their deeds to be similarly immortalised in story: Sam muses upon the possibility of he and Frodo being "put into any songs or tales" (697), while Théoden seeks to "make such an end as will be worthy of a song" (527). Like Odysseus and Aeneas, Frodo and Sam live to hear themselves pass into oral history as they survive to witness a bard performing, "The Tale of Frodo of the Nine Fingers and the Rings of Doom". Interestingly, just as Odysseus sheds tears upon hearing the story of his own exploits and Aeneas views the images of his fallen city with "many tears and sighs" (Aen. 1.658), Sam upon hearing the heroic lay composed in his and Frodo's honour weeps to hear that "all [his] wishes have come true" (933).

Given The Lord of the Rings' connections with the epic form, this thesis will attempt to examine some of its similarities with classical epic in particular, both with regard to particular characters and archetypes and to more general themes and motifs. It will investigate the manner in which these allusions function in Tolkien, and how they contribute to our understanding of Middle-earth as at least partially an epic world with epic ideals of heroism. At the same time, however, it will attempt to identify the ways in which Tolkien changes or subverts such classical ideals and archetypes as they combine with other cultural influences, and evaluate the extent to which The Lord of the Rings can be regarded as creating an epic for the modern world. 


\section{CHAPTER ONE: THE HOBBIT}

While at least some of the epic qualities of The Lord of the Rings are relatively obvious, Tolkien's original children's book is much less obviously connected to the tradition of Homer and Virgil. Much like the beginning of The Lord of the Rings, The Hobbit's famous opening line gives little hint of the epic narrative that it later, albeit briefly, becomes: the 'hero' is not even human, but a hobbit living in a "hole in the ground" (1), the key feature of which is not danger or suffering but "comfort" (1). The world of hobbits in which the story begins is not merely 'not epic' but actually anti-epic, with Tolkien often knowingly subverting established tropes of the genre. Honour among hobbits is gained specifically through the lack of deeds, with the Bagginses considered "very respectable ... because they never had any adventures or did anything unexpected" (1), rather than through the accomplishment of great deeds as in traditional epic. More elaborately, while classical epic (particularly the Odyssey) makes use of ritualised hospitality scenes where characters play hosts to wandering heroes, Bilbo is tricked by Gandalf into playing host to the dwarves (and by extension to "a most wretched adventure" (10)) against his will. Like epic hosts, Bilbo is clearly aware of a set of guidelines to which he must adhere in his welcome of guests - he knows, for example, "the correct thing to say" (9) when greeting a guest - but the forms these take are comically realistic rather than ritualised and gently ridicule Bilbo's unsuitability for a heroic world: the dwarves fall forward onto the mat when Bilbo opens the door "like a pop-gun" (10), the practicalities of preparing food for fifteen leaves him "very hot, and red in the face, and annoyed" (11), his duty "as the host" which he knows and "stick[s] to ... however painful" (7) involves the possibility of going without cakes if they "run short" (7), and the dwarves' role as guests involves helping with the washing up with Bilbo terrified of the possibility of broken crockery. This parodic use of traditional epic conventions continues throughout the conversation that, as with epic hospitality scenes, follows the meal. A digression into Bilbo's famed ancestor "Bullroarer, who was so huge (for a hobbit) that he could ride a horse" (17) begins almost in heroic fashion (though allowing for hobbit size), seeming to surprisingly stress his prowess in battle as we learn how he "charged the ranks of the goblins of Mount Gram in the Battle of the Green Fields, and knocked their king Golfimbul's head clean off with a wooden club" (17). However, in the very next sentence this set-up neatly collapses into an anachronistic joke: "[The head] sailed a hundred yards through the air and went down a rabbit-hole, and in this way the battle was won and the game of Golf invented at the same moment" (17). Bilbo's own attempt to draw on his ancestry in a fit of traditional heroic boasting is dismissed by the dwarves with, "yes, but that was long ago" (18), and Warriors and Heroes are dealt with in tongue-in-cheek fashion by Gandalf who refers to them (along with Burglars) in terms of a job description. Though Tolkien is clearly familiar and comfortable with forms of epic narrative, this familiarity is shown here not through his evocation of them but through his gentle parody of them and of Bilbo and the dwarves through them.

This lack of conventional heroic behaviour is continued throughout the early sections of the book. If the hobbits 
of The Lord of the Rings are folk-tale heroes in an epic world, Bilbo and the dwarves begin The Hobbit as folktale heroes in a decidedly folk-tale world, with the threats faced by Bilbo and the dwarves throughout their journey to the Mountain clearly suited to their stature. While trolls and spiders are both encountered also in The Lord of the Rings, here they are not bestial monsters for the heroes to slay but anthropomorphised enemies, speaking in regionalised accents, for the heroes to trick. (The trolls are named Tom, Bert and William, names difficult to imagine belonging to the cave-troll Frodo stabs in Moria.) Similarly, the book's elves and goblins are folk-tale versions of the Elves and Orcs of the later books - the elves singing childish songs, "sitting on sawn rings of felled trees" (140), and often speaking in lower-class, colloquial dialogue ("Here's the old villain with his head on a jug!" (168)) - while creatures such as "stone-giants... hurling rocks at one another for a game" (53) and the skin-changer Beorn appear that would be entirely out of place in the world of an epic and thus vanish from the Middle-earth of The Lord of the Rings. The one creature who would later survive transplantation to the sequel largely unchanged, Gollum, is the character most grounded in the world of the modern novel with a verbalised psychological complexity rarely found in either myth, epic or folk-tale. Not only is this a folk-tale world, it is for the most part a "Northern world" (268) that draws on Anglo-Saxon and Norse mythology: the tales Bilbo remembers hearing of "dragons and goblins and giants" (5) prove an apt summary of the story in which he finds himself.

There is, however, one recurring folk-tale allusion that features throughout the book which does have roots in classical epic: that of the episode of Odysseus' defeat of the Cyclops from Homer's Odyssey. Although taking place in an epic, the Cyclops section of the Odyssey has been often identified as an archetypal folk-tale, and in The Hobbit, variations of the story occur in three separate and key episodes. The first occurs early, when the dwarves and Bilbo, momentarily deserted by Gandalf, encounter three trolls. These trolls, who like the Cyclops are man-eating and dwell in caves, capture the adventurers when Bilbo attempts to steal from them (as Odysseus and his men do from Polyphemus), and during an escape attempt Bert is subsequently stabbed through the eye by Thorin with "a big branch all on fire at one end" (37) just as Odysseus blinds Polyphemus with an olive branch heated to "the point of catching fire" (Od. 9.379). The trolls are ultimately defeated by the trickery of Gandalf, who appears throughout as a trickster figure who uses the Odyssean model of disguise and revelation. ${ }^{1}$ Later, the escape from Thranduil's palace likewise contains similarities to the escape from the Cyclops, as the elven butler and chief guard are lulled to sleep with strong wine and the adventurers subsequently escape concealed inside wine barrels as Odysseus and his men escape strapped to the underside of sheep. It is notable, however, that in these two instances Bilbo himself does not correctly fulfil the heroic role exemplified by Odysseus in folk-tale mode. In the first, he succeeds only in being caught by the trolls, with first Thorin and then Gandalf then taking over the parts of the rescue that in the Odyssey belong to Odysseus alone. In the second, though Bilbo formulates the Odyssean plan of escape (itself a miniature

1 The parallels between Gandalf and Odysseus are developed in more depth over the course of The Lord of the Rings. 
version of the Trojan Horse in reverse) and takes advantage of the elves' drunkenness, he does not orchestrate this drunkenness himself as does Odysseus, but merely takes advantage of a fortunate chance.

This changes with the third, most important and arguably most sustained comparison with the Cyclops episode, which takes place during Bilbo's eventual encounter with Smaug. Though this encounter undeniably draws more on Sigurd's conversation with the dragon Fafnir in the Volsunga saga (as noted by Rateliff 534), it also bears similarities to Odysseus' encounter with Polyphemus in the Odyssey. Both Polyphemus and Smaug dwell in caves into which the hero has ventured with the intent to steal, both are characterised by a single "roving eye" (Hobbit 206) which is foiled by the trickery of the hero (the blinding of the Cyclops in Odysseus' case, the use of the magic Ring in Bilbo's), and both engage in mock-courteous banter with the hero. During this conversation, both Bilbo and Odysseus take care to conceal their names through use of riddling pseudonyms (as does Sigurd at first talking to Fafnir), Odysseus famously giving his name as 'Nobody' while Bilbo evades Smaug's questioning by describing himself as "the clue-finder, the web-cutter, the stinging fly... I came from the end of a bag, but no bag went over me" (205). Like Odysseus, Bilbo is doing the "wise" (205) thing in keeping his name and purpose concealed, yet like Odysseus he allows his pride to overcome him as he is escaping, to his detriment. Odysseus finds he cannot forgo heroic boasting, and declares his name to Polyphemus as his ship leaves the island only to subsequently incur the wrath of Poseidon, Polyphemus' father, while Bilbo cannot resist adding "and so do burglars" as a "parting shot" (208) as he flees the cave, angering Smaug enough to "sen[d] forth fire and vapour to pursue him" (209) from his nostrils that scorches Bilbo badly. This incident marks a turning point in the use of the Cyclops episode throughout the book: finally, not only does the danger Bilbo faces equate to if not exceed the danger faced by Odysseus, but he exactly and successfully fills the hero's role without the intervention of other characters or fate. Although this does not cause Bilbo to become an epic hero, in some ways the intersection of folk-tale and epic inherent in the Cyclops episode - essentially a folk-tale story within an epic narrative - allows the book itself to begin to rise to a more elevated tone with the successful completion of the analogy.

As Bilbo successfully grows into his role as the most epic of folk-tale heroes, the story begins a new chapter with an abrupt switch in focus to the world of men, and an equally abrupt transformation in tone accordingly. As many including C.S. Lewis have noted (cited in Duriez 92), the authorial voice used by Tolkien begins at around this point to shift from a colloquial, first-person address to children that often interrupts its own narrative, to a far more elevated and impersonal style. Though the exact stylistic features of an epic are not yet present, many appear in fledgling form as Smaug attacks Lake-town: the people of Lake-Town see the dragon approach "as a spark of fire rushing toward them" (227) and Tolkien says of his attack that "no fireworks you ever imagined equalled the sights of that night" (227), foreshadowing the use of Homeric simile that develops later. Moreover, for the first time an enemy is not defeated by trickery but killed in combat of epic proportions 
as Smaug falls "with a shriek that deafened men, felled trees and split stones" (229). If the tone remains pervaded with a sense of realism, it is no longer the comic realism of a world where formulaic hospitality scenes entail "washing-up" and a threat of broken crockery, but a darker realism where formulaic battle scenes entail an aftermath of "much sickness and great hunger" where "many t[ake] ill of wet and cold and sorrow... and afterwards die, who had escaped uninjured from the ruin of the town" (232).

Perhaps the most concrete departure from folk-tale in this section, however, is the introduction of Bard, the book's first and only human hero whom Rateliff sees as a forerunner to Aragorn (557). As Rateliff points out, both Bard and Aragorn are dispossessed heirs (Bard being "a descendant in the long line of Girion, Lord of the Dale, whose wife and child had escaped down the Running River from the ruin long ago" (229)) who achieve great victories in battle and live to re-establish their kingdoms and dynasties (Rateliff 557). Fittingly for a dragon-slayer, however, Bard is drawn far more specifically from both Sigurd and Beowulf than Aragorn is from any equivalent literary inspiration, with Tolkien 'borrowing' elements from the legends of the north rather than evoking a more general epic tone as he does later in The Lord of the Rings. Bard, introduced with the alliterative "grim-voiced and grim-faced" (229) in a way that evokes Anglo-Saxon descriptions of heroes including the "hréoh ond heorogrim" ("fierce and deadly-grim") Beowulf (23.1564), can understand the speech of birds as Sigurd gains the ability to do after tasting the blood of Fafnir and, like Beowulf, slays his monster with a weapon of special lineage that is lost in the victory. In Bard's case, the black arrow from "the forges of the true king under the Mountain" which he "had... from [his] father and he from of old" (229) destroys Smaug when it "smote [him] and vanished, barb, shaft and feather, so fierce was its flight" (229), while Beowulf slays Grendel's mother with a sword forged by giants that later melts away at the touch of the venomous blood (much as Merry's does after striking the Witch-King in The Return of the King) (Rateliff 558-9). Like Beowulf, who descends under water to kill Grendel's mother and is believed dead by his companions only to return in triumph, Bard is considered lost in the lake with Smaug until he returns wet and with "a fierce light in his eyes" (230) to announce:

"Bard is not lost!" he cried. "He dived from Esgaroth, when the enemy was slain. I am Bard, of the line of Girion; I am the slayer of the dragon!" (230)

The character of Bard also, however, draws on more general epic tropes. In particular, the simmering rivalry between Bard and the Master of Laketown exemplifies the "epic theme" of tension between a king and a hero figure that Jackson argues is common to all major epics including Beowulf and the lliad. This theme, also apparent in the threat to Denethor's rule presented by Aragorn's arrival to claim the kingship, sees an established rule of a king threatened in some way by the arrival or rise of an outsider hero figure "who often proves more powerful than the ruler to whose court he comes" (4). Bard is not a newcomer to the town, though he is an outsider in that he has in origins in exile, but after his defeat of Smaug the people of Lake-Town rise 
and attempt to supplant the Master with "King Bard" (231); the conflict is deferred only by the advent of war. As with Aragorn, however, the conflict it seems Bard must inevitably face once the external threat has been dealt with is circumvented by the convenient madness of the existing ruler: in this case, Bard succeeds peacefully to the 'throne' when the Master "being of the kind that easily catches such disease ... fell under dragon-sickness, and took most of the gold and fled with it, and died of starvation in the Waste" (278). Interestingly, this "disease" is depicted here and throughout as both an external and internal force, outwardly caused by "dragon-sickness" but only suffered by those who already carry the seeds of greed within them (Thorin similarly falls under its spell completely, while Bilbo is able to "keep his head more clear of the bewitchment" (220)). ${ }^{2}$ In this, which foreshadows the use made of the Ring and its temptations in The Lord of the Rings, Tolkien adopts an epic view of madness, where powerful emotions (not always negative) are attributed simultaneously to the influence of a god and to the character of the hero themselves without contradiction.

As the story continues to grow larger in scope, Tolkien turns repeatedly to epic as the genre perhaps best suited to convey the book's new-found sense of grandeur and historical weight. If the introduction of a lone hero protecting a town from dragon attack overall begins to shape The Hobbit along the lines of Beowulf and the Volsunga Saga, the ensuing large-scale Battle of Five Armies pushes the story firmly into the realms of Homer's epic battles. At first Tolkien attempts to alleviate this with the authorial asides that characterised the early sections of the book: as the dwarves begin to speak in the elevated language associated with epic and romance, for example, he explains that, "This, of course, in the polite and rather old-fashioned language of such occasions, meant simply: 'You have no business here. We are going on, so make way or we shall fight you!"' (255). As Gandalf announces the approach of the goblin army, however, any remaining pretence of folktale narration is clearly dispelled:

'"Halt!' cried Gandalf, who appeared suddenly, and stood alone, with arms uplifted ... 'Halt!' he called with a voice like thunder, and his staff blazed forth with a flash like the lightning. 'Dread has come upon you all! Alas! It has come more swiftly than I guessed. The Goblins are upon you! ... Behold! The bats are above his army like a sea of locusts."' (257)

Gandalf's comparison of the bats above the goblin army with "a sea of locusts" marks the first echo of Homeric simile within the book: the movement of the Trojan army in the lliad is similarly compared with "locusts escaping/ into a river swarm[ing] in air" (21.12-13). These similes become rapidly more prevalent as the battle builds in intensity. The goblins themselves burst onto the field "like the incoming sea" (521), a comparison that Tolkien would develop further to describe the approach of the Uruk-Hai in The Two Towers' Battle of Helm's Deep and that evokes Homer's description of the Greek army "surging to and fro like the waves of the Icarian sea" (II. 2.144-145). It is perhaps telling that both these similes in Homer occur when the armies in question are in cowardly retreat, the Trojans fleeing Achilles and the Greeks racing for their ships after Agamemnon's

2 Rateliff discusses "dragon-sickness" and the way in which Tolkien's ideas regarding it developed in more detail pp 595ff. 
attempt to test their courage. Accordingly, although the situation itself is lent weight and dignity by the comparison with Homeric epic, the goblin army itself is not. By contrast, Thorin Oakenshield in the grip of his battle rage is described in the language of Achilles' aristeia in the lliad Book 22: where the latter approaches Hector with armour "shining like the flare of blazing fire or the sun in its rising" (22.134-135), Thorin's dwarves are clad in "shining armour" with "the great dwarf" himself "gleam[ing] like gold in a dying fire" (260). The shift in tone that begins with the introduction of a human hero culminates in the dwarves themselves becoming epic heroes, moving from folk-tale treasure seekers to warriors in Homeric-style warfare. Bilbo alone remains true to his folk-tale style origins, and he is literally and metaphorically invisible throughout: not only can he not be seen, he is "quite unimportant" (259) to the epic events around him. Although he does once comment on the action in non-epic fashion, his naivety this time does not only provide humour but also a note of sober realism that critiques the epic glorification of death in battle: "I have heard songs of many battles, and I have always understood that defeat may be glorious. It seems very uncomfortable, not to say distressing" (262).

As the battle concludes and Bilbo returns to Bag End, the style and narrative of The Hobbit similarly begin to return to a gentle comic fantasy that plays on our expectations of epic to create humour rather than awe. However, there is a subtle shift in the manner in which Tolkien's parody operates that sets the mold for the comedy of The Lord of the Rings. While earlier the humour came from comic versions of epic tropes and typescenes (hospitality scenes that encompass washing up, heroic ancestry involving the invention of golf), now the tropes themselves are played straight with the humour coming from the juxtaposition of Bilbo's homely hobbit manners against them. The dwarves give Bilbo a proper, ritualised farewell, wishing him "Good-bye and good luck, where-ever you fare! ... If ever you visit us again, when our halls are made fair once more, then the feast shall indeed be splendid!" (268); it is Bilbo who immediately and unconsciously breaks the epic tone by replying, "If you are ever passing my way ... don't wait to knock! Tea is at four; but any of you are welcome at any time!" (268). Like the hobbits of The Lord of the Rings, Bilbo has become a folk-tale hero at large in an epic world. This is perhaps most tellingly shown in Rivendell, where Bilbo learns in passing that during Gandalf's continued absences throughout the book, he has been at "a great council of the white wizards, masters of lore and good magic; and that they had at last driven the Necromancer [Sauron] from his dark hold in the south of Mirkwood" (272). Not only has Bilbo's story become greater in scope, it is shown operating on the fringes of a story greater still.

Moreover, though the tale has once again "shrunk", Bilbo retains the associations with Odysseus he gained throughout the journey, which are now allowed to encompass not only the folk-tale elements of the hero but the epic elements of his ten-year nostos (homecoming), albeit adapted in parodic fashion to fit his smaller stature. Bilbo's journey home, undergoing "many adventures and hardships before he got back" (269) and delayed by long stays at places of rest is in many ways Odysseus' in miniature, neatly encapsulated by Bilbo's 
observation that although he has been away for one year, it "seem[s] to him more like ten" (274). His homecoming itself similarly bears comic parallels to Odysseus', as he arrives to find his home in the process of being auctioned off as his belongings are sold to the highest bidders just as Odysseus finds his over-run with suitors seeking to marry his wife. Like Odysseus, Bilbo must prove his identity and reclaim his home after being presumed dead, but the struggles he faces in order to do so are hardly what epic poems are made of: "The legal bother," we are told, "lasted for years. It was quite a long time before Mr Baggins was in fact admitted to be alive again. The people who had got specially good bargains at the Sale took a lot of convincing" (276-7). Although Bilbo is perhaps always too small to achieve epic heroic status within the epic world, respected though he is, he has none-the-less grown to his own kind of epic status in contrast to the folktale world from which he started.

The Hobbit in many ways serves as a prototype for The Lord of the Rings in the way it moves from folk-tale to epic to something of a mixture of the two as Tolkien begins to use his knowledge of the literary forms to evoke humour and awe as fits his purpose. Bilbo ends the story, in Gandalf's words, "quite a little fellow in a wide world" (279), but it is a world that throughout the course of the story has grown with him and finally outstripped him in its ability to encompass not only the everyday comedy and bravery of the folk-tale but the grandeur of classical epic. 


\section{CHAPTER TWO: HEROES}

Perhaps one of the most immediately obvious differences between The Hobbit and The Lord of the Rings, and contributing to its sense of a far greater scale, is the continual involvement of human heroes such as Aragorn, Boromir, and later Faramir. Like Bard, these are heroes not only in the literary sense of being the story's main protagonists or even in the Christian sense of being characterised by virtue and moral superiority, but in the epic sense of being leaders of mortal yet super-human ability, "superior in degree to other men but not to [their] natural environment" (Frye 33-34). The characteristics that entail classical heroism differ not only between the two major epic poets Homer and Virgil but between the individual heroes of the Aeneid, the Odyssey, and especially the lliad, encompassing acts of martial prowess, skill in debate, fame, the accomplishment of great deeds and obedience to the gods. Within this broad framework, however, Aragorn and the Gondorian brothers in particular echo a number of classical archetypes, in ways that signify both their status as epic heroes and, more interestingly, the differences in the way this heroism operates in Middle-earth.

Heroism in Tolkien, of course, is not even as simple or clearly defined as it is in classical epic, having been mediated through not only Tolkien's own beliefs but through centuries of influence from a variety of cultures both modern and ancient, and The Lord of the Rings features many characters that are undeniably heroes without being necessarily epic heroes. While an epic hero is human, for example, Gandalf possesses abilities that elevate him closer to demi-god status, while the hobbits, conversely, possess qualities that at first root them firmly in the realm of the fairy-tale or folk-tale. Nonetheless, it quickly becomes apparent that the lines between genres are more fluid in The Lord of the Rings than even in The Hobbit (where Bilbo can never quite achieve epic status), and despite their different backgrounds these characters also engage extensively with aspects of both Homeric and Virgilian heroism. Their engagement, however, is arguably even more complex, not only negotiating elements of classical heroism as does Aragorn but at different points denying or subverting aspects that conflict with the characters' own moral codes.

\section{"Unlike They Were, And Yet Also Much Akin": Boromir, Faramir and Epic Heroism}

Though arguably not among the most important heroes of The Lord of the Rings, the characters that conform most simply and most obviously to the epic hero mould are the two brothers, Boromir and Faramir. Boromir and Faramir are tellingly described as "unlike ... and yet also much akin" (657), providing contrasting and in some ways complementary examples of heroic behaviour in ways that do not make specific allusions to classical heroes so much as exemplify certain types of classical heroism. While Boromir embodies the proud, brave, "self-regarding" (650) heroism of Achilles and later Turnus, Faramir tempers the noble, duty-bound heroism of Aeneas with Hector's humanity and desire to protect his city, essentially becoming an Aeneas 
without obligation to his own destiny. Together, their strengths and weaknesses constitute a commentary on the differing classical notions of honour and bravery that in many ways mirrors Virgil's contrast of Turnus and Aeneas in the latter books of the Aeneid, as Boromir's heroic qualities ultimately prove unsuitable and therefore dangerous in the moral universe for which his brother is uniquely suited.

Alone among the members of the Fellowship, Boromir's heroism has its basis in Homeric-style martial prowess, with Boromir a valued captain among his own people desirous of both "the victory of Minas Tirith" (656) and "his own glory therein" (656). Our introduction to him at the Council of Elrond presents him immediately as "a speaker of words and one who accomplishe[s] in action" (II. 9.443), the aim given to Achilles by his father and seen by Jenkyns as "the Homeric hero's ideal" (9), as he fluently recounts the "deeds" and "valour" of the men of Gondor that he fears "few ... know of" (239). This speech shows Boromir clearly adhering to the classical idea of kleos, or public honour: while for Aragorn, protection must be secret and therefore unpraised in order for those they protect to be "free from care and fear" (242), Boromir requires the deeds of the men of Gondor to be known and spoken of, rewarded by "those who shelter behind us giv[ing] us praise" (239). Perhaps more importantly, however, while the majority of those present at the Council see the conflict with Sauron as at least partly a spiritual struggle in the Christian tradition, Boromir's speech indicates his understanding of the war as purely a physical conflict conveyed in heroic language. To Boromir, the Ring is a "weapon" (261), Saruman is a "traitor" (260) to their side but not to any moral code (he sees his plan as having "a glimpse of wisdom" (260)), valour requires "first strength, and then a weapon" (260), and Sauron is merely a powerful "Enemy" who must be fought by "strength of arms" (239). Boromir's practical heroism is gently corrected by Elrond and Gandalf when it drives him to suggest using the Ring against Sauron, but it is by no means condemned, and he goes on to prove invaluable to the Company. In matters where "heads are at a loss [and] bodies must serve" (284), Boromir is judged superior even to Aragorn, most notably taking the lead both literally and metaphorically in forcing a path through the slopes of Caradhras after the living mountain "cut[s] off [their] escape" (285) with a snow drift. As he moves through the snow, the manner in which he "seem[s] to be swimming or burrowing with his great arms rather than walking" (284) bears comparisons with Achilles "leap[ing] into the river like some immortal" (II. 21.18) after the Trojans until "his hands grew weary of killing" (II. 21.26), and Pippin in particular "marvel[s] at his strength, seeing the passage he had already forced with no other tool than his great limbs" (285-6).

Although this display of physical strength is admired, however, there are also hints that it is somewhat out of place in Middle-earth. While the hobbits are appreciative of Boromir's efforts, Legolas affectionately mocks of the idea that "the strongest must seek a way" (284), watching the "Strong Men" (285) "with a smile upon his lips" (284) before effortlessly running over the snow "like a runner on firm sand ... quickly overtaking the toiling men with a wave of his hand" (285). Even Boromir upon his return, though boasting of his and Aragorn's 
'doughtiness', wryly admits that in this case "lesser men with spades might have served you better" (285), somewhat dampening the heroism of the moment. Moreover, in clearing the snow Boromir is explicitly doing battle with the personified Caradhras "the Cruel", one of the "evil and unfriendly things in the world that have little love for those that go on two legs, and yet are not in league with Sauron, but have purposes of their own" (282). While this elevates work that could otherwise indeed have been accomplished by "lesser men with spades" to more heroic status akin to Achilles' battle with the river Skamandros, it is also the only instance in the book where one of Tolkien's heroes is depicted doing battle with natural phenomena: in all other cases, this is the province of the dark forces, as when the Nazgul are defeated by Elrond's river and Saruman by the Ents. This makes it doubly strange that, although Boromir acquits himself well in other conflicts, this is the only 'victory' in which he is explicitly glorified, with even his final redemptive battle to save the hobbits unsuccessful in a practical sense and reported only retrospectively by himself and later the hobbits. As Reckford suggests, if Boromir is in some ways a figure of Achilles-style heroism, he is perhaps not, like Achilles, one in a world in which such heroism is apt but, like Turnus, the self-styled "Achilles" of the Aeneid (9.990), one in a world in which such heroism is admirable but inadequate, and thus dangerous (Reckford "Some Trees in Virgil and Tolkien" 63).

The similarities between Boromir and Turnus are in fact apparent from his introduction, with Boromir introduced at the Council with the phrase "proud and stern of glance" (234) and standing to speak in the manner of an epic address "tall and proud" (239) in a manner that evokes "proud Turnus" speaking at the assembly. This quality of pride, however, ultimately proves his downfall in Turnus-like fashion, as Frodo is forced to "sav[e] the Ring from the proud grasp of Boromir" (650) when Boromir like Turnus "succumb[s] to furor" (Reckford, "Review" 175) and attempts to take the Ring for his own. Just as Allecto, inspiring Turnus to take revenge on Aeneas, "cast[s] a torch at Turnus,/ fixing the firebrand within his breast, / and there it smoked with murky light" (Aen. 7.603-605) so that "lust for the sword and war's damnable madness / are raging in him and - above all - anger" (Aen. 7.609-610), under the influence of the Ring Boromir's "fair and pleasant face [i]s hideously changed; a raging fire [i]s in his eyes" (390). Rage, and rage characterised by imagery of light and burning, is of course also a dominant characteristic of Achilles, but while that destructive rage is deemed natural and even appropriate - it is Agamemnon who is deemed "mad" (II. 9.116) for "dishonour[ing] a great man" (II. 9.110) - Turnus' anger is not only his own response to what as he perceives as a slight but the direct influence of Allecto. As a result, when Turnus' eyes are later decribed as "burning" (12.893), it not only connotes personal madness but also divine possession, "display[ing] the supernatural influence of his infernal possessor and... his forced appropriation of the Fury's madness" (Hershkowitz 93). Similarly, the "raging fire" (390) of Boromir's anger is inspired at once by his natural desire to protect Gondor and by the Ring itself: as early as the Council of Elrond, Boromir's eyes are described as "glint[ing] as he gazed at the golden thing" (241), a reaction common to those under its influence. Like those taken by the "dragon-sickness" in The 
Hobbit, Boromir has been driven not only to madness, but to a particularly epic form of madness, deriving at once from a supernatural external source and a powerful internal emotion. In Boromir's case, however, this emotion is not greed but the very desire to "drive the hosts of Mordor [with] all men... flock[ing] to [his] banner" (389) that is the root of classical epic heroism, just as the impulse that drives Turnus to refuse to let another steal his bride is the root of not only Achilles' heroism but the entire Trojan War. Interestingly, we learn after Boromir's death that had he survived, he may have become a Turnus-like figure of opposition to the destined king of Gondor: Faramir tells Frodo that "it always displeased [Boromir] that his father was not king" (655), and that despite his reverence for Aragorn "the pinch had not yet come. They had not yet reached Minas Tirith or become rivals in her wars" (655). Boromir does receive the forgiveness and redemption at the hands of Aragorn that Turnus seeks and is denied at the hands of Aeneas, and in true epic fashion "die[s] well, achieving some good deed" (654). However, like Turnus he is still ultimately required to die in order for a new form of heroism to survive; doubly so, as he is sacrificed by the narrative not only so that Aragorn can claim the throne, but so that Aragorn can claim the throne without an internal struggle that would sit uneasily in Tolkien's moral universe.

By contrast, the heroism of Boromir's younger brother Faramir resembles the pius heroism of Virgil's Aeneas, characterised by "virtue, duty, loyalty, responsibility - duty to one's family, to one's people, and to the gods" (Jenkyns 56). Faramir, although a great warrior who leads his men in "perilous ventures" (645), "do[es] not slay man or beast needlessly, and not gladly when it is needed" (650), and finally goes into battle motivated "not ... by his own choosing" (798) but by his duty to his father, just as "it is not [Aeneas'] own free will" (Aen. 4.492) but his duty to the gods and his son that finally sends him to Italy. Moreover, although there is no explicit presence of gods or religion in The Lord of the Rings, Faramir none-the-less exhibits reverence toward his ancestors and the mythic past. While Boromir's address to the Council is fixated on Gondor's present deeds, Faramir's conversation is focussed on Gondor's past history and the greatness of the Men of the West, and he and his men are shown observing obliquely spiritual rituals that others do not, pausing before eating and looking out to "Numenor that was, and beyond to Elvenhome that is, and to that which is beyond Elvenhome and will ever be" (661). This concept of heroism as encompassing duty to others above personal needs and a respect for "High" (663) things is validated soon after Faramir's first appearance in the same way that Boromir's is discredited: when confronted by the Ring. Where Boromir's personal code fails him, Faramir's sense of duty ensures that "even were [he] such a man to desire this thing" (666) he would uphold his former vow that "not if I found it on the highway would I take it" (665-6), while his piety tells him that "there are some perils from which a man must flee" (666). If Faramir is "unlike" (657) Boromir, he is also implicitly better, "less self-regarding, both sterner and wiser" (650).

Moreover, Faramir shares with Aeneas an affinity for dreams and visions. Aeneas is, as Morse points out, 
prone to visitations from gods and dead loved ones, and Faramir is from his first mention characterised by the same, receiving the prophetic vision that sends Boromir to Rivendell many times whilst in "troubled sleep" (239) and, more significantly, a vision of Boromir after his death that bears similarities to the vision of Hector Aeneas receives at Troy. Although the circumstances are very different, both take place at night - Aeneas in a dream, Faramir this time awake yet in a "dreamlike" (652) state - and both see the bodies of loved ones killed in battle, Hector standing with "his beard unkempt, his hair ... thick with blood / [and] b[earing] the many wounds he had received / around his homeland's walls" (Aen. 2.382-384) and Boromir less brutally laid in his funeral boat with "many wounds on him" (652). Just as Aeneas cries to Hector, "O light of Troy, O Trojan's trusted hope! / What long delay has held you back? From what / seashores, awaited Hector, have you come? I... Why these wounds?" (Aen. 2.385-392), Faramir similarly addresses his brother: "Boromir! ... Where is thy horn? Whither goest thou? O Boromir!" (652). Faramir's vision is not as important to his own survival as Aeneas': while Hector does not answer Aeneas' questions but warns him of the impending fall of Troy, Boromir does not speak at all. However, this affinity for the supernatural also gives Faramir, like Aeneas, an ability to perceive "divine" aspects of other characters that later allows Faramir to recognise Aragorn as the rightful king. While Boromir upon meeting Aragorn asks his identity and receives the answer with "doubt... in his eyes" (241), Faramir, seeing Aragorn for the first time after being recalled from unconsciousness, looks at him with "love... kindled in his eyes" (848) and despite his disguise greets him with, "My lord, you called me. I come. What does the king command?" (848). Similarly, in the Aeneid Turnus is slow to recognise deities, mocking the disguised Allecto as an old woman and earning her wrath, whereas Aeneas frequently glimpses the divinity of disguised gods if not their actual identities: although he does not actually recognise his mother Venus in Book One, for example, he notices her "voice is not like any human voice" (Aen. 1.464) and persists in addressing her as "goddess" (Aen. 1.526) despite her claim to be a girl of Tyre. In the case of The Lord of the Rings, Faramir's ability to perceive beyond the physical world in which Boromir is at home allows for the peaceful restoration of Aragorn to the throne in the way Boromir's involvement would have denied, and implicitly brings about the Fourth Age of Middle-earth.

It is notable, however, that unlike Aeneas Faramir's destiny is not to bring about the Fourth Age himself, but to recognise Aragorn's right to do so. While Aeneas is a superhuman hero, a demi-god with a high destiny akin to that of Aragorn, Faramir is explicitly a more human version of this basic type. Pippin's first impression of him is of "one with an air of high nobility such as Aragorn at times revealed, less high perhaps, yet also less incalculable and remote: one of the high Kings of Men born into a later time, but touched with the wisdom and sadness of the Elder Race" (792). This impression tellingly comes after seeing Faramir returning from battle to Minas Tirith, in a sequence that in some ways mirrors that of Hector's brief return to Troy in Book Six of the lliad in the way it emphasises the humanity of the heroes and what they are fighting for. Both, for example, focus on the heroes' exhaustion, with Hector "tired [from] defending [his] neighbours" (II. 6.262) and Faramir 
visibly "weary" after "rid[ing] fast and far, and under shadows of evil in the air" (796), and both attract a "press of people" (792) from the cities upon their arrival. Even more significantly, both involve an intensely domestic environment, Hector encountering in rapid succession his mother, his brother, and his wife and child while Faramir, who significantly has none of these, visits the private chamber of his father for what begins as a warmeeting but quickly dissolves into family drama as Denethor admonishes his son for his perceived inferiority to his brother ${ }^{3}$. Though he shares qualities with Aeneas, Faramir's heroism is also, like Hector's, firmly rooted in a desire to protect home and family, Hector as eldest son and Faramir in the stead of the eldest son. Just as Hector, by his own admission, has "learned to be valiant/ and to fight always among the foremost ranks of the Trojans / ... For I know this thing well in my heart, and my mind knows it: / there will come a day when sacred Ilion shall perish, / and Priam, and the people of Priam of the strong ash spear" (6.444-449), Faramir's heroic deeds are similarly motivated by love for his city and sadness for its decline:

"War must be, while we defend our lives against a destroyer who would devour all; but I do not love the bright sword for its sharpness, nor the arrow for its swiftness, nor the warrior for his glory. I love only that which they defend: the city of the Men of Numenor; and I would have her loved for her memory, her ancientry, her beauty and her present wisdom. Not feared, save as men may fear the dignity of a man, old and wise." (656)

Despite the Aeneas-like stress on Minas Tirith's "memory [and] ancientry" rather than Hector's "strong ash spear", Faramir is in his own eyes ultimately fighting not for the glory of a future city (as Aragorn is), but for the love of a city whose glory is already in the past.

Unlike Hector, however, Faramir's allegiance to his city's past glories does not result in his inevitable death before its walls, nor is he required to give it up for a new city like Aeneas. Instead, Aragorn's return brings with it a return to the "days of [Gondor's] first glory" (947), yet one which is at the same time a new age that sees Gondor "more fair than it had ever been" (947). As a result, "fate spares [Faramir] for some other end" (645), and he lives both to see his city prosper and to marry Eowyn (who, as will be argued elsewhere, is in many ways a Dido figure). If Boromir's death in the manner of his classical predecessor marks his form of heroism as admirable, but unsuitable for the different moral and spiritual landscape of Tolkien's world, Faramir's survival in a manner that surpasses either of his own predecessors marks his form of heroism as ideal, able to encompass duty, self-sacrifice, an awareness of the unseen and love for others. Given Tolkien's Catholic beliefs, it is perhaps no coincidence that the Virgilian figure seen as "the proto-type of a Christian hero" (Eliot 10) and the Homeric hero who sacrifices himself for his home and family combine to provide a hero perfectly adapted to live in the Fourth Age.

3 This admonition casts Faramir, unfairly, into the role occupied in the lliad by Paris: a younger brother criticised for his cowardliness in contrast to his heroic older sibling. 


\section{"Strider and Dunadan Too": Aragorn, Odysseus and Aeneas}

If Faramir represents a convergence of two very similar heroic types, one Homeric and the other Virgilian, Aragorn combines two superficially similar yet very different models of classical heroism to possibly even greater effect. As a wandering hero who begins the story divorced from his true heroic status and yet goes on to reclaim the kingdom that is his by right, Aragorn embodies a particular mythic archetype that he shares with both Homer's Odysseus and Virgil's Aeneas. While this archetype itself is not necessarily classical in origin Bard in The Hobbit, as has been mentioned, bears similar characteristics while drawing very specifically on Tolkien's beloved Northern mythology - Aragorn does appear to share a number of distinct character traits and motifs with the classical heroes in a way that seems deliberately calculated to evoke their epic status. More interestingly however, Tolkien's depiction of Aragorn not only utilises the more general 'wandering hero' archetypes that both Odysseus and Aeneas have in common, but also combines the aspects of the characters in which they differ, balancing the cunning intelligence of Odysseus with the piety and high destiny of Aeneas.

Both Odysseus and Aeneas (understandably, as the first six books of the Aeneid are widely considered to have been inspired by Homer's Odyssey) begin the book shipwrecked, adrift from their rightful kingdoms and subsequently from their roles as epic heroes. In much the same way, Aragorn is introduced to the book not as the hero and rightful king he is but as "a strange-looking weather-beaten man" (153) known only as Strider. Aragorn, like Odysseus, is alone, and his ragged appearance, with boots "caked with mud" and a "travelstained cloak" (153), serves to further isolate him from those around him in much the same way Odysseus' appearance, without clothing and "all crusted with dry spray" (Od. 6.137), isolates him: both heroes are described as dishevelled to the point of inspiring distrust and fear in the hobbits and Nausikaa's servants respectively. At the same time, however, like Aeneas Aragorn is in fact not truly alone, but described by Barliman as "one of the wandering folk" (153), leader of "the last remnant in the North of the great people, the Men of the West" (215) just as Aeneas is leader of the last remnants of the Trojan race. Similarly, the kingdom from which Aragorn is displaced is one he is, like Odysseus, returning to, having previously spent years in Minas Tirith aiding Denethor's father under an assumed name. However, as Aragorn never took the throne or even revealed his true identity during his time there, it simultaneously serves as a kingdom which he has not yet claimed but, like Aeneas, has been promised by prophecy. Tolkien draws on classical traditions to create an image of Aragorn as simultaneously Odysseus and Aeneas, both an experienced, solitary traveller returning to his birthright and a skilled leader whose home and high destiny is still before him.

Moreover, both Odysseus and Aeneas are presented in this first appearance as divorced not only from their heroic status but from their identities, marked as nameless and displaced. In the Odyssey, Odysseus is initially 
introduced only as "the man of many ways" (1.1), with his name not mentioned until line 21 of the poem, while Virgil, perhaps slightly competitively, introduces his hero only as "a man" (Aen. 1.1) and does not name him until line 131. Aragorn, too, is first introduced only as a "weather-beaten man" (153), and when Frodo inquires as to his identity Barliman claims to have "never heard" it, knowing only that "he's known round here as Strider" (153). Tolkien, however, takes this symbolic namelessness even further than his classical predecessors. Unlike Homer and Virgil, Tolkien's narrative voice is aligned not with the wandering hero but with the stranger who encounters the wandering hero, in this case Frodo, and as a result Aragorn's true identity is at first concealed not only from his allies and enemies alike but also from the reader. Even when Aragorn's name is revealed, Tolkien himself chooses to withhold it from him while his status is still that of a wandering hero and not that of a king actively seeking to reclaim his rightful throne, referring to him consistently as Strider until his presence at the Council of Elrond sets him on the path to fulfil his Aeneas-like destiny. ${ }^{4}$ Moreover, this reluctance to name Aragorn until he is restored to his proper heroic status is not only symbolic but operates on a plot level, with Aragorn himself often concealing his identity throughout the book. This is not usually a part of Aeneas' character, but it is very much a part of Odysseus', whom Aragorn echoes in his use of pseudonyms as well as his ragged appearance. Unlike most epic heroes, who rarely forgo an opportunity for heroic identification, both heroes avoid declaring their own name: Aragorn, as Frodo notes, has "a lot a names" (226) by which he is known by different people, while Odysseus throughout his travels is prevented from introducing himself by others pre-empting him and telling him his own identity, as well as famously using the name "Nobody" when questioned by the Cyclops. For both Aragorn and Odysseus, and to a lesser extent Aeneas, homelessness is directly equated with namelessness, and the quest for their rightful kingdoms is also a quest for their rightful identities.

When Aragorn does declare his name, he does so under very similar circumstances to both Odysseus and Aeneas. Although Aeneas does declare himself openly upon arriving in Carthage, he inadvertantly does so only to Venus (who already knows it), and when he comes to Dido's palace he finds himself concealed within "folds of fog" (Aen. 1.727) and thus able to observe Dido's reception of his countrymen without revealing his presence. It is only when Dido declares her sympathy with the fallen Trojans and her desire to provide shelter to Aeneas that

... suddenly

the cloud that circles them is torn; it clears

away to open air. And there Aeneas

stood, glittering in that bright light, his face

and shoulders like a god's. Indeed, his mother

4 Although this can partially be attributed to Tolkien's desire to reflect the perception of Frodo in the early parts of the book, it is notable that the one exception to this rule occurs as Frodo is watching Aragorn talking to Arwen in Rivendell, where the sudden use of his proper name elevates him to her status and foreshadows his future role as her husband. 
had breathed upon her son becoming hair,

the glow of a young man, and in his eyes,

glad handsomeness

'The man you seek is here. I stand before you,

Trojan Aeneas, torn from Libyan waves.' (Aen. 1.825-837)

Similarly, Aragorn declares his identity only after it has already been revealed by a letter from Gandalf, wary of "traps" (167) and wishing to be certain of the reception he would receive. Like Aeneas, Aragorn's selfidentification is accompanied by a perceptible change in appearance and imagery of light, although the veil of secrecy torn away is metaphorical rather than literal:

He stood up, and seemed suddenly to grow taller. In his eyes gleamed a light, keen and commanding. Throwing back his cloak, he laid his hand on the hilt of a sword that had hung concealed by his side. They did not dare to move ... 'I am the real Strider... I am Aragorn son of Arathorn, and if by life or death I can save you, I will."' (168)

Interestingly, this element of supernatural revelation does not occur in the Odyssey when Odysseus first reveals his name to the Phaiacians, though Odysseus similarly only does so when Alcinous has already pledged his loyalty and with a heroic identification very similar to Aragorn's. Instead, it is when Odysseus is trying to gain the trust of first Nausikaa and then his wife Penelope that Athena makes him "seem taller / for the eye to behold, and thicker, and on his head she arranged / curling locks that hung down like hyacinthine petals" (6.229-231; 23.156-158). Unlike Aeneas, Odysseus is not hidden from view by a goddess, but hidden in plain sight throughout the book under the disguise of a ragged traveller, taking on the guise of a beggar as early as the Trojan War (as we learn from Menelaus' anecdote) and ending his journey with an extended period as a beggar in his own house. As a result, his supernatural revelations are less revelations of his presence than they are of his latent heroism, and in both cases invite the other party to recognise and respond to his true status as an epic hero. Aragorn, too, employs disguise throughout the book. Although his ragged appearance when the hobbits encounter him is - much like Odysseus' in the early part of the epic - in part an honest result of "lying for days in hedges and ditches" (167), Frodo notes at their first meeting that he has been disguising his voice to "talk like... the Bree-folk" (163), and he admits to withholding his identity from them: like Odysseus, both out of suspicion ("the Enemy has set traps for [him] before" (167)) and a desire to test the hearts of the hobbits, hoping that they would "take to [him] for [his] own sake. A hunted man sometimes wearies of distrust and longs for friendship" (167). Tolkien downplays the overtones of deceit in this practice explicit in Homer: Aragorn, unlike Odysseus, is a "hunted man" rather than merely a cautious one, making his disguise one of necessity, and while he often withholds information, he never actively lies. Nevertheless, for Aragorn too subsequent quasi-supernatural revelations of identity serve as explicit demands 
for allegiance, finally declaring his name to Eomer with the question, "Will you aid me or thwart me?" as he "seem[s] to have grown in stature while Eomer had shrunk" and "his living face [reveals] a brief vision of the power and majesty of the kings of stone" (423). Interestingly, however, this Odysseus-like revelation is balanced by being in part a revelation of his destiny like those of the Aeneid, with the "white flame [that] flickered on the brows of Aragorn like a shining crown" (423) seemingly echoing the "lambent flame ... which gently spread / Around [Ascanius'] brows" (Aen. 2.930-32, trans. Dryden) in order to foreshadow his prophesised kingship. Once again, the use of both traditions allows Aragorn to draw on the iconography of Odysseus, a solitary hero employing disguise and resourcefulness to determine whom to trust, with all the moral authority of Aeneas, a pious social hero who works not for himself but for the future he represents.

This mixture of Odyssey and Aeneid references becomes even more explicit as Aragorn undertakes an Underworld journey to reach his kingdom - through the Paths of the Dead - that is in many ways a combination of those undertaken by Odysseus and Aeneas before him. Aragorn's foremost motivation for the journey is the practical concern of enlisting the help of the Dead to save Gondor, perhaps more similar to Odysseus' practical need of advice from Teiresias than Aeneas' pious obedience to his father. However, it is nonetheless made possible and necessary by both Aragorn's ancestry as "the heir of him to whom the oath [the Dead] swore" (764) and his destiny as a future king of endangered Gondor, just as Aeneas is motivated by both his duty to his father and the promise of learning about his future kingdom. For both Aragorn and Aeneas, the journey is a way of at once fulfilling their obligations to the past and looking forwards toward the future. Both do so with the guidance of prophets, Aragorn following the words of Malbeth the Seer that he shall "call [the Dead] from the grey twilight" (764) and Aeneas actively guided by the Sibyl. Moreover, the depiction of the Paths themselves echoes Virgil's description of the classical underworld. As Aeneas draws near the entrance to the underworld, he sees:

"...a wide-mouthed cavern, deep and vast

and rugged, sheltered by a shadowed lake

and darkened groves; such vapour poured from those

black jaws to heaven's vault, no bird could fly

above unharmed..." (6.318-322).

Similarly, the Paths of the Dead are approached through "the gloom of black trees that not even Legolas could long endure" (768), and entered through the "Dark Door" in the side of a sheer rock wall, described once again with the imagery of jaws that "gape before them like the mouth of night" (768). Perhaps most tellingly, the literal vapour of Virgil's underworld is echoed metaphorically as "fear flow[s] from [the Door] like a grey vapour" (768) that deters not only birds but horses and causes the "heart[s]" of the heroes to "quail" (769). Once the heroes enter the Paths, they find themselves traversing a road surrounded by an "unseen host that followed in the dark" (769), much like the intricate passages that house the spirits of Virgil's underworld. 
However, while Aeneas' goal is to seek the ghost of his father in his own environment, Aragorn's is ultimately to summon the dead into the world of the living, in a manner that echoes Odysseus (who in fact never enters the underworld itself). Upon emerging from the cavernous paths, Aragorn and his companions find themselves in a chasm "so deep and narrow that the sky was dark, and in it small stars glittered" despite the fact that "it was still sunset of the day on which they had set out from Dunharrow" (771). As they progress, they find themselves in a valley, where "all was grey in that hour, for the sun had gone, and far below lights twinkled in the homes of Men" (771). Although the darkness in question is a natural phenomenon rather than of supernatural origins, the explicit absence of the sun and sense of timeless gloom in an inhabited land evokes the constant darkness in the "city of the Kimmerian people" (Od. 11.14) where Odysseus must journey to summon the dead. This land is described as "hidden in fog and cloud" (11.15), and we are told that "nor does Helios, the radiant/ sun, ever break through the dark to illuminate them with his shining / ... but always a glum night is spread over the wretched mortals" (11.14-19). Once reaching this land, Odysseus must follow Circe's directions to "a rock ... and the junction of two thunderous rivers" (10.513), where he stops and makes a sacrifice to summon the ghosts of the underworld. Similarly, though the Dead have already been "summoned" (771) by Aragorn, following him with "pale banners like shreds of cloud and spears like winter thickets on a misty night" (771) in a way that evokes the "men killed in battle, stabbed with brazen spears, still carrying their bloody armour upon them" that come "swarming around [Odysseus'] pit with inhuman clamour" (Od. 11.42-43), Aragorn must make a similar journey through the Morthond Vale, following "the long chill river that flows at last to the sea" (771) to the Stone of Erech, in order to blow the prophesised horn and demand their allegiance.

It is notable, however, that while for Aeneas and Odysseus the voyage is at least in part a heroic and even scientific venture, with both eager to question the Sibyl and the ghostly spirits respectively as to the nature of the underworld and the stories of the dead, Aragorn explicitly rejects this aspect of the journey. Upon discovering "the bones of a mighty man" (770) before a closed door, Aragorn pauses to wonder, "Whither does it [the door] lead? Why would he pass?" (770), in much the same way Odysseus stops to question the dead and Aeneas stops before Tartarus to enquire, "What kinds of crimes are these?.../ ...What loud lamentations fill the air?" (Aen. 6.740-2). However, while Odysseus is free to indulge his curiosity and Aeneas receives an answer but is urged, not for the first time, to remember his mission and move on quickly (Aen. 6.834-5), Aragorn goes on to add, "None shall ever know! For that is not my errand! ... Speed only we ask" (770). It is one of many instances in which statements that from Aragorn's classical predecessors reflect a desire for personal satisfaction - whether of curiosity, glory, or revenge - are inverted by Aragorn in a way that subordinates his own desires to the needs of the wider quest. In much the same way, Gandalf's death earlier causes Aragorn to briefly despair, wondering, "What hope have we without you?" only to add immediately to the Fellowship, "We must do without hope... At least we may be avenged" (324). As Morse notes, this is once 
again similar to a statement made by Aeneas, when, upon seeing the destruction of Troy, he urges his men to battle saying, "The lost have only this one deliverance: to hope for none" (2.478-9). Where Aeneas' concept of vengeance requires, "rush[ing] to arms and d[ying]" (Aen. 2.478), however, requiring the intervention of Venus to remind him of his social obligations, Aragorn's already involves living on, telling the Company to "gird [them]selves and weep no more ... We have a long road, and much to do" (324). Just as the physical revelations of Aragorn's heroism come not from overt divine influence but seemingly from within Aragorn himself, the social aspect of Aragorn's heroic code comes not from divine intervention but from Aragorn's own engrained pattern of behaviour, moderated as it is by Tolkien's own Catholic ideology of self-sacrifice. If Odysseus, the Homeric hero, is not only encouraged but required to satisfy his personal desires and Aeneas, the Virgilian hero, must be repeatedly warned away from doing so at the expense of his social obligations, Aragorn's personal desires and social obligations appear to be one and the same, marking him as not only a mixture of Odysseus and Aeneas but the next stage from them in classical heroism.

Ultimately, Tolkien's engagement with Homeric and Virgilian heroism through Aragorn complicates that already presented through Boromir and Faramir. Boromir, despite his inherent nobility, remains mired in "Homeric" heroism and thus must die, for both the sake of the new social order and his own spiritual redemption. Faramir remains instinctively true to the form of heroism associated with Virgil (although also seen in elements of Hector) and thus survives as a perfect citizen of the new Age of Middle-earth. Aragorn, however, embodies the figure of the wandering hero common to both Homer and Virgil, and does so not by conforming to either Homeric or Virgilian heroism but by successfully navigating both, drawing on often contradictory qualities from both Odysseus and Aeneas and adapting them to his own moral code. As a result, he is able to usher in the Fourth Age itself, correctly fulfilling the heroic destinies of his two classical predecessors in a way that arguably elevates him above them both.

\section{"As An Old Man Hooded and Cloaked": Gandalf, Saruman and Odysseus}

Boromir, Faramir, and Aragorn are epic heroes, and as such their engagement with classical epic heroism is one that examines what it means to be an epic hero in Tolkien's Middle-earth. Gandalf and Saruman, however, while equally as powerful if not more so than the human heroes, do not follow the epic mode so closely. Nevertheless, they do draw on classical epic, most notably the trickster figure of Odysseus, and do so in a way that both critiques and validates different aspect of Odyssean heroism. The figure of Odysseus has always been morally ambiguous, with his intelligence, eloquence, adaptability, skill at trickery, and frequent use of disguise causing him to be at separate times admired and mistrusted by not only the characters but also the writers who choose to deal with him: as Stanford points out, "Homer admires Odyssean wiliness, Virgil seems 
to detest it" (5). If Tolkien's depiction of Aragorn dilutes the negative connotations of Odyssean heroism by combining them with aspects of the intensely honourable Aeneas, the depiction of Gandalf and Saruman engages with this ambiguity by separating elements of Odysseus into two similar yet contrasting characters. Like Faramir and Boromir, Gandalf and Saruman are described in a manner that invites comparisons between them ("Like, and yet unlike" (564)), but in this case the comparisons are of the very different ways both draw on the same epic hero. While Gandalf offers a positive interpretation of Odysseus within the context of Tolkien's moral code, carefully using the disguised hero motif in such a way as to avoid overtones of deceit, Saruman embodies the worst criticisms laid against Odysseus, an utterly amoral "liar" (565) who uses treachery and manipulation to serve his own ends at the expense of those who trust him.

The parallels between Gandalf and Odysseus originate as early as his first appearance in The Hobbit, where he appears unrecognisable but as "an old man with a staff' (3) in a manner that bears comparison with Odysseus' disguise as an old beggar-man, and continue throughout the remainder of the book as Gandalf is cemented as both trickster figure and wanderer. Like Odysseus, Gandalf repeatedly employs deception and story-telling both in order to defeat his enemies (imitating the trolls' voices to keep them arguing until sunrise) and to manipulate his friends' hospitality (as when he "clever[ly]" tricks Beorn into playing host to the party of dwarves whom he would normally have "sen[t] ... off at once like suspicious beggars" (Hobbit 114-5)). Moreover, as the story builds to its climax at the Battle of Five Armies, the disguise motif established in his first appearance becomes more prevalent and is coupled with the related motif of revelation of identity, mirroring the manner in which Odysseus begins to reveal his identity to his allies prior to his climactic battle with the suitors. Both characters frequently remain hidden in the garb of "an old man wrapped in a dark cloak" (Hobbit 250) until an opportune moment, whereupon they announce their presence: when Thorin angrily wishes for Gandalf upon discovering Bilbo's treachery, for example, the previously unidentified "old man in the casket ... thr[ows] aside his cloak and hood" to announce, "Stay! Your wish is granted! ... Here is Gandalf!" (Hobbit 252); similarly, when Philoitius in the Odyssey prays to Zeus that "the man himself would come home with the divinity guiding him" (21.201), Odysseus announces, "I am he" (Od. 21.207). Though Gandalf is less of a trickster in The Lord of the Rings, possibly to accommodate the change in tone from its prequel, these associations continue to run through his early appearances in the book. Gandalf makes his entrance once again as a wandering "old man" (24) whose true "difficult and dangerous" (25) business is unknown to those around him, and within the Fellowship serves as leader, experienced traveller, and strategist.

After Gandalf's apparent death defeating the Balrog, however, his associations with Odysseus appear to shift to his arch-rival and fellow wizard, Saruman. Saruman already possesses Odyssean qualities of his own, as we learn retrospectively from Aragorn who illustrates Saruman's "great[ness]" (553) before his fall with characteristics that could apply equally well to the epic hero: "His knowledge was deep, his thought was 
subtle, and his hands marvellously skilled; and he had a power over the minds of others. The wise he could persuade, and the smaller folk he could daunt" (553). Interestingly, this is a form of greatness that seems to uncharacteristically adhere to the epic rather than the Christian definition, encompassing "fame" (553), power and clever speaking yet devoid of moral connotation. After Saruman's betrayal is revealed, however, these Odyssean characteristics are accompanied by others previously the province of Gandalf, and in the context of Saruman begin to become morally charged. Just as Gandalf possesses "many ... names in many countries" (655), Saruman after his betrayal takes the epithet "of Many Colours" (252) to reflect his mutability and adaptability, qualities that characterise Homer's Odysseus on his travels yet here specifically suggest the ability to switch allegiances rather than merely identity, and he is described as "both cunning and dwimmercrafty" (426), echoing the metis or cunning intelligence associated with Odysseus yet pairing it with dangerous magic. Moreover, though Saruman is at this point not a true wanderer, still inhabiting Isengard, Eomer describes him as wandering in disguise for the purpose of gathering intelligence, "walk[ing] here and there ... as an old man hooded and cloaked, very like to Gandalf" (426) and using "many guises" (426) to fool his enemies. Although this in itself is in keeping with Odysseus - as Menelaus recounts, Odysseus uses the garb of a beggar to infiltrate Troy long before circumstances see him become homeless himself, and does so without loss of status - the comparison with Gandalf draws attention to the two wizards' differing motives. Saruman is therefore clearly defined within Tolkien's moral universe as a dark reflection of Gandalf, and thus a darker version of Odysseus that supersedes that presented earlier.

Just as it seems that Saruman is beginning to take on and vilify Gandalf's Odyssean attributes in his absence, however, Gandalf returns to Middle-earth in the form of Gandalf the White in a scene that carries markers of Odysseus' return to Ithaca and subsequent recognition scenes. Gandalf appears to Aragorn, Legolas and Gimli at first as Odysseus does to the members of his household, "an old beggar-man" clothed "in dirty grey rags" and "walking wearily, leaning on a rough staff" (481). As both cast aside their disguises, however, their appearances change dramatically in a moment of seemingly supernatural revelation: while Athena causes "[Odysseus'] mantle and the tunic that covered / his chest turn bright and clean [and] increase[s] his strength and stature" (Od. 16.173-174), Gandalf flings back his "hood and grey rags" (484) to reveal shining white garments as "he st[ands], grown suddenly tall, towering above them... His hair was white as snow in the sunshine; and gleaming white was his robe; the eyes under his deep brows were bright, piercing as the rays of the sun" (484)..$^{5}$ Similarly, Gandalf announces his return from the dead as a return from a physical journey in the language of Odysseus, his claim to have "passed through fire and deep water since [they] parted" (484) echoing Odysseus' claim to have returned through "hardships and suffering" (Od. 16.205) to reach his family. Just as Telemachus and Penelope refuse to believe at first that Odysseus has truly returned but fear

5 As with Aragorn, it is left ambiguous whether this is a literal change in appearance as with Odysseus, or merely a shift in the way the other characters are able to perceive him, and the change is not directly attributed to divine influence. However, the manner in which it is described at least bears clear supernatural overtones. 
supernatural trickery at the hands of "some divinity / [that] beguiles [them], so that [they] must grieve the more, and be sorry"' (Od. 16.194-195), the companions mistake Gandalf for Saruman and fear enchantment by him, Gimli even suggesting they kill him before he can "speak, or put a spell on [them]" (481). Even more interestingly, both Gandalf's and Odysseus' returns are surrounded by an ambiguity of naming and identity. As has been frequently noted by critics, Odysseus never reveals himself with his name, using instead more epithets and pronouns such as "your father", "I, myself" and "the man", suggesting to critics such as Stewart questions surrounding his true identity after the changes wrought upon it by his long travels, at least until he has successfully reclaimed his old life (Stewart 32). Gandalf at first appears seemingly reluctant to name himself, answering Aragorn's question with, "Have you not guessed [my name] already? You have heard it before, I think" (483). However, while Odysseus does not choose to use his name until others use it first, it becomes apparent Gandalf literally cannot remember his name until first named by Aragorn:

"Gandalf," the old man repeated, as if recalling from old memory a long disused word. "Yes, that was the name. I was Gandalf ... Yes, you may still call me Gandalf." (484)

In some ways, Gandalf's return as Gandalf the White literalises the idea present in the Odyssey that Odysseus' long absence "has effectively changed his character, and he may not be Odysseus any longer" (Stewart 32).

It is perhaps more notable, however, that the effect of having Gandalf's revelation be not only a reclamation but a remembrance of his old identity also has the effect of negating the idea of disguise. Gandalf is not consciously hiding the fact that he is Gandalf, as Odysseus might; he in a sense is no longer Gandalf, at least until he is named so by Aragorn. This marks a shift in the way Gandalf uses the Odyssean trope of concealment that continues throughout the remainder of the book. Although Gandalf does employ a mild form of disguise entering Theoden's court, claiming his magical staff as "prop for age" (500) alone and appearing "old and weary" (498) with a "tattered cloak" (503), he no longer lurks as an unnamed figure in key scenes but declares his identity openly at the doors of the Golden Hall and always afterward, announcing, "I am Gandalf. I have returned" (498). Moreover, it becomes implied that those who are unable to see past Gandalf's outward beggar-like appearance are unable to do so not from any active intent at disguise on Gandalf's part but due to a lack of perception that seems tied to moral failing: while Wormtongue, for instance, describes Gandalf and his companions as "three ragged wanderers in grey, and [Gandalf] the most beggar-like of the four" (502), the guard at the gates sees easily that though Gandalf appears "old and weary" (498) he is in fact "fell and grim beneath" (498). Though in The Hobbit Gandalf could hide in disguise from Bilbo without entailing a criticism of either character, in The Lord of the Rings Saruman's appropriation of the disguised hero motif requires Gandalf to balance it with a positive interpretation equally valid to Odysseus, wherein the disguise reflects a changed identity and conceals a hidden strength recognisable to those loyal to him. 
If Gandalf the White essentially eschews or at least downplays the negative aspects of deceit inherent in Odysseus, he also even more explicitly embodies a positive interpretation of Odyssean heroism, most notably as leader of the embassy to the gates of Mordor directly before the climax. In this scene, Gandalf is explicitly endowed with Odyssean qualities: Sauron's Messenger, himself in some ways an embodiment of the dark side of Odysseus with his lack of name, cunning and desire for "evil knowledge" (870), identifies him as both traveler and strategist, having heard of him "and [his] wanderings, ever hatching plots and mischief at a safe distance" (871). More significant, however, is Gandalf's role as ambassador, which picks up on the instances of the Odyssey in which Odysseus' potentially dangerous eloquence is framed in a positive social context. Odysseus' skill in public speaking, famed throughout both the lliad and the Odyssey, is conveyed most simply through the Trojan Antenor's recollections of embassy sent to Troy to negotiate for Helen's return. Odysseus, seen through the eyes of Antenor, at first seems an unlikely ambassador, appearing "a sullen man, and a fool likewise" (II. 3.220), but this impression is abruptly reversed when "he let[s] the great voice go from his chest, and the words came/ drifting down like the winter snows" (3.221-222), whereupon "no other mortal/ man could stand up against [him]" (3.222-223). Gandalf's appearance through the eyes of others is similarly emphasised by Tolkien throughout the scene, and as with Odysseus it is at first far from impressive, with the Messenger describing him as an "old greybeard" (871) and even his allies seeing him momentarily as "an old and wizened man, crushed, defeated at last" (872). These descriptions, recalling once again Odysseus' guise as an aged beggar, are abruptly reversed when he responds to the Messenger's attempts to trick him into surrender. Gandalf does not only impress with his verbal retort, but his physical appearance in the eyes of others is transformed once again in the manner of an Odyssean revelation of identity. This time, however, the revelation is coded explicitly as a revelation of not only strength but moral purity, as "he cast[s] aside his cloak, and a white light shone forth in that black place" (872). The Messenger's shocked and fearful reaction mirrors that of the suitors realising the beggar Odysseus' true identity, conveyed in Homeric language as his face "twist[s] to the likeness of some wild beast that, as it is crouches on its prey, is smitten on the muzzle with a stinging rod" (872), and he is not only unable to "stand up against" Gandalf verbally but unable to speak at all, with "shapeless sounds of fury ... strangling from his throat" (872-3). Odyssean traits are glorified by the standards of both classical heroism and Tolkien's own moral code, as Gandalf's intelligence, eloquence, propensity for disguise and inner power culminate in a moment akin to a Christian hero banishing a demon.

By contrast, Saruman after Gandalf's return becomes even more a living embodiment of the criticisms laid upon Odysseus by moralists from classical times onwards. If Gandalf at the gates of Mordor is Odysseus as shrewd negotiator, Saruman in a similar scene is Odysseus as deceitful manipulator, as Theoden, Aragorn and Gandalf visit him in the ruins of Orthanc. Like Gandalf and Odysseus, Saruman's appearance is unimpressive and beggar-like, that of "an old man swathed in a great cloak" (564), and like Odysseus he is endowed with the ability to persuade others that Aragorn cites as the source of his earlier greatness. Just as "no mortal man 
c[an] stand up against Odysseus" (II. 3.223) once he begins to speak, those listening to Saruman feel "all [his voice] said [to be] wise and reasonable, and the desire woke in them by swift agreement to seem wise themselves", while the voices of dissenters seem "harsh and uncouth but contrast" (564). However, while Odysseus' ability to speak well can be considered a heroic attribute according to Homeric social norms, Saruman's ability is explicitly not due to his eloquence but to his voice, "its very sound an enchantment" (564). It is this voice personified, not Saruman himself, that is described throughout as compelling, and Tolkien tells us that those listening can afterwards "seldom report the words they had heard; and if they did, they wondered, for little power remained in them" (564). The element of deceit inherent in Odysseus' skills of persuasion is amplified and stripped of any redeeming heroic quality as Saruman becomes not wise but merely "an old liar with honey on his forked tongue" (565). Moreover, the hint Stanford finds in Homer that Odysseus' deceitfulness has lead to an inability to trust even after his return to Ithaca is made explicit in the characterisation of Saruman. Just as Odysseus finds himself, having "deceived so many others", unable to accept "that others were not always trying to deceive him" (Stanford 23), Saruman is unable to accept the mercy repeatedly offered to him by Gandalf because he attributes it to the deceifful motives he is himself driven by, causing Gandalf to remark that "the treacherous are ever distrustful" (568). Odysseus is not punished for this trait, however: Athena even admires his clear-headedness in refusing to "run happily off to see his wife and children in his halls" until he has first "made trial of [his] wife" (Od. 23.333-336). Saruman, by contrast, finds himself cut off from his "last chance" (961) to find redemption through the "wisdom and mercy" (961) of Aragorn and Gandalf explicitly because of this inability to perceive in others the honesty that he himself lacks, mirroring Sauron's fateful inability to imagine "that having the Ring [any] may seek to destroy it" (262).

By the time Saruman last encounters Gandalf, the two have reversed the relation in which they stood to one another at the beginning of the book, with Gandalf in the position of fame and renown and Saruman described with the exact words used for Gandalf's first appearance in The Hobbit, "an old man leaning on a staff' (960). While Gandalf was described in Odyssean terms as a wanderer, traveller and trickster, however, Saruman is referred to with the similarly Odyssean but far less complimentary term "beggar", with Wormtongue accompanying him as "another beggar, slouching and whining" (960). There is some hint in the scene that, as with Odysseus, this beggar form may be at least in part a disguise: the term is used almost solely by Saruman himself, and used in order to 'test' the hobbits' generosity towards him in a similar way to Odysseus' use of his disguise to test the loyalty and hospitality of Eumaeus and Penelope. Gandalf also correctly believes him able to act as a trickster figure, at least in the form of accomplishing "some mischief still in a small mean way" (962). Unlike Gandalf, however, Saruman's "rags of grey" (960) do not cover an inner light, and when his identity is revealed later in the book after his "mischief" has been accomplished he manages only to appear "well-fed and well-pleased" (994), a physical rather than numinous transformation. Saruman ultimately ends 
the book not only as a dark Odysseus but a subversion of Odysseus, using his guile to usurp the homes of the returning hobbits rather than to reclaim his own home from usurpers, ${ }^{6}$ and, in perhaps the greatest criticism of Odyssean manipulation yet, meets his death as Wormtongue finally rebels against "always doing what [Saruman] says" (996).

If Faramir and Boromir can be seen as contrasting versions of epic heroism, Gandalf and Saruman can be seen as contrasting versions of the same epic hero, a fact alluded to by Gandalf himself, as he explains, "Indeed I am Saruman, one might almost say, Saruman as he should have been" (484). Gandalf essentially embodies the positive attributes of Odysseus while the problematic elements are siphoned into his dark counterpart Saruman, allowing for a different kind of moral engagement with classical heroism than that seen with either Faramir and Boromir or with Aragorn. In Tolkien's Middle-earth, the figure of the trickster hero is not inherently incorrect like that of Achilles, but instead remains a potentially honoured yet dangerous figure, with Gandalf and Saruman separated from each other only by the use each chooses to make of their heroic qualities.

\section{"Though I Do Not Know the Way": Frodo, Sam and Aeneas}

The least obviously epic of The Lord of the Rings' major heroes are Frodo and Sam, more usually compared with folk-tale or fairy-tale heroes with their status that of "little m[e]n both literally and figuratively" (Flieger 124). Despite this, however, Frodo embodies Aeneas' pius heroism in largely unaltered form, stripped of its physicality yet as a result concentrating even more on the "virtue, duty, loyalty [and] responsibility" (Jenkyns 56) that such heroism entails. If, as W.H. Auden argues, the difference between an epic hero and a folk-tale hero is that the "superior arete [of the first] is manifest to all" while the "arete [of the second] is concealed" (46), then Frodo is in fact somewhere between the two, possessing the sudden revelation of arete that characterises epic wandering heroes such as Odysseus and Aeneas: at one point, for example, it "appear[s] to Sam that his master had grown and Gollum had shrunk" (604), with Frodo becoming "a tall stern shadow, a mighty lord who hid his brightness in grey cloud" (604) just as Aeneas is hidden by Venus' "dark mist" (1.587) until he is revealed "glittering in that bright light" (1.828). As a result, Frodo from the beginning of the book is able to maintain and often validate Virgilian heroism.

As the focus of the hobbits' plot-line gradually shifts from Frodo to the even less epic Sam, however, this alignment with Aeneas becomes more complicated, as Sam takes over Frodo's association with Aeneas but does so in terms of his own far more homely personal moral code. Where Frodo's loyalty, like Aeneas', is to the quest and to the good of his people, Sam's loyalty is solely to Frodo, introducing a degree of conflict that

6 This will be discussed further in Chapter 5. 
highlights subtle differences in the way Virgil and Tolkien perceive fate and virtue.

Frodo's alignment with Aeneas begins early, with the manner of his undertaking of the quest closely mirroring that of Aeneas' gradual acceptance of his role in the founding of Rome. Both quests begin with "exile, a flight from danger into danger" (61), with Aeneas forced against his will to flee the destruction of Troy to ensure the safety of his family and Frodo forced equally reluctantly to leave the Shire to ensure the safety of its inhabitants. At this stage the scale of the two stories appear very different, to the point of Tolkien's almost appearing parodic in the manner of the early sections of The Hobbit (the Sackville-Bagginses who take over Bag End, for example, are highly unpleasant but hardly bear comparison with the marauding Greeks who take over Troy). However, while Bilbo's search for treasure is clearly in the realm of folk-tale, compared by Frodo implicitly with "a kind of holiday" (61), Frodo's quest is already given epic importance despite its unepic trappings, and the "burden" (60) of the Ring that Frodo carries from his home is easily comparable in importance with the burden of the household gods that Aeneas carries from his. As a result, Frodo unlike Bilbo is coded as heroic from the start, and as acting in a heroic way explicitly because of his awareness of "duty to one's family [and] to one's people" (Jenkyns 56) that forms the basis of Virgilian pietas. Instead, the differences in circumstances highlight the different codes of behaviour which the heroes must reject in order to fulfil their duty. Aeneas, as a pure epic hero, instinctively desires to "rush to arms and die" (2.478) in defence of his home, but duty requires him instead to leave the ruins of his home carrying sacred artifacts he must protect from destruction. Frodo, by contrast, has been brought up in a society that advocates "never hav[ing] any adventures or d[oing] anything unexpected" (The Hobbit 1), yet must leave the safety of his home carrying a dangerous artifact he must destroy. Both are required to demonstrate their sense of duty by using it as an alternative to their engrained patterns of behaviour, different though those patterns may be.

For both Aeneas and Frodo, however, the true extent of their pietas is tested and displayed when they find momentary shelter at a place of rest - Rivendell in Frodo's case, Carthage in Aeneas' - where they are given the option of abandoning their responsibility to the quest and living in peace. Instead, Aeneas reluctantly resumes his quest for Rome after a reminder of his duty from the gods, and Frodo takes up the burden of the Ring again when Elrond more kindly refuses to lay it on him unwillingly. Both heroes, as Morse points out, accept their duty with no certain idea of how to achieve it, Frodo literally not "know[ing] the way" (264) to his destination just as Aeneas does not know "where fate / will carry [them] or where [they] will settle" (Aen. 3.910) when he leads his people from Troy, and do so out of a sense of not only social obligation but obligation to the workings of destiny. Frodo's choice is not explicitly ordained by fate or divine will as is Aeneas' decision to leave Carthage to seek Italy, but there is nonetheless a sense of destiny at work, as Frodo feels himself "awaiting the pronouncement of some doom that he had long foreseen and vainly hoped might after all never be spoken" (263). When he finally, despite his "overwhelming longing to rest and remain at peace by Bilbo's 
side in Rivendell" (263), volunteers to take the Ring, he "wonder[s] to hear his own words, as if some other will was using his small voice" (263), just as Aeneas longs to remain "squandering [his] ease" (4.363) in Carthage but submits to the will of the gods that he continue his quest. Like Faramir, Frodo shares with Aeneas an affinity for dreams and visions (Morse 8), and as the quest continues, Frodo repeatedly voices a sense of his will being acted upon by forces outside his own knowledge at crucial points in the book where a decision is to be made, usually urging a more difficult course of action over that which Frodo would prefer: when Boromir suggests Frodo travel to Minas Tirith, for example, Frodo agrees that this may seem the best course of action "but for the warning of [his] heart ... against delay. Against the way that seems easier" (388). Crucially, however, in both books this awareness of fate and higher authority is held in tension with the idea that the characters must exert their own will in order to obey it. Frodo, while sensing that "this task was appointed to [him]" (264), nonetheless forces himself to speak and claim it "with an effort" (263), just as Aeneas conversely must force himself not to speak in response to Dido's distress when his "task" calls him away from her, "struggl[ing], press[ing]/ back care within his breast" (Aen. 4.446-447). This idea of fate as something that a hero must make a conscious and difficult decision to follow despite its inevitability is what allows the "heroic choice" that Reckford argues is essential to both Tolkien's and Virgil's conception of heroism: the decision to "cast away voluntarily what they hold most precious" (Reckford "Some Trees" 61) for the greater good.

Perhaps most importantly, both Aeneas and Frodo take on this quest not only "unwilling, at others' asking" (666), but purely for the benefit of others rather than their own personal glory. Aeneas is not ultimately "kindle[d]" by "the brightness of such deeds" (4.364) or "[his] own fame" (4.366), but by remembrance of "the hopes [he] hold[s]/ for lulus, [his] own heir, to whom are owed / the realm of Italy and the land of Rome" (4.367-369), while Frodo desires simply to "save the Shire" (61). Although both gain honour in the process, neither take enjoyment in their deeds or in boasting later in Homeric fashion, with Tolkien remarking somewhat dryly that Frodo recounts his journey from the Shire to the Council of Elrond "less willingly than Bilbo" (243) and Aeneas himself admitting that retelling his experience of his flight from Troy causes his "mind, I remembering, [to] recoil in grief and tremble" (2.16-17). For both, their heroic journeys are coloured as dark memories that prefigure only further suffering without ultimate benefit to themselves: Aeneas will found Rome for his descendants, at the cost of Dido and Carthage, while Frodo will save the Shire for others at the cost of "los[ing] it" (1006) for himself. These related qualities of reluctance and self-sacrifice are unusual in a Homeric hero, but are intrinsic to both Virgil's and Tolkien's conception of heroism, and Tolkien emphasises this by making it necessary not only on a thematic level but a plot level: it is his very resolve to "guard [the Ring]" (60) from harming others, "whatever it may do to [him]" (60), rather than use it for his own glory, that protects Frodo to some extent from its "evil" (60).

When Sam begins to take over Frodo's role as the "chief hero" (Tolkien Letters 178) of The Lord of the Rings, 
he does so by explicitly appropriating the aspects of Frodo associated with Aeneas. In particular, the choice Frodo shares with Aeneas of the acceptance of an epic quest is mirrored even more closely by Sam after his defeat of Shelob. Like Aeneas, Sam is forced to choose the correct code of behaviour to follow, torn between his personal desires and the wider social obligations that fall upon him with Frodo's apparent death, and his conflict follows a curiously similar pattern to that faced by Virgil's hero when confronted with the fall of Troy. Like Aeneas facing the fall of Troy, Sam's thoughts after Frodo's death run first to "black despair" (714) and pointless revenge. Sam feels that "if once he could go [from Frodo], his anger would bear him down all the roads of the world, pursuing, until he had him at last: Gollum. Then Gollum would die in a corner" (715); Aeneas describes how "anger spurs [him] to avenge/ [his] falling land, to exact the debt of crime" (2.775-776) by killing Helen as she "crouche[s], a hated thing,/ beside the altars" (2.773-4). Although Gollum and Helen of Troy may seem very different objects of loathing, through the eyes of Sam and Aeneas at least the two bear surprisingly similar attributes. Both are acknowledged as unworthy opponents, with Aeneas admitting that "there is no memorable name / in punishing a woman" (2.785-786), but both are nevertheless explicitly considered "one / who merits penalties" (2.789-790); in Gollum's case, the question of whether the fact that he "deserves death" (58) excuses "dealing out death in judgement" (58) is central to the book. Both Sam and Aeneas refrain from pursuing vengeance, not in this case out of mercy but out of their awareness of wider social obligation. In Aeneas' case, Venus literally prevents him, catching him by the hand and reminding him of his duty to her and to his family, while Sam more prosaically realises that killing Gollum "was not what he had set out to do. It would not be worthwhile to leave his master for that" (715). Next Sam contemplates death, looking "on the bright point of the sword [and thinking] of the places behind where there was a black brink and an empty fall into nothingness" (715), just as Aeneas in his first rush of despair urges his men to "rush to arms and die" (2.478). However, Sam like Aeneas is forced to abandon this desire also, realising that "there was no escape that way ... That was not what he had set out to do" (715).

Forced finally to pin down what it is that "he had set out to do", Sam's thoughts return inevitably to his duty as "the last of all the Company", and his obligation to ensure the safety of "Lorien, and Rivendell, and the Shire and all" (715) by destroying the Ring. As Sam makes his decision, the internal debate that in Virgil is represented by the intervention of a goddess is dramatised as the intervention of Sam's "head" (723) over his heart, which argues for his social responsibility to fulfil his quest despite his personal feelings:

"He quailed still, but his resolve grew. 'What? Me take the Ring from him [Frodo]? The Council gave it to him.'

But the answer came at once, 'And the Council gave him companions, so the errand should not fail. And you are the last of the Company. The errand must not fail."' (715)

Just as Aeneas is ultimately forced to abandon both his personal longing for vengeance and death and his dead wife Creusa for "exile, vast plains/ of sea that [he] must plough" (2.1051-1052), Sam must leave Frodo 
and any hope of avenging his death to continue his journey across Mordor. Both decisions culminate in the two characters taking up burdens, in Aeneas' case both Anchises and the household gods and in Sam's the great weight of the Ring, and "ma[king] for the mountains" (2.1082).

However, it is telling that while Aeneas leaves while "the star of morning r[i]se[s] / above high Ida's ridges, guiding the day" (2.1078-1079), Sam leaves with the Phial of Galadriel echoing less optimistically "the soft radiance of the evening star in summer" (716), and even this is soon diminished as he "stumble[s] on into the growing dark" (715). Unlike Aeneas, Sam does not feel his choice to be the correct one, but instead is haunted by doubt until finally the approach of orcs towards Frodo causes him to abruptly reverse his Virgilian actions, "fl[i]ng[ing] the Quest and all his decisions away, and fear and doubt with them" (718) to return to Frodo's aid. While Aeneas' attempt to defend Troy is partly motivated by the idea of "how fine a thing it is to die in arms" (2.433), Sam specifically rejects the idea of glory associated with death in battle: although he ponders briefly whether "any song will ever mention... how Samwise fell in the High Pass and made a wall of bodies round his master", he quickly realises that if he falls "the Ring'll be found, and there'll be no more songs" (718). Nonetheless, he maintains that he simply "can't help it. [His] place is by Mr Frodo" (718), and "Elrond and the Council, and the great Lords and Ladies with all their wisdom" whose "plans" in this scenario are almost substitutes for the will of Olympian gods "must understand that" (718). Sam's brief unconscious adoption of the Virgilian heroic code is not inappropriate in a practical or even necessarily a moral level: Frodo is not dead, but Sam does not know this, and it is in fact only because Sam at least at first does leave him that the Ring is not taken by the enemy. However, it is none-the-less coded as wrong for Sam, simply because it is "altogether against the grain of his nature" (716). Interestingly, while Aeneas' incorrect behaviour is brought about by acting on his feelings, coupled with the despair that leads him to decide that "the lost have only this one deliverance: to hope for none" (2.479), Sam attributes his own Virgilian 'civic-minded' decision precisely to "trust[ing] his head" over his feelings and "never really ha[ving] any hope" (723), and as a result deems them incorrect: "Never leave your master, never, never" is his "right rule" (724), and his rejection of it is not clear thinking but a momentary lapse of faith for which he hopes to be "forgiven" (724). Unlike Aeneas, who at times must do morally questionable things in order to obey the will of the gods (most notably his abandonment of Dido), for Sam pietas may entail placing the will and safety of others before his own life, but not before his own intuitive moral code; perhaps because Tolkien refuses to conceive of a correct quest where the workings of fate would require him to do so.

Although the analogy remains unfulfilled, this incident and Sam's subsequent rescue of Frodo nonetheless marks a turning point in Sam's rise to heroic status. The burden of the Ring returns to Frodo, but the Aeneaslike burden of decision-making has now entirely fallen on Sam, as Frodo has become "too much occupied with his burden and the struggle in his mind to debate, and almost too hopeless to care" (914) what befalls them. 
Not only does Sam come to assume a leadership role in the quest, notably maintaining a constant cheerful tone to "keep fear away at the very last" (929) just as Aeneas "counterfeits hope" to his men while "his pain/ is held within, hidden" (1.292-293), but he has come to possess the understanding which Frodo began with that saving the Shire will inevitably mean they themselves will be unable to return to it. At the end of their journey, Sam's heroic role climaxes in the manner in which Aeneas' begins, with Sam carrying Frodo up Mount Doom just as Aeneas carries his father Anchises from the destruction of Troy. Aeneas addresses Anchises, "Come then, my dear father, mount upon my neck;/ l'll bear you on my shoulders. That is not/ too much for me. Whatever waits for us, / we both shall share one danger, one salvation" (2.956-959). Sam's address to Frodo before Frodo "cl[ings] upon his back, arms loosely around his neck" (919) is near identical in both words and sentiment, though crucially translated from the high language of epic into lower-class colloquialism:

"'Come, Mr Frodo!' he cried. 'I can't carry it for you, but I can carry you and it as well. So up you get! Come on, Mr Frodo dear! Sam will give you a ride."' (919)

With this action, Sam fulfils the parallel with Aeneas that he earlier aborted, bearing a burden up a mountain. In this case, however, it is fulfilled correctly. Just as Aeneas bears Anchises, who in turn bears the "holy vessels and [their] homeland's gods" (2.970) that Aeneas cannot touch while still "filthy with war" (2.971), Sam carries Frodo who in turn carries the Ring that Sam cannot touch. More importantly, however, it conforms with Sam's own code of conduct, the concept of bearing of a burden for the greater good which Sam cannot fully comprehend being coupled finally with the idea of loving service that is intrinsic to his character.

As the hobbits reach Mount Doom, both Frodo's and Sam's actions once again engage with Aeneas' in a way that both validates and subverts Virgilian heroism. Reckford points out that both Frodo and Aeneas ultimately fail their final tests, Aeneas succumbing to anger and killing Turnus, and Frodo finally succumbing to the power of the Ring (interestingly already linked with powerful anger through the parallels between Boromir and Turnus) and claiming it for his own ("Review" 175). If Frodo's personal failure arguably mirrors Aeneas', however, it is interesting that Sam in almost the same scene proves himself superior to Aeneas (at least in the eyes of Tolkien) specifically with his ability to show pity and mercy to a defeated enemy, as Frodo himself has done earlier. Both Sam and Aeneas find themselves at the climax of the story with their arch-enemies in their power, Aeneas defeating Turnus in single combat and Sam standing over Gollum with his "blade drawn ready for battle" (923) only to have Gollum surrender and plead for his life. Once again, Sam finds himself faced with a crucial decision - reduced in scale but not in importance - comparable to that which Aeneas must confront, and once again the depiction of both his thought processes and his emotional state is eerily similar. Aeneas "stay[s] his hand" (12.1253) briefly before Turnus' pleas for his life, but ultimately becomes "aflame with rage" (12.1264) and deals out justice to Turnus in the name of his victims, telling him, "It is Pallas/ who strikes, who sacrifices you, who takes/ this payment from your shameless blood" (12.1266-1268). Sam is likewise "hot with wrath and the memory of evil" (923), and realises that "it would be just to slay this treacherous, murderous 
creature, just and many times deserved; and also it seemed the only safe thing to do" (923). However, at the same time "his hand waver[s]" (923) as Gollum supplicates him, and he realises that "he could not strike this thing lying on the dust, forlorn, ruinous, utterly wretched" (923). The crucial difference, of course, is that while Aeneas succumbs to his wrath in a way that is uneasily neither validated nor condemned by Virgil, Sam, like Bilbo and Frodo before him, spares Gollum regardless of the possible danger, and is almost immediately proved correct in doing so when the Ring is destroyed as a result. In the moral and heroic code of The Lord of the Rings, pity is deemed more important than justice, and ultimately leads to the successful completion of the quest when all other traditional heroic values fail to do so. More importantly, however, the idea of acting above all for the good of the quest is once again subverted by the idea that acting on intuitive moral codes will, through the workings of fate, always be to the good of the quest. Ultimately, both Frodo and Sam survive and triumph not only because they know when to follow the Virgilian heroic code, but because they know when to allow other codes to supersede it. 


\section{CHAPTER THREE: WOMEN}

As has been pointed out by critics, women are scarce in The Lord of the Rings, and those that do appear are often marginalised, even more so than in classical epic. Nonetheless, the major female figures do engage with classical archetypes in a manner just as complex as that of the more fully-developed heroes, and the way in which they use and subvert these archetypes illuminates the heroic roles expected of both men and women in Middle-earth.

\section{Evenstar of Her People and Morning of Pale Spring: Arwen and Eowyn}

The Lord of the Rings is noticeably lacking in the wives and lovers that populate classical epic, and apart from the homely, understated romance of Sam and Rose Cotton and the undefined relationship of Tom and Goldberry, there are only two women presented in such a light: Arwen, Elrond's daughter and Aragorn's future Queen, and Eowyn, the "passionate, untamed warrior maiden" (Reckford "Some Trees" 62). Between them, however, Arwen and Eowyn engage with their classical counterparts in ways that both employ and modify classical notions of femininity.

Interestingly, Arwen is described in terms of a classical goddess or woman of high birth, her "white arms [and]... bright eyes, grey as a cloudless night" (221) echoing such epithets as "goddess of the white arms, Hera" (II. 1.55 etc) and "goddess grey-eyed Athene" (II. 1.206 etc). In her first appearance, however, she perhaps most closely evokes the figure of Helen of Troy. The two women, both of whom are acknowledged within their respective stories as "the noblest and fairest [lady] who now walks the earth" (1034), are described in ways that are at least superficially similar: Arwen is introduced sitting "against the woven cloths against the wall" (221), while Helen is famously seen "weaving a great web, a red folding robe, and working into it the numerous struggles... endured for her sake" (3.125-128), and both are described in terms of their shining clothing, with Arwen wearing a "cap of silver lace netted with small gems, glittering white" (223) and Helen "wrap[ping] herself in shimmering garments" (3.141). More significantly, however, both women are positioned as observed, with descriptions of their beauty quickly giving way to a focus on male admiration of that beauty. Helen is "s[een]... along the tower approaching" (II. 2.154) by "chief men of the Trojans" (2.153), who comment to each other on the "likeness of her face to immortal goddesses" (2.158), while it is Frodo who "s[ees] her whom few mortals had yet seen; Arwen, daughter of Elrond, in whom it was said that the likeness of Luthien had come on earth again" (223). This male gaze reinforces the concept of both women as functioning, at least in part, as a potential 'prize' awaiting a hero after victory in war. In the case of Helen, this is stated overtly many times, with Iris pointing out to her that, "Menelaos the warlike and Alexandros will fight / with long spears for your possession. / You shall be called the beloved wife of the man who wins you" (2.136-138). Similarly, the 
Aragorn's marriage to Arwen is conditional upon Aragorn becoming "the King of both Gondor and Arnor" (1036), something able to be achieved only after the defeat of Sauron. In this, Arwen not only resembles Helen but the Virgilian Helen of Troy figure Lavinia. Like Lavinia, Arwen is both the reward that awaits the hero upon the achievement of his destiny, and the means of founding a great race, as Arwen's union with Aragorn is described as the means through which "the kingship of Men may be restored" (1036).

It is telling, however, that where Helen is introduced actively (and ambiguously) weaving a pattern that depicts the surrounding warfare, and by extension also weaving the warfare "endured for her sake" (3.128), Arwen sits passively before a cloth already woven. While the Trojans gazing upon Helen's beauty use it to speculate that "surely there is no blame on Trojans and strong-greaved Achaians / if for long time they suffer hardship for a woman like this one" (2.156-157), aligning female beauty with potential danger to men, there is no such alignment in Tolkien. Arwen may be the reward granted to Aragorn upon achieving victory in the war, but she is not herself the cause of that war, and there is no rivalry over her affections as in the case of both Helen and Lavinia. Furthermore, there is no hint in Tolkien that a war born of sexual jealousy would even be a possibility. Although, interestingly, Arwen's description is immediately followed by a reference to battle fought by men on behalf of a captive woman, as Arwen's brothers are explained to be absent "out upon errantry ... r[iding] often far afield with the Rangers of the North, forgetting never their mother's torment in the dens of the orcs" (221), the focus is on a son's duty to his mother, and thus rendered entirely asexual. Similarly, though Frodo's gaze is technically masculine, his admiration of her beauty is characteristically child-like, noting her "loveliness" (221) as that of a "living thing" (221) rather than treating it as specifically feminine. Where Helen's reception by the Trojans encapsulates classical epic's frequent positioning of women as "fascinating, but inscrutable and dangerous" (Griffin 19), with the men admiring her yet desiring her to "go away in the ships, lest / she be left behind, a grief to us and our children" (2.159-160), Tolkien's desired outcome is for Arwen to be left behind in Middle-earth while her people depart in ships, in large part to ensure the continuity of the Dunedain through her children. Unlike Helen and Lavinia, Arwen and her potential marriage to Aragorn represents not a source of disorder, but an opportunity for restoration of order through idealised romantic love.

If Arwen can be seen as the Lavinia to Aragorn's Aeneas, however, then Eowyn can in many ways be seen as the Dido figure, in a way that at least at first complicates the idealised love seen elsewhere in the book. As with Arwen and Helen, the ways in which Dido and Eowyn are introduced are superficially similar: both are depicted as golden-haired and beautiful, with Dido "lovely-bodied" (Aen. 1.700) and Eowyn "fair [of] face" (504), and both are identified as women of power and lineage, with Dido a queen "dealing judgments to her people" (1.715) and Eowyn more passively a "daughter of kings" (504), yet none-the-less "strong... and stern as steel" (504). Furthermore, both characters are seen for the first time playing hostess to travelling heroes, in ways that emphasise their status and position within their respective societies. In a moment very much in the 
style of an epic type-scene detailing a social custom, Eowyn responds to Theoden rising from his throne by "at once... c[oming] forth bringing wine" (511), which she offers to Theoden with the apparently ritualised words, "Ferthu Theoden hal! ... Receive this cup now and drink in happy hour. Health be with thee at thy going and coming!" (511). After Theoden has drunk from the cup, she then "proffer[s] [it] to the guests" (511), who drink also. Although almost certainly modelled on Wealhtheow's cup-bearing scene in Beowulf, 7 the scene also resembles the ritual recounted in Book One of the Aeneid to welcome Aeneas and his men to Carthage. In this scene, Dido calls for "a golden cup, / massive with jewels" (1.1015-1016), fills it with wine, and pours out a libation to the gods with a prayer, similar to Eowyn's but addressed specifically to Jupiter, that "this / may be a day of happiness for those / who come from Tyre and Troy" (1.1020-1022). She then drinks from the cup herself, before passing it to Bitias, one of her courtiers. The similarities between the two scenes do highlight differences in the power both women command. Where Dido drinks first after the libation is poured, marking her power in Carthage as second only to that of Jupiter, Eowyn passes the cup to Theoden, marking him as the ruler and herself as a hostess, like Wealhtheow but without the political power the role is shown granting to Wealhtheow (Neville 108). However, this difference is less clearly drawn as it may appear, as by the end of the scene Eowyn is nonetheless given the power of a ruler at least in Theoden's absence, and power specifically coded as masculine: "[Eowyn] is fearless and highhearted," Hama advises Theoden. "All love her. Let her be as lord to the Eorlingas, while we are gone" (512). Despite Eowyn being more obviously marginalised than Dido, both women are nonetheless presented in a capacity that shows the valued role each plays within their respective societies.

For both Eowyn and Dido, however, this introduction and subsequent cup-bearing scene does not only serve to establish their role and status within their own lands, but also to mark the beginning of an ill-fated love for a man of higher destiny than that which they can offer. Both Eowyn's introduction to Aragorn and Dido's introduction to Aeneas is tied to the realisation or revelation of the the men's hidden power: Eowyn is "suddenly aware" of Aragorn as a "tall heir of kings, wise with many winters, greycloaked, holding a power that yet she felt" (504), while Dido is "startled" (1.861) as Aeneas is more literally revealed "glittering in that bright light, his face / and shoulders like a god's" (1.828-829) as "the cloud that circled [him] is torn" (1.826). For Eowyn, it is this first recognition of Aragorn's greatness that occasions her love, while Dido's love is the direct result of subsequent enchantment by Cupid. Nonetheless, Eowyn's "mistaken love" (Tolkien Letters 161) is comparable to sudden enchantment, striking her "for a moment still as stone" (504) just as Dido is "caught between love's pain/ and press" (4.1-2) when "[Aeneas'] face, / his words hold fast her breast" (4.5-6), and is later described in the language of supernatural madness. Both Dido and Eowyn are said to be burning, with

7 This scene sees Wealhtheow in her role as queen and hostess, offering Beowulf and his men a cup of mead in a ritual that cements their allegiance to Hrothgar just as Eowyn does to Aragorn. This does not, however, necessarily mean that Eowyn is intended to be read as Wealhtheow: Neville argues instead that "[Eowyn] is, if any character in Beowulf, Freawaru, the daughter (or sister's daughter) who could have been married to the visiting hero but is not..." (108). 
Dido "eaten by a secret flame" (4.3) that renders her "insane" (4.102), and Eowyn looking at Aragorn with "her eyes... on fire" and "in great torment of mind" (766). While in Dido's case, this appropriately parallels Turnus' similar divine possession, with Allecto's firebrand causing him to similarly burn with "lust for the sword and war's damnable madness" (7.610), it is interesting that Eowyn, despite being possessed only by her own emotions, is described with the same imagery used elsewhere only to convey characters' insane desire for the Ring: just as Boromir looks at the Ring for the first time with his "eyes glint[ing] as he gazed at the golden thing", for example, Eowyn's "eyes [are] shining" (511) as she offers Aragorn the cup during their first exchange. Unlike that of Aragorn and Arwen, Eowyn's love is coded as incorrect, specifically through the use of classical imagery that allows for destructive potential.

The parallels between Dido and Aeneas and Eowyn and Aragorn are highlighted in the most significant exchange between the latter pair, shortly before Aragorn departs for the Paths of the Dead. Like Aeneas, who is forced to abandon Dido and Carthage for "fields assigned by fate" (4.484), Aragorn is called away from Eowyn and the Rohirrim for "a path appointed" (766), and in both cases this prompts a furious debate. Although Aragorn has made no attempt to deceive Eowyn as Aeneas has Dido, Eowyn's distress mirrors that of the Queen of Carthage, with "her eyes ever upon Aragorn ... in great torment of mind" (766) just as Dido "scans [Aeneas'] body with her silent eyes" (4.495) and her "mind is helpless" (4.402). Both attempt to convince the hero first to turn aside from their destinies and then to remain with them (or, in Eowyn's case, for her to be allowed to remain with Aragorn). Both women, however, are gently rebuffed. Aeneas insists that "it is not / [his] own free will that leads to Italy" (4.491-492), and Aragorn similarly states that he "do[es] not choose paths of peril" (766). Despite the women's protests and their own regret, Aragorn and Aeneas both hold firm to their appointed paths, Aeneas turning back to his fleet "though groaning long and shaken in his mind" (4.542) while Aragorn "r[i]de[s] away, and d[oes] not look back, and only those who knew him well and were near to him saw the pain that he bore" (768).

Crucially, from Aragorn's perspective at least the two scenes are very different. Although Morse sees both Eowyn and Dido as "potential distraction[s]" who seek to "keep [the hero] from his duty" (19), Eowyn in fact explicitly "d[oes] not bid [Aragorn] flee from peril, but to ride to battle where [his] sword may win renown and victory" (767), and does not ask that Aragorn remain with her but that she herself be allowed to "ride in [his] following" (767). This idea is not entirely incompatible with Dido, who briefly considers whether she should "sail away on Trojan ships, to suffer there even their harshest orders" (4.742-3) upon Aeneas' departure. In Eowyn's case, however, it reflects not only a desire for Aragorn but for the "hope of glory and great deeds" (849) he represents and therefore lessens the responsibility placed on Aragorn himself for her distress. More importantly, however, while Aeneas loves Dido and must forsake her for a marriage with Lavinia that carries no promise of personal happiness, Aragorn does not love Eowyn, and forsakes her for a path that will lead to 
marriage with Arwen (Reckford "Review" 174-5). Although both Aragorn and Aeneas claim to be acting from duty rather than "[their] own free will" (Aen. 4.492), the two heroes' professed preferred actions are very different: where Aeneas goes on to say that "if fate had granted me to guide my life to my own auspices ... then I should cherish first the town of Troy... my hand would plant again a second Pergamus for my defeated men" (4.460-467), Aragorn says more simply that, "Were I to go where my heart dwells, far north I would now be wandering in the fair valley of Rivendell" (766) (Reckford "Review" 174-175). Unlike Aeneas, who wishes a return to the past but must instead face "long exile" (2.1052), Aragorn's "path of peril" (766) is leading to him to the future he desires, and Eowyn's love is a source of "bitterness and shame" (849) for him not because he returns it but because he "cannot" (849). The danger of romantic passion that in classical epic is capable of creating war between Greece and Troy is therefore contained by the fact that Aragorn is operating according to a non-classical code, more akin to that of chivalric romance. For Eowyn, however, who is essentially living in a different epic, the effect of Aragorn's rejection of her is almost that of Aeneas' rejection of Dido, lacking only Dido's desire for revenge. Eowyn, like Dido, is depicted watching the departing soldiers in anguish, "stand[ing] as still as a figure carven in stone ... until they passed into the shadows" (768) before "turn[ing], stumbling as one that is blind, and [going] back to her lodging" (768) in a way that Libran-Moreno argues evokes Dido turning from Aeneas in the Underworld with "eyes to the ground.../ as stubborn flint or some Marpessan crag" and "fle[eing]... into the forest/ of shadows" (Aen. 617-622) (Libran-Moreno 87). Both, having failed to obtain the love they desire, "desire to have nothing" (943), but instead choose to die and "set aside [their] sorrow by the sword" (Aen. 4.758-9).

Eowyn, however, does not only bear comparison with Dido, but also, as Reckford points out, with Camilla ("Some Trees" 62), and therefore her means of seeking death is very different. Interestingly, Dido herself is in her first introduction also linked with Amazons, described with the simile of "Diana / incit[ing] her dancers" (1.703-704) immediately after a description of Penthesilia on the Catharge frieze, just as Eowyn's Dido-like first introduction is punctuated with a description of her as "stern as steel" (504) that foreshadows her "clear voice... like the ring of steel" (823) as she faces the Nazgul Lord in battle. Where Dido's 'warrior woman' associations appear at the height of her power and vanish after succumbing to Cupid, however, Eowyn's are only strengthened by her disappointed love for Aragorn. It is in direct answer to Aragorn's refusal to allow her to follow him to war that Eowyn declares herself to be "a shield-maiden ... Of the house of Eorl and not a servingwoman. I can ride and wield blade, and I do not fear either pain or death" (767), echoing Virgil's description of Camilla as "a warrior; her woman's hands have never grown accustomed to distaffs or the baskets of Minerva; a virgin, she was trained to face hard battle and to outrace the wind with speeding feet" (7.1057-61). Unlike Camilla, Eowyn is forced to ride to war in disguise as Dernhelm, a male Rider. However, the moment when her identity is revealed sees her proclaim her gender as a threat to her enemy in a way that parallels the Amazon warrior, telling the Nazgul Lord with a laugh that "no living man am I! You look upon a woman" (823), much as 
Camilla jeeringly tells her enemy, "The day has come / that, with a woman's weapons, will refute / your nation's threats" (11.906-908). Witnessed in "amazement" (823) by Merry just as Camilla is looked on by a crowd that "marvel, staring, in astonishment" (7.1068), Eowyn in this moment is described in similar terms to Camilla, both stressing the "bright hair" (823) of the two women in contrast to their armour and weapons and thus their mix of masculine and feminine qualities. Tellingly, however, Merry goes on to note that "Eowyn it was, and Dernhelm also. For into [his] mind flashed the memory of the face that he saw riding from Dunharrow: the face of one that goes seeking death, having no hope" (823). The fate Eowyn intends for herself following Aragorn's rejection is one that attempts to merge both Dido's and Camilla's, with Eowyn seeking to "set aside her sorrow by the sword" (Aen. 4.758-9) not through Dido's suicide but through Camilla's "brave death in battle" (943). In Eowyn's greatest heroic moment, she is not only "Eowyn ... yet Dernhelm too" (823), but also Dido, yet Camilla too, both a "maiden of the Rohirrim" (823) seeking to "do great deeds" (767) and a "child of kings" (823) scorned in love.

The death Eowyn seeks appears at first to be granted in epic fashion, as Eowyn after her climactic defeat of the Witch-King "f[alls] forward upon her fallen foe" (824). Later her 'body' is found by her brother, who is subsequently seized by a "fey mood" (826) comparable to Achilles' fury at the death of Patrocles or Aeneas' at the death of Pallas, ${ }^{8}$ and leads his men on a furious charge while Eowyn herself is borne away in ritual fashion and the elements themselves "weep ... quenching the fires of the City with grey tears" (827). However, the familiar pattern is unexpectedly reversed as Imrahil points out that Eowyn is, in fact, alive, and able to be healed by Aragorn. Unlike the heroines whose code of conduct she is unconsciously adopting, Eowyn finds herself having to live beyond her own epic death. At first, Eowyn's reaction to this is essentially to try again, asking to be allowed to "ride to war like ... Theoden the king, for he died and has both honour and peace" (939). Instead, however, the "healing ... which [Aragorn] cannot bring" (849) comes at the hands of Faramir, and through a restoration of the idealised love that characterises Aragorn and Arwen's relationship.

Interestingly, Faramir has himself survived Dido-like immolation on a funeral pyre, though the attempted suicide was not his own but his father's. More importantly, however, Faramir is, as has been argued earlier, an Aeneas figure without Aeneas' heroic destiny. As a result, he is able to enter into a union with Eowyn that is denied Aeneas and Dido, and Eowyn subsequently begins to revise her opinion of her own behaviour to better match the story in which she has unexpectedly found herself. Upon meeting Faramir, Eowyn "for the first time... doubt[s] herself" (938) and her desire for death in battle, afraid that Faramir may "think her merely wayward, like a child" (938). Meanwhile, Faramir correctly reframes her previous love for Aragorn as not true

8 Libran-Moreno points out that Eowyn lying near death in the House of Healing and the description of Pallas' death in the Aeneid are described with very similar imagery (76): Eowyn is compared by Aragorn with "a white flower . . . still fair to see, but stricken, soon to fall and die" (Tolkien 84), much as Pallas lies "like a flower plucked by a young girl's fingers, a sweet violet or a drooping hyacinth, whose brightness and beauty have not yet faded, but whose native earth no longer nourishes it, or gives it strength" (Aen. 11.68-71, cited by Libran-Moreno 76). 
romantic love as it operates in Middle-earth but the admiration of a "young soldier" for a "great captain" who "seem[s] to [her] admirable" (943), while seeking her love for himself. Significantly, where Aeneas gives Dido "a veil... / once worn by Argive Helen, / who had borne them off to Troy and her unlawful / wedding when she had fled Mycenae" (1.907-910), Faramir gives Eowyn "a great blue mantle... wrought for his mother, Finduilas of Amroth, who died untimely, and was to him but a memory of loveliness in far days and of his first grief" (940). Although both are tokens of past grief associated with feminine beauty, Helen and her "unlawful / wedding" (1.909-910) serve as a reminder of love's destructive potential, while Finduilias and Faramir's sorrow at her death evoke only a son's correct devotion to his mother, akin to that of that of Arwen's brothers referenced at her first appearance. Once again, the idea of dangerous passion is replaced with idealised love associated with non-sexualised family relationships (it is perhaps significant that Faramir's first impression of Eowyn's beauty, as with that of both Arwen and Findulias, is characterised with the platonic term "loveliness" (938)).

Ultimately, the union Eowyn finds with Faramir "heal[s]" (944) her not only of her despair but also of her associations with the doomed women of the Aeneid. Just as Camilla's position as a warrior woman is repeatedly tied to her virginity, when Eowyn falls in love she subsequently renounces arms, declaring, "I will be a shieldmaiden no longer, nor vie with the great Riders, nor take joy only in the songs of slaying" (943). It is not only Camilla's associations that are abandoned upon her successful union with Faramir, however, but also Dido's, as she tells Faramir that, "no longer do[es she] desire to be a queen" (943), implicitly because "[Faramir] is not a king" (943). Instead, Eowyn opts to be "a healer, and love all things that grow and are not barren" (943), and Faramir proposes that they depart to "in happier days... dwell in fair Ithilien and there make a garden" (943-4). Although Libran-Moreno argues the imagery used can still be traced back to a Latin heritage, it now belongs not to the language of epic but of the pastoral, more usually associated in The Lord of the Rings with the hobbits. Where Faramir is able to avoid the fates of either Hector or Aeneas by successfully integrating aspects of both, Eowyn attempts to embrace the fate of both her classical models, only to survive it and subsequently reject her resemblance to either. In this sense, she exemplifies the bittersweet "passing of the 'Heroic Age"' (Bradley 82) that Bradley identifies as central to both Eowyn's story and that of The Lord of the Rings as a whole.

\section{"Few Escape Her Nets": Galadriel and Shelob}

If classical wives and lovers such as Helen, Lavinia and Dido are often ambiguous, offering the potential for both domestic stability and dangerous passion, this ambiguity is heightened in the figures of the enchantress or goddess that are also common to classical epic, perhaps most famously exemplified by Circe in Homer's Odyssey. In many ways, Circe can be read as simultaneously representing feminine power and the fear of 
feminine power, serving as both a threat and a guide to Odysseus and his men. In The Lord of the Rings, the equivalent enchantress figure is Galadriel, who like Circe is presented to us at first as "perilous" (329) and yet swiftly becomes a powerful ally of the Fellowship.

Before the Fellowship encounter Galadriel, she is introduced to us through the fears of Boromir, who has heard rumours of Lothlorien as a "perilous land" where "few come out who once go in, and of that few none have escaped unscathed" (329), and these are supplemented later by Eomer's descriptions of the "Lady of the Golden Wood" of whom it said that "few escape her nets" (422). Although the motif of a sorceress inhabiting an enchanted forest is common to many cultures, Galadriel and Lothlorien notably bear similarities to Circe and her island of Aeaea in the Odyssey. Aeaea, like Lothlorien, houses a powerful enchantress in "a forest glen" (Od. 10.210) (although, here and elsewhere, Tolkien's descriptions of the environment in question are far more detailed and evocative than Homer's "undergrowth and forest" (Od. 10.150)), and is, as Aragorn says less literally of Lothlorien, a place where "none have escaped... unchanged" (329) as Circe uses her powers to turn men into animals. Both, despite the rumours surrounding Lothlorien and the initial dangers of Aeaea, come to serve as places of rest and cleansing from long travel and the loss of companions, with Odysseus being "washed... from the great cauldron /... to take the heart-wasting weariness / from [his] limbs" (10.361-364) just as Frodo feels "all weariness... washed from his limbs" (339) by the waters of Nimrodel. Both parties are offered hospitality there, with Galadriel inviting the Fellowship to "not let [their] hearts be troubled. Tonight you will sleep in peace" (348) just as Circe tells Odysseus' men, "No longer raise the swell of your lamentation.../ Come now, eat your food and drink your wine, until/ you gather back again into your chests that kind of spirit/ you had in you when first you left the land of your fathers" (Od. 10.457-463). Moreover, both parties ultimately spend longer availing themselves of this hospitality than they intend. Odysseus and his men spend "a year... feasting on unlimited meat and sweet wine" (10.468) while "the months wasted away, and the seasons changed, and the long days were accomplished" (10.469). Meanwhile, though the Fellowship feel they have only spent "some days" (349) in Lothlorien, doing "little but eat[ing] and drink[ing] and rest[ing]" (349), they find later that they have been there a month while "the old moon passed, and a new moon waxed and waned in the world outside" (379).

If there are similarities between Aeaea and Lothlorien, the similarities between Circe and Galadriel are even more pronounced. As Burns points out, Galadriel is frequently referred to as a weaver, either metaphorically of "webs of deceit" (502) and "nets" which "few escape" (422), or literally of the semi-magical cloaks that "she herself and her maidens wove" (361) for the Fellowship. This trait, which "borrow[s] from the long-standing tradition of female spinning and weaving and the magic and danger these activities suggest" (Burns 120), is one she shares not only with Circe, who is discovered weaving "a great design on a loom" (10.222), but also with Helen of Troy and Penelope, all of whom link weaving with trickery or danger toward men. In keeping with 
this, Galadriel continually displays evidence of powers associated with classical feminine magic, like Circe being linked with prophecy and giving guidance to the heroes. In the Odyssey, Odysseus is reminded by his men after a year of his desire to return home, and subsequently seeks help from Circe. Circe sends him on a quest to the Underworld, telling him how to obtain the prophesies of Teiresias, and upon his return gives him crucial instructions regarding his passage home, including various warnings about the Sirens, Skylla, Charybdis, and the cattle of Helios. Interestingly, in The Lord of the Rings Tolkien delegates the practical instructions to Celeborn, and it is he who describes the Fellowship's path upon their departure and gives a warning (perhaps crucially an incorrect one) to avoid "becoming entangled in the Forest of Fangorn" (364). Galadriel, by contrast, claims she is "not a counsellor" (354), and yet she takes an even more active role in the giving of prophecy than Circe. Like Odysseus' men, after spending an indeterminate length of time in Lothlorien Sam suggests to Frodo that "if we've got to go on, then we'd best get it over" (352), whereupon "as if in answer to their words" (352) Galadriel approaches and beckons them. Frodo and Sam follow Galadriel to an "enclosed garden" (352) (similar to both the "grove of Persephone" (Od. 10.509) where Odysseus summons the dead upon Circe's instruction and the "deep, enormous grotto" (Aen. 7.13) in the forest where Aeneas encounters the Sybil), and are shown images of "things that were, and things that are, and things that yet may be" (352) through a Mirror that give them hints of the road ahead.

Unlike Circe, however, who sends Odysseus to Teiresias for prophecy, and Aeneas' Sybil, who gives prophecies after being forcibly possessed by Apollo, Galadriel's magic is independent of masculine control: she is "able to command the Mirror" (352) herself if she chooses, and in fact it is Gandalf who later becomes the messenger for her prophecies as she uses him to send cryptic messages to Aragorn, Legolas and Gimli. In this, she perhaps more closely resembles a classical goddess, something also hinted at in her ability to shift the way other characters perceive her. Just as Venus is seen by Aeneas transforming from her "face and dress... like a maiden's /... [with] her hair... free, dishevelled by the wind" (Aen. 1.446-453) to her true form with "her neck... glittering with a rose brightness; / her hair anointed with ambrosia /... [and] even/ her walk... sign enough that she was a goddess" (Aen. 1.576-578), Galadriel tempted by the Ring briefly seems to Frodo "tall beyond measurement, and beautiful beyond enduring, terrible and worshipful" (356) before returning to "a slender elf-woman, clad in simple white, whose gentle voice was soft and sad" (356). Interestingly, this scene is also the closest The Lord of the Rings ever comes to the alliance of feminine beauty with danger that permeates classical mythology, with the "Queen" (356) Galadriel would become upon possession of the Ring described as "beautiful and terrible as the Morning and the Night ... All shall love me and despair!" (356). Briefly, Galadriel is shown with the potential to become not only a beautiful, powerful goddess-figure, but one that is dangerous precisely because of her beauty and power in the manner of the often "fascinating, but inscrutable and dangerous" (Griffin 19) women of epic. 
However, as with Arwen, this dangerous potential of Galadriel is largely nullified by Tolkien. Interestingly, unlike Circe or other sorceress characters of epic, Galadriel is married, and although her husband Celeborn has a much lesser role in the story they are introduced together "side by side" (345) and it is Celeborn who at first conducts the ritual greeting of the guests. This establishment of Galadriel as a wife (and, though it is less emphasised, a mother) is made more striking by the fact that, while wives and mothers are common figures in Homer and Virgil, Galadriel is one of only three married women of The Lord of the Rings until the very end of the book: while the nymph-like Goldberry is married to Tom Bombadil and Lobelia Sackville-Baggins is a caricature of a wife and mother, the major characters are for the most part unmarried, with their mothers either dead (as in the case of Frodo, Sam, Eomer and Eowyn, Faramir and Boromir, Aragorn and even Arwen), or simply not mentioned..$^{9}$ As a result, while Circe's dangerous power is tied to her sexuality and powers of seduction, Galadriel is not available romantically to any other character, and is never made to appear so. While she is repeatedly described by male characters as beautiful, in her first introduction our impression of her beauty is mediated through descriptions allying her with her husband: "both" (345) Celeborn and Galadriel are "very tall ... grave and beautiful" (345), and while "the hair of the Lady was of deep gold ... the hair of the Lord Celeborn was of silver long and bright" (345). The characters who do later praise her beauty most explicitly are Sam and Gimli, neither of whom, as a hobbit and a dwarf, are in a position to serve as a romantic interest. Gimli's devotion to Galadriel, in fact, is occasioned not by her beauty but by the "love and understanding" (347) displayed by her speaking his own language, and clearly meant to be read as an idealised (and semi-comic) exercise in chivalry, with Gimli requesting and receiving a 'token' in the form of a lock of her hair. In this way, Galadriel is, like Arwen, contained within her correct social context, and works as a cause of peace rather than war: like Arwen, her coming to Minas Tirith upon Aragorn's coronation represents a restoration of order, while on a more personal level Gimli's love for Galadriel is the origin of his friendship with Legolas, "greater than any that has been between Elf and Dwarf" (1055).

Moreover, while Galadriel as well as her land continues to be referred to as "perilously fair" (664) throughout the book, this fear of her is revealed to be unfounded, or at least misunderstood. Aragorn corrects Boromir's initial assessment of Lothlorien as "perilous" (329), saying that while it is indeed "fair and perilous... only evil need fear it, or those who bring some evil with them" (329). Although the men are discussing magic, the use of the phrase "fair and perilous" (329) once again evokes the classical alliance of beauty (specifically feminine beauty) with danger to men, yet reconfigures the danger to become something that originates with the man's response. Sam later expands on this, qualifying Galadriel's 'peril' in particular as something not consciously wielded as Circe does her own power. Rather, it is akin to a force of nature, which like the Ring acts on desires that are already present but unlike the Ring does so not by manipulating those desires but by showing them

9 This is true not only for the major characters, but for the supporting characters: the Citadel Guard Beregond, for example, has a son, but the boy's mother is not mentioned. 
for what they always were:

"It strikes me that folk takes their peril with them into Lorien, and finds it there because they've brought it with them. But perhaps you could call [Galadriel] perilous, because she's strong in herself. You, you could dash yourself to pieces on her, like a ship on a rock, or drownd yourself, like a hobbit in a river. But neither rock nor river would be to blame." (664-665)

Ultimately, however, any truly dangerous element to Galadriel is surrendered by Galadriel herself. Faced with the choice to take the Ring for herself, Galadriel chooses instead to "diminish, and go into the West, and remain Galadriel" (357), and Frodo later sees her upon their parting "again standing like a queen, great and beautiful, but no longer terrible" (367). Far more consciously than Eowyn, Galadriel (who is revealed in The Silmarillion to have been, like Eowyn, originally of "Amazonian disposition" (Letters 428, cited in Burns 151)) gives up the parts of herself most closely associated with classical epic in order to allow the passing of Middleearth's Heroic Age after the defeat of Sauron.

If for the most part however the female characters of The Lord of the Rings are unambiguously positive and idealised, if often marginalised, there is one telling exception to this rule, which comes in the form of Shelob. Burns suggests that Galadriel and Shelob, an "evil thing in spider-form" (707), can be seen as matched in much the same manner as Gandalf and Saruman, an ideal character linked with a "specific negative one[...], thereby suggesting a darker, undeveloped side" (94). Though this mirroring of Galadriel and Shelob is certainly not as apparent as that of the two wizards, it is clear that the element of monstrous femininity, often prevalent in mythology but eschewed in Tolkien's presentation of his female characters, is embodied in extreme form in Shelob. Shelob literally weaves the "nets" to ensnare passing travellers that Galadriel is unjustly accused of weaving metaphorically (Burns 120), and her feminine association with the natural world is with darkness and decay where Galadriel's is with light and growth in the form of the Golden Wood. Moreover, if Galadriel (along with most of Tolkien's female characters) is carefully not sexualised, Shelob possesses a "particularly unattractive sexuality" (Burns 117), characterised by "lust" (707) and "hunger" (707) and giving birth to thousands of "lesser broods, bastards of the miserable mates, her own offspring, that she slew" (707). Partly as a result of this, Shelob is unrelentingly physical in direct contrast to the ethereal "loveliness" (938) of Tolkien's human and Elven women, and her "huge swollen body" (709) is not only repeatedly described but described in highly sensualised terms, possessing smell (a "foul stench" (712)), texture ("soft" and "knobbled" (709)), and even sound ("creaking" and "squelching" (709)). ${ }^{10}$ While the dangers of feminine seduction and temptation present in classical epic remain absent from The Lord of the Rings, Shelob clearly represents a darker, more repulsive form of femininity, characterised by "flesh" (712), greed and destructive fertility.

10 This last is at least in part merely the convention of a monster fight: the Nazgul Lord's winged steed is similarly "naked [with] vast pinions... as webs of hide between horned fingers, and it stank". However, the fact that the winged steed (as well as Tolkien's other monsters, such as the Balrog and the Watcher in the Water) is without gender while Shelob is very specifically female does make her unique. 
In this, Shelob echoes female monsters found in many cultures, but in classical epic seen most clearly in Virgil's Harpies and Homer's Sirens and "evil monster" (Od. 12.87) Skylla. The harpies, like Shelob, are characterised by hunger and "stench" (Tolkien 709; Aen. 3.299), have "bellies [that] drip with a disgusting discharge" (3.285-6) just as Shelob's "vast belly" (711) when wounded "leav[es] a trail of green-yellow slime" (713), and are at first seemingly impervious to swords which men stab at them from below, with "no blow" able to "wound [the Harpies'] wings or scar their backs" (3.316) while Shelob's "age-old hide" (711) is "scored ...

with a dreadful gash, but those hideous folds could not be pierced by any strength of men" (711). Meanwhile, the Sirens live on a beach "piled with bonecaps of men now rotted away, and the skins shrivel on them" (Od. 12.45-46) loosely reminiscent of Shelob's lair with its "foul reek, as if filth unnameable were piled and hoarded in the dark within" (701), and Skylla lives in a high cave that is "misty-looking and turned toward Erebus and the dark" (Od. 12.80-81), just as Shelob lives in a tunnel filled, perhaps metaphorically, with "a black vapour wrought of veritable darkness itself" (702). Skylla likewise has multiple feet, and waits in her tunnel to devour dolphins, dogfish, sea-monsters and passing travellers with jaws that are "full of black death" (Od. 12.92) much as "all living things are [Shelob's] food and her vomit darkness" (707). Like these monsters, Shelob is a primal force of nature that can be foiled but never entirely defeated: unlike the Nazgul's winged steed, Shelob remains alive at the end of the book. More interesting, however, is the fact that as with both Skylla and Charybdis in the Odyssey, Shelob is foiled at least in part by the wisdom and foresight of a corresponding powerful enchantress figure. While it is Circe who advises Odysseus how to pass both the Sirens and Skylla with minimal loss of life, first Frodo and then Sam are able to repel Shelob by using the Phial of Galadriel, given to them to be "a light ... in dark places" (704). As in the Odyssey (and classical mythology in general, seen more usually in the aid of Athena against monsters such as Medusa and the Furies), opposing paradigms of femininity are set against each other, with the more ambiguous tensions between the various female characters of the Odyssey transformed by Tolkien into a Christian battle of light and spirituality against physicality and the "powers of night" (704).

\section{Conclusions}

What some critics have identified as the marginalisation of women in The Lord of the Rings can be partially explained by the conventions of both the epic and medieval quest narratives on which Tolkien is drawing, which tend to confine adventuring strictly to the masculine world. However, it is undeniable that women have a far lesser presence in Tolkien than in any of the classical epics. Where the lliad, the Odyssey and the Aeneid are populated with wives, mothers, daughters, queens and prophetesses, female characters are scarce in The Lord of the Rings, and with the exception of Eowyn their relationships with the male heroes feature very little in the book. Though Arwen's heartfelt grief and inability to "despite all her wisdom and lineage... forbear to plead 
with [Aragorn] to stay yet a while" (1037) on his death-bed is easily equal to Andromache pleading with Hector to "stay here on the rampart,/ that you might not leave your child an orphan, your wife a widow" (II. 431-432), where the latter forms an important part of the epic, Arwen and Aragorn's domestic scene is relegated to the appendix. The Lord of the Rings is far from lacking in the glorification of qualities traditionally regarded as feminine: the hobbits, for example, are paragons of domesticity, while the greatest heroes in Tolkien, including Aragorn, are valued not only for the classically masculine ability to bear arms but for their ability to nurture and heal (Burns 129-130). These qualities, however, rarely require the presence of actual females. If the women in The Lord of the Rings conform largely to classical archetypes, they do through the lens of the intervening Victorian era and Tolkien's own cultural and personal prejudices: as Burns points out, "Tolkien was, after all, a Victorian by birth, and the particulars of his upbringing - the loss of his mother when he was twelve, his years spent as the ward of Father Francis Morgan, the traditionally male education he received - no doubt gave him a more than usually rigid conception of the female role" (131). Moreover, like the heroes, they do so through the lens of Tolkien's Christian beliefs, which allow for less moral ambiguity than those of Homer or even Virgil's era. As a result, just as the positive and negative aspects of the wily trickster Odysseus are siphoned into the contrasting and competing figures of Gandalf and Saruman, the positive aspects of classical femininity are idealised in figures such as Arwen and Galadriel while the negative are (literally) embodied by the monstrous form of Shelob.

Given this, however, the few women that are depicted in The Lord of the Rings are nonetheless crucial to both the story itself and how the motifs of classical epic play out within it. In their engagement with their epic counterparts, all three of the major female characters use and supersede classical ideas of femininity in ways that exemplify how these ideas operate in Middle-earth. Ultimately, like the heroes, the women must navigate codes of behaviour both classical and non-classical, and willingly relinquish those out of place in the age being born around them. Eowyn surrenders her parallels to both Dido and Camilla in favour of healing and being healed, Galadriel refuses the goddess-like power the Ring would allow her, and Arwen, already lacking the sexual power usual to a Helen or Camilla figure, cements her domestic role by giving up her immortality and becoming Aragorn's Queen. This is presented not as disempowerment, but as a bitter-sweet necessity that forms the basis of Tolkien's conception of heroism. 


\section{CHAPTER FOUR: AN EPIC WORLD}

As most commentators have identified, one of the primary functions of classical epic is social, arising from the need for an oral record of culture, custom and established history (Merchant 1) that "sorts through and makes comprehensible important communal experience" (Toohey 33). Unlike those depicted in classical epic, the societies of The Lord of the Rings are, of course, purely fictional, and not representative of the culture Tolkien himself was writing in. Despite this, however, the books can to a surprising extent be read as what Reichl terms "normative epic, a narrative in which the values of heroic behaviour are presented within the cultural value system of the society depicted in the epic" (68-9), containing many examples of epic type-scenes that illustrate the correct manner in which a hero should behave both in peace and in battle. Most notably, the ritualised hospitality episodes that appear frequently throughout the book can be read in much the same manner as the various hospitality scenes in the Odyssey, showing the way in which to receive, and behave as, a guest, while the way in which battle is depicted exemplifies a particular kind of heroic code influenced in part by classical ideals.

\section{Meeting Your Match in Courtesy: Hospitality in Middle-earth}

As pointed out previously, in many ways Bilbo's welcome of the dwarves in The Hobbit can be seen as a comic version of a classical hospitality scene, and as the book continues hospitality scenes recur in a more serious (though still very much a folk-tale) vein as first Elrond and then Beorn play host to Bilbo, Gandalf and the dwarves. In The Lord of the Rings, however, hospitality comes to play a far more important role in Tolkien's conception of Middle-earth, with the travellers becoming the guests of hosts as varied as Tom Bombadil, Galadriel, Theoden, Faramir and Treebeard, and the scenes themselves come to be described with a ritualistic attention to pattern and detail unusual in a modern novel but crucial to Homeric and Virgilian epic. As with all elements of The Lord of the Rings, these hospitality scenes draw also from a variety of non-classical sources, with the Rohirrim in particular using Northern motifs such as the questioning by the door-warden and Eowyn's function as cup-bearer. However, they also bear strong similarities to the classical depiction of xenia, particularly when compared to Reece's grid of thirty-eight elements commonly found in Homeric hospitality scenes. According to Reece, these elements consist of:

I. An encounter with a maiden at a well/youth on the road

II. Arrival at the destination

III. Description of
a. the residence
b. the person sought
c. others present 
IV. A dog at the door

V. Waiting at the threshold

VI. Supplication

VII. Host
a. catching sight of the visitor
b. hesitating to offer hospitality
c. rising from their seat
d. approaching the visitor
e. attending to the vistor's horses
f. taking the vistor by the hand
g. bidding the visitors welcome
h. taking the visitor's spear
i. leading the visitor in

VII. Visitor being seated

IX. Feast
a. Preparation
b. consumption
c. formulaic conclusion

X. After-dinner drink

XI.a. Host questioning the visitor

b.visitor revealing their identity

XII. Exchange of information

XIII. Entertainment

XIV. Visitor pronouncing a blessing on the host

VX. Visitor sharing in a libation or sacrifice

$\mathrm{XVI}$. Visitor asking to be allowed to sleep

XVII. Bed

XVIII. Bath

XIX. Host detaining the visitor

$X X$. Host gives the guest a gift

XXI. Departure meal

XXII. Departure libation

XXIII. Farewell blessing

XXIV. Departure omen and interpretation

XXV. Escort to visitor's next destination 
Reece notes, however, that "no hospitality scene contains every element on this grid; in fact, no hospitality scene in Homer is exactly identical to any other" (6-7).

The hospitality scenes in The Lord of the Rings do not necessarily follow these elements in the classical order, and some of the underlying principles are entirely absent: most strikingly, the idea at the centre of Greek xenia that a guest need not identify himself until after the meal does not occur, with Eomer at one point even declaring it etiquette that "the stranger should declare himself first [before the host]" (422). None-the-less a distinct pattern is established early, in the hobbits' encounter with Tom Bombadil, and continues through all other major hospitality episodes; moreover, as in classical epic, it is one that provides a way of reading individual instances of the relationship between guest and host.

The Tom Bombadil episode - in many ways the hobbits' first real foray into the wider epic world - is in some ways a reversal of the epic trope of a god seeking hospitality in disguise: instead, the hobbits receive hospitality from Goldberry, "daughter of the River" (121), and Tom, "Master of wood, water and hill" (122), in a simple cottage in the Old Forest. Despite this, however, it also, as the first and most lengthy hospitality scene of the book, serves as an example of the way hospitality functions among the civilised races of Middle-earth, and closely follows the model of xenia seen in classical epic, containing twenty-two of Reese's thirty-eight elements. Upon the hobbits' arrival at Tom's house (II), the surroundings of the house as well as the house itself is described in detail (III.a.), as well as Goldberry herself, who like a number of classical hosts is engaged in the act of music and singing (III.b.). The hobbits wait at the threshold, or more precisely just beyond it as they "step[...] over the wide threshold and st[an]d still, blinking" (121) (V), until Goldberry welcomes them as "good guests" (VII.g.), "spr[i]ng[ing] lightly up" (121) (VII.c.), "r[u]n[ning] laughing toward them" (121) (VII.d.) and "taking Frodo by the hand" (121) (VII.f.). She then invites them to "sit now" (VIII), and wait for Tom, who is already "tending [their] tired beasts" (122) (VII.e.). After being seated, the hobbits watch Goldberry prepare their supper (IX.a.), then at Goldberry's reminder Tom offers them a bath (XVIII) before they begin "a long and merry meal" (123) (IX.b.). In this case, although the hobbits clearly expect conversation after the meal, it is forestalled with the explanation that "some things are ill to hear when the world's in shadow" (124) and the guests are shown to a bed with "mattresses and pillows... soft as down and... blankets... of white wool" (124) akin to that offered to Odysseus by Eumaeus (XVII). This is remedied the following day, however, when the hobbits wake to rain that causes Tom to declare it "too wet for hobbit-folk" (127) (XIX) and proceed to entertain them with "many remarkable stories" (127) (XIII). These lengthy stories give way to further supper and entertainment, whereupon they are finally "plied with questions" (130) in exchange for that which Tom has answered for them (XII). ${ }^{11}$ The night before departure, Frodo has a significant vision ("either in his dreams or

11 It is, however, not necessary for the hobbits to reveal their identities as Tom "appeared already to know much about them" (130); instead, it is Frodo who tries unsuccessfully to ask his host's identity (twice). 
out of them" (132)) that almost entails an omen (XXIV), as he sees the "far green country under a swift sunrise" (132) that prefigures his final departure to the Grey Havens. The hobbits subsequently leave Tom's house following a nondescript breakfast $(\mathrm{XXI})$, receiving as they do so a farewell blessing from Goldberry ("North with the wind in the left eye and a blessing on your footsteps!" (133)) (XXII). Moreover, although the guests have essentially a 'false start', departing Tom's house without seeing the Master of the House, they almost immediately require Tom's assistance, and after parting with him for the second time he gives them gifts in the form of swords from the Barrow (like those given in epic, the gifts are valued for their history, "forged many years ago by Men of Westernesse" (142)) (XX) and an escort to the borders of his lands, with the hobbits requesting he come with them as far their next destination (XXV). Notably, the episode is long and elaborate, described with the same attention to physical detail and ritual actions given to classical type-scenes (the hobbits are not merely served food, for example, but "yellow cream and honey-comb, and white bread, and butter; milk, cheese, and green herbs and ripe berries gathered" (122)) and the hobbits are referred to throughout the scene as "guests" by both their hosts and by Tolkien's narration, alluding to the role they are playing in a formulaic procedure.

Moreover, the book's adherence to these epic patterns of behaviour is not merely a narrative convention, but something shown as employed consciously by the characters themselves. Not only do the characters, as might be expected, possess an unspoken awareness of their obligations to be courteous to guests or hosts such as when Goldberry reminds Tom pointedly to consider his guests - but they also appear aware of the pattern this hospitality entails, and remark on or apologise for significant divergences from it: when Celeborn and Galadriel, for example, greet the Fellowship in otherwise perfect ritual fashion but move straight to conversation without offering food and drink, Celeborn subsequently invites them to a parting feast as "though you have been our guests ... you have not yet eaten with us" (364). In particular, all hosts are fully conscious of an obligation to give their guests gifts upon their departure. Though in the case of Tom Bombadil this is slightly vague, at first providing them only with provisions and later giving them daggers from the Barrow but not explicitly as parting gifts, Galadriel later gives the Fellowship "gifts which the Lord and Lady of the Galadhrim now offer you in memory of Lothlorien" (365), Theoden offers Gandalf "a gift ere we go, at your own choosing" (510) while "[his] other guests" are given "such things as may be found in [his] armoury" (511), and Faramir apologises for the fact that he "has no fitting gifts to give [Frodo and Sam]" as they leave him yet gives them "staves [that] may be of service to those who walk or climb in the wild" (679). As in classical epic, this adherence to formal codes of behaviour mutually understood by both parties serves as a marker of civilisation, with the interactions characterised by "courtesy" (356), good-will and mutual respect.

Not only does a character's correct fulfilment of the rules of xenia indicate social and moral order, however, but in both classical epic and The Lord of the Rings a disruption to this pattern is used to indicate social and moral 
disorder. For Homer, the incorrect behaviour of guests is the source of the main conflicts at the heart of both his epics, with the Trojan War itself occasioned by Paris' abduction of Helen while a guest in Menelaus' palace and Odysseus' return home is complicated by the legion of suitors abusing their privileges as guests by occupying his palace. In Book One of the Odyssey, the breakdown of Ithaca in Odysseus' absence in particular is explicitly shown by the breakdown of the host/guest relationship, with the correct behaviour of Telemachus and Mentes/Athena contrasted by the suitors "insolent[ly]... seem[ing] to swagger about in their feasting / all through the house" (Od. 1.227-228) with no consideration of the host or their own responsibilities as guests (Reece 50). In much the same way, the degeneration of Rohan under Wormtongue's influence in The Lord of the Rings is reflected by a corresponding degeneration of hospitality, in this case embodied by the host rather than the guests. ${ }^{12}$ Not only are Gandalf, Aragorn and Legolas treated with suspicion upon their arrival, referred to by Tolkien as "strangers" (502) rather than the term "guests" used for the members of Fellowship in Tom's house and Lothlorien, but Theoden "d[oes] not move in his chair" (501) or speak to greet them when they approach him, leaving "a silence" until "at length" (501) Gandalf speaks himself. When Theoden does reply, though he is clearly aware of the greeting he should be giving - he notes that the travellers "look for welcome" (501) - he actively denies it to them, instead asking Gandalf to justify "why [Theoden] should welcome [him]" (501). When Gandalf remarks that "the courtesy of [Theoden's] hall is somewhat lessened of late" (502), the sentiment echoes Athene's observation to Telemachus that "a serious man" (Od. 1.228) coming to Odysseus' palace "could well be scandalised, seeing much disgraceful behaviour" (Od. 1.229), and draws attention not only to the personal insult of such behaviour but to the corruption of social and moral structures it implies. In both cases, the kingdom has fallen under the control of others due to the absence or inability of the leader - Odysseus is missing and Telemachus is too young to lead, leaving the suitors essentially in charge, while Theoden when the travellers arrive is "so bent with age that he seemed almost a dwarf' (501) and has succumbed to the influence of Wormtongue - and the lack of hospitality shown stems directly from the usurpers. Conversely, however, Meduseld's restoration of order upon Theoden's "healing" (507) is immediately marked by a restoration of hospitality and ritual. Wormtongue is exiled from the kingdom by the king in a more "merciful" (509) version of Odysseus' slaughter of the suitors, and the stones he had "defiled" with his spit "washed clean" (509) by servants just as Odysseus orders Telemachus and Eumaeus to "wash the beautiful / chairs and tables clean" (Od. 22.438-439) of the suitor's blood and thereby "get all the house back into good order" (Od. 22.440) both literally and symbolically. After this, Theoden immediately returns to ritualised patterns of hospitality, inviting the travellers (who he for the first time addresses as "my guests" (511)) to come inside for "such refreshment as haste allows" (511) which is followed by conversation, gift-giving and an 'after-dinner drink'.

12 The same is true of Hobbiton in "The Scouring of the Shire", where the first signifier that something is very wrong in the Shire comes when the returning hobbits find themselves greeted with "no welcome, no beer, no smoke, and a lot of rules and orc-talk instead" (977). In particular, the new rules against "taking in folk off-hand like, and eating extra food" (976) are in direct contrast to the most basic principles of hospitality in both Tolkien and epic. 
This use of hospitality type-scenes as a marker of civility (or lack thereof) is carried even further in the depictions of the Orcs, whose behaviour comes close to being a parody of conventional hospitality in the manner of the Cyclops in the Odyssey. As Reece points out, the various races encountered by Odysseus upon his travels consistently deviate from or pervert traditional hospitality in some way, and his encounter with the Cyclops is the most extensive instance of this, with "the parody of the theme of hospitality ... woven through [the] episode from beginning to end" (125). After declaring flagrant disregard for Zeus, god of guests, Polyphemus proceeds to follow the laws of hospitality in a parodic manner, most notably devouring Odysseus' men in the place of offering a meal and giving Odysseus the "gift" of being eaten last (Reece 10-11). Similarly, the Orcs' behaviour towards their captives can in some ways be read as a subversion of the behaviour a host should display toward a guest: sneering mockingly at Pippin to "rest while [he] can" (435) where Tom, Galadriel and Faramir invite their guests to "sleep ... in peace" (666); dragging Pippin up by hair and telling him to "sit up!" (438) to receive nourishment instead of inviting him to sit down; forcing a "burning liquid" (438) down his throat in place of a meal; and in the case of Grishnakh even attempting to steal from them in the place of giftgiving before their departure (or in this case, escape). Interestingly, though there are slight hints that the Orcs, like Polyphemus, are in fact aware of the rules of hospitality they are breaching (such as when they reply to Merry's tongue-in-cheek question of when they "get bed and breakfast" (438) with "You'll get bed and breakfast all right: more than you can stomach" (438)), the Orcs seem more genuinely uncaring of the laws of hospitality, notably referring the hobbits as "prisoners" where Polyphemus uses "guests". As a result, any parody operates on a narrative level alone rather than something orchestrated by the characters. Nonetheless, in the book's first sustained encounter with the Orcs, Tolkien chooses to illustrate their bestial natures precisely by the manner in which they treat guests, with their extreme deviation from accepted practices marking them as a hopelessly corrupted race.

Where The Lord of the Rings differs from classical epic, however, is in the portrayal of acceptable variations in the way hospitality and gift-giving is practiced by the differing races, something seen clearly during Frodo and Sam's time as Faramir's guests in Ithilien. Despite being forced to lead the hobbits blindfolded to their outpost (something he apologises for), Faramir is one of the book's most exemplary hosts, providing his guests with rest, water for washing, food and drink, conversation, bed, and gifts upon departure, and for the most part his pattern of hospitality accords well with the classical example common to both races. In many ways, however, the races of the host and the guests approach this pattern from two different genres, the hobbits' version born from the social comedy and domestic realism demonstrated in Bilbo's welcome of the dwarves in The Hobbit and Faramir's a mixture of pre-Christian epic and medieval culture. As a result, while both clearly operate from the same underlying principles that characterise classical xenia, both encounter aspects of the other's culture with which they are unfamiliar. Frodo and Sam, for example, are unaware of the non-classical custom (akin to 
the Christian idea of saying grace) of "look[ing] toward Numenor that was, and beyond to Elvenhome that is, and to that which is beyond Elvenhome and will ever be" (661) before eating and need it to be explained to them. This could in classical terms be read as a sign that the hobbits are less civilised than Faramir, and indeed the fact that this custom is missing from Shire etiquette does cause Frodo to feel "strangely rustic and untutored" (661), something which he counters by explaining to Faramir his people's own non-classical customs: "But if we are guests, we bow to the host, and after we have eaten we rise and thank him" (661). Faramir's version of xenia is however marked as culturally distinct in ways that are not attributable to the hobbits' ignorance, as when he says farewell by "embrac[ing] the hobbits ... after the manner of his people, stooping, and placing his hands upon their shoulders, and kissing their foreheads" (679), and these various differences are in general something that interest, impress and sometimes amuse both host and guest rather than indicate corruption of hospitality by either side. ${ }^{13}$

The sense of a cultural gap is taken to extremes in the case of Treebeard, who immediately after their "visit" among the Orcs provides hospitality to Merry and Pippin. In some ways, Merry and Pippin's stay in an enthouse parodies the classical hospitality pattern as surely as their previous captivity among the Uruk-Hai: they sit on the table; they are given strengthening water instead of food and wine; and they are invited to stand to sleep after conversation, all of which comically befits what are essentially living trees. Crucially, however, Treebeard is not ignorant or scornful of social customs as are the Orcs, but possesses his own which he is repeatedly attempting to adapt to the needs and expectations of his guests. When entering, for example, Treebeard is not able to seat his guests on chairs, but he is clearly aware that he should and offers a compromise: "This is an ent-house ... and there are no seats, I fear. But you may sit on the table" (460). Similarly, his announcement that he is going to "stand and take a little sleep" (467) and his invitation to Merry and Pippin to do the same is clearly the Entish version of bed after conversation, and when Merry reminds him that they "usually lie down to sleep" (467) he is quick to offer them a bed. Much later, Treebeard sends Merry and Pippin to find food and welcome Theoden's party to Isengard in the hope that they "know the right fashion of Men's words for such a lord better than Ents" (559), indicating a clear knowledge of a difference between customs and a desire to adhere to those of the guest. While civilisation in classical epic is shown largely by uniformity of culture, with even the warring Trojans and Achaeans in the lliad not usually marked as distinct from each other in their customs and traditions, civilised races in The Lord of the Rings are marked by uniformity of the principles of hospitality, but with the ability to accommodate one another's differences within their own culture's set framework.

13 Sam submerging his head in the proffered basin of water, for example, elicits both "astonishment and amusement" (661) from Faramir's soldiers, one of whom asks if it is "the custom in [Sam's] land to wash the head before supper" (661). 


\section{"The Glory You Reap Shall Be Yours Forever": Warfare}

The Hobbit's increasingly epic battle scenes established the formula of epic tropes and similes at moments of dramatic weight juxtaposed against the more homely language and observations of the hobbits, and this continues to an extent in the early sections of The Lord of the Rings. The Fellowship's brief battle with wolves approaching Moria, for example, contains a highly concentrated series of epic features involving the nonhobbit characters, including single combat ("Through the throat of one huge leader Aragorn passed his sword with a thrust" (291)) and at least proto-epic similes ("Gandalf ... rose up, a great menacing shape like the monument of some ancient king of stone set upon a hill" (291)); yet the battle ends with Sam comically observing, "That was an eye-opener and no mistake!" (291). As with hospitality scenes, however, scenes depicting battle and warfare become both more prevalent and increasingly ritualised as the book progresses, and the way in which characters use, misuse or modify epic patterns of behaviour becomes central to the depiction of Middle-earth. Though Homeric and Virgilian battle sequences are similarly composed of common repeated elements both at the level of action (such as a spearman missing his mark and killing an enemy charioteer instead) and formulaic description (such as "he fell to the ground with a thud and his armour rattled around him") (Fenik 3), these are far more varied than those employed in hospitality scenes and Tolkien's battles do not use them to a significant extent. However, particularly in later battles, Tolkien does employ the more common type-scenes found within battle narratives, including the heroes arming for battle, individual warriors in combat, boasting between combatants, and the aristeia.

Though there are instances of decidedly epic combat in the early stages of the book, particularly in Moria, epic warfare in The Lord of the Rings appears in its purest sense (as in The Hobbit) when the story has shifted to the world of men, in this case when Gandalf, Aragorn, Legolas and Gimli travel to the land of Rohan. Despite drawing most substantially on Northern traditions, the Rohirrim as a society also come closest in the books to possessing a classically heroic attitude toward war and glory, often expressing desires such as Theoden's to "make such an end as will be worthy of a song" (527); Tolkien himself once described them as 'Homeric' horsemen" (Letters 159). It is unsurprising, then, that the first sustained large-scale conflict in The Lord of the Rings, the Battle of Helm's Deep, takes place between the people of Rohan and the Uruk Hai, and as with Smaug's attack on Laketown in The Hobbit is told almost entirely in epic style without the intrusion of non-epic characters. Though far more condensed in form than most Homeric or Virgilian battle scenes, the battle itself and surrounding scenes are constructed largely of versions of epic type-scenes, beginning with Aragorn and Legolas meticulously arming for battle in "shining mail ... Helms too they chose, and round shields: their bosses were overlaid with gold and set with gems, green and red and white" (511). The depiction of the battle itself (the details of which, perhaps not coincidentally, echo Turnus' attack on the Trojan battlements in Book Nine of the Aeneid, with both involving the breaching of a wall by the enemy host, a river, the enemy use of 
fire, and the arrival of reinforcements through quasi-divine intervention) similarly uses the epic method of alternating between broad sweeping descriptions of the armies and individual warriors in combat, usually Eomer, Aragorn or Gimli. More surprisingly, given the Christian emphasis on humility usually present in Tolkien's heroes, the fight also contains an example of boasting between combatants, as Aragorn faces the enemy forces from above the gate and exchanges threats with the Uruk-hai. Although such scenes are common in the lliad, the dialogue and setting here most closely echoes Numaneus' insulting of Ascanius in the Aeneid: not only are the Uruk-hai, like the Italians, positioned beneath a defended tower, but their insults, like those of Numaneus, are focussed on the superiority of their own race compared to that of the defenders, with their claim that, "We are the Uruk-hai: we do not stop the fight for night and day, for fair weather or for storm" (527) echoing Numaneus' boast that the Italians are "a race from sturdy stock / ... [who] bear our infants to the river / and harden them by cruel frost and water; / and... always take delight / in our new plunder, in a violent life" (Aen. 9.805-819). (Aragorn, however, while making the classically acceptable reply, "Depart, or not one of you will be spared. Not one will be alive to take back tidings to the North. You do not know your peril" (527), characteristically proves his royal lineage not through an unexpected feat of arms but merely by revealing "so great a power and royalty ... as he stood there alone above the ruined gates before the host of his enemies, that many of the wild men paused" (528).) The battle culminates in a version of an aristeia, as Theoden and Aragorn charge from the gates so that "captains and champions fell or fled before them [and] neither orc nor man withstood them" (528). Where Achilles appears in the lliad with armour "shining / like the flare of blazing fire or the sun in its rising" (22.134-135), the arrival of Theoden and his people literally coincides with "the rising of the sun" (528), with the sunlight "glimmer[ing] on their spears" (529).

Similarly, the battle of Helm's Deep is consistently described in the language of epic warfare, with the use of Homeric similes that began in the Battle of Five Armies and early battles of The Lord of the Rings continuing here on an even greater scale. Most significantly, The Hobbit's description of the goblins arriving on the battlefield "like a tide" (259) is expanded here as the Uruk Hai army is compared with "a great field of dark corn, tossed by a tempest of war, and every ear glinted with barbed light ... They wavered, broke and fled back; and then charged again, broke and charged again; and each time, like the incoming sea, they halted at a higher point" (521). This twin motif of an army as a field of corn and a stormy sea occurs not only in the lliad, where the Greek army

"sway[s] like the great rollers of the Icarian Sea when they are swollen by a south-easter rushing down from Father Zeus' clouds. As a west wind rushes tumultuously down to sway a deep harvest of corn, and the ears bend underneath it, so the whole assembly was swayed" (II. 2.144-148, trans. Rieu) but also in the Aeneid, which also carries Tolkien's imagery of glinting light and an advancing wave: the Latium farmers appear as

"... a horrid harvest 
of unsheathed swords that bristle far and wide,

and arms of brass that glisten when the sun

strikes ...:

as when a wave, beneath the wind's first breath,

begins to whiten; slow by slow, the sea

will lift its combers higher until, at last,

it climbs to heaven from its lowest depths." (Aen. 7.691-8).

Interestingly, like the earlier Homeric simile (which is used to describe the Greeks fleeing to their ships), the Virgilian simile does not describe a grand army but a collection of "fearless farmers" (Aen. 7.685) roused by Allecto, arguably degrading the Uruk Hai by association even while the scene itself is glorified. The Uruk Hai are at other points compared with a "dark tide" (520) and described as "roar[ing] like a sea" (523), while the Hornburg "held fast, like an island in a sea" (524).14 By contrast, Eomer and Aragorn run into battle "like fire" (521), setting not only the element of fire against water but the similes evoking ignoble armies against one that references a single hero, Hector, "stalk[ing] through the ranks of the champions... / looking like the flame of Hephaistos" (II. 17.87-88). Unlike in Homer and Virgil, where Ajax can be compared with a "donkey, stubborn and hard to move" (II. 11.557) without apparent loss of dignity, the similes used in The Lord of the Rings can be read as carrying value judgements when set against their classical predecessors. More generally, though, they allow the book to read as straight epic narrative, lending mythological and historical weight to "the deeds and destinies of great heroes" (Griffin 13) in fact drawn from no existing mythology or history.

Moreover, the otherwise intensely 'human' scale of the conflict at Helm's Deep climaxes in a distinctly supernatural element, as a "nameless wood" (529) later discovered to be the Huorns of Fangorn Forest arrives to entrap the fleeing Orcs. Perhaps the greatest difference between any aspect of Middle-earth and classical epic is the absence of the equivalent of the classical gods: though The Silmarillion and other works contain a complex mythology of deities that Purtill argues have some commonalities with the Olympians (39), the Valar do not in The Hobbit or The Lord of the Rings interfere with mortal affairs in the manner of such gods, and nowhere is there an example of the gods engaging in 'human' warfare as is seen in the lliad and the Aeneid. The Lord of the Rings does, however, contain many instances of nature itself engaging in battle with human characters in a way that evokes the river-gods and spirits of classical mythology. The Fellowship themselves are attacked by the mountain of Caradhras, one of the "evil and unfriendly things in the world that have little love for those that go on two legs" (282), while the Nazgul are simlarly defeated by the River Bruinen "ris[ing] in anger when [Elrond] has great need to bar the Ford" (218). This latter instance even bears specific classical

14 This consistency in simile also occurs elsewhere in Tolkien and often complements or builds up to a more extended 'Homeric' simile. Repeated comparisons between the Orcs and "marching ants" (520), for example, are expanded in the climax of the book to: "As when death smites the swollen brooding thing that inhabits their crawling hill and holds them all in sway, ants will wander witless and purposeless and then feebly die, so the creatures of Sauron, orc or troll or beast spell-enslaved, ran hither and thither mindless..." (928). 
parallels to the river god Skamandros rising against Achilles to prevent him "storm[ing] the great city/ of lord Priam" (II. 21.309-310), with Skamandros' urging to his fellow river to "make full your currents / with water from your springs, and rouse up all of your torrents / and make a big wave rear up and wake the heavy confusion / and sound of timber and stones, so we can stop this savage man..." (21.311-314) coming very close to Frodo's perception of the River Bruinen's assault on the Ring-wraiths:

"There came a roaring and a rushing: a noise of loud waters rolling many stones. Dimly Frodo saw the river below him rise, and down along its course there came a plumed cavalry of waves ... The three Riders were overwhelmed; they disappeared, buried suddenly under angry foam ... Then Frodo felt himself falling, and the roaring and confusion seemed to rise and engulf him together with his enemies." (209)

Though clearly not intended to be the equivalent of classical gods in their own right, the role the Huorns play in Helm's Deep does fulfil the conventions of such divine intervention, with the Huorns even able to "wrap themselves in shadow" (551) to hide themselves much like the mist Athena lifts from Diomedes' eyes to enable him to distinguish men from gods (II. 5.128).

If the attitudes and fulfilment of such type-scenes demonstrated in Helm's Deep exemplifies correct war-time behaviour much as the correct fulfilment of established hospitality type-scenes exemplifies correct peace-time behaviour, then as with hospitality a disruption to this pattern indicates incorrect behaviour, and this is seen once again in Tolkien's depiction of the Orcs. With the patterns of warfare more flexible than those of hospitality, the Orcs' lack of any social or moral code is this time not shown through the subversion of conventional patterns and type-scenes, but through the lack of them. Though we know from previous chapters that the Orcs possess both names and personalities, they are not treated in battle as individual warriors as honoured as Aragorn or Theoden, as are members of the enemy army in both the lliad and the Aeneid, but instead only as a faceless "assailing host" (520). At no point does any one member of this host receive either arming scene, successful individual combat, an exchange with a hero before battle, or an aristeia. Instead, any specific behaviour of the Orcs centres around acts that would be dishonourable even by classical standards, usually involving the desecration of corpses: at Helm's Deep, for example, two Orcs take Aragorn and Eomer by surprise by "[lying] motionless among the slain" (522) (similarly a grotesque example of a combatant "strik[ing]... by stealth, watching/ for [their] chance" (II. 7.242-243) in the manner scorned by Hector), while others, we learn later, "hewed Hama's body before the gates of the Hornburg, after he was dead" (566) much as Achilles wrongfully mutilates Hector's body.

Similarly, if natural forces are in battle scenes the equivalent of minor classical deities, Saruman's felling of Fangorn Forest (in direct contrast to the Rohirrim, who "would not have dared to take an axe to the strange trees" (532)) can be read as Tolkien's equivalent of a hero failing to respect the gods, and in fact the scene in 
which the Ents rise up against Isengard closely parallels that of the river god Skamandros in the lliad rising against Achilles in revenge for the pollution of his waters. In this case it is the forest rather than the river that rebels against the "wastes of stump and bramble where once there were singing groves" (463) just as Skamandros complains that "the loveliness of my water is crammed with corpses, I cannot / find a channel to cast my waters into the bright sea / since I am congested with the dead men you kill so brutally" (II. 21.218220). However, the victory of the Ents is followed by a return of the river, as the Ents break the dams and flood Isengard. Moreover, Skamandros' attack on Achilles is countered by Hephaistos, the god of industry, who sends jets of fire at the water so that "the elms burned, the willows and the tamarisks, / the clover burned and the rushes and the galingale, all those / plants that grew in abundance by the lovely stream of the river" (II. 21.350-353). While this is purely a battle between gods, recounted objectively by Homer, the equivalent counter-attack in Tolkien literalises Hephaistos' flame as Saruman's "precious machinery" (554) in a way that almost constitutes an environmental statement, with the Ents attacked with "fires and foul fumes" so that "several of the Ents got scorched and blistered" (554): just as Hephaistos' flame causes the water to burn "as a cauldron that is propped up over a great fire boils up / dancing on its whole circle with dry sticks" (II. 21.362363), the waters meeting Saruman's machinery causes Isengard to look "like a huge flat saucepan, all steaming and bubbling" (555).

However, unlike in classical epic but as with Tolkien's hospitality scenes, The Lord of the Rings does present significantly different perspectives on battle and versions of heroism that are not only just as acceptable as the traditional epic versions, but provide a new perspective on established tropes and type-scenes. In the case of warfare, this is a more gradual progression as, much as the threat of epic battle in The Hobbit is first introduced through Bard before spreading to encompass the previously folk-tale dwarves and Bilbo, Merry and Pippin in particular begin to become assimilated into the epic narrative and the heroic culture it entails. Where Bilbo remains largely immune to the epic tone his story takes and The Hobbit's dwarves move seamlessly into epic heroic status, Merry and Pippin's initial fit in the epic world is at once possible yet poignantly difficult. Merry in the service of Theoden is "armed for battle" (784) in what is almost an heroic arming scene, but it is tempered with acknowledgement of hobbit size as Eowyn explains that they have "no mail ... to fit [him] ... nor any time for the forging of such a hauberk" (785), and this combined with the shield "which was like the shield that had been given to Gimli" (785) is a strong contrast to the elaborate armour forged by the gods especially for Achilles and Aeneas in classical epic (or even that worn by Aragorn and Legolas). Despite his ill-fitting armour, however, Merry quickly adopts the heroic code of both epic and the warrior society in which he has found himself, arguing with Theoden to be allowed to ride with him into battle in heroic terms despite touches of the homely language that generally characterises hobbits:

"But why, lord, did you receive me as sword-thain, if not to stay by your side? And I would not have it said of me in song only that I was always left behind!" (786) 
Moreover, Merry does eventually succeed in battle in epic terms, assisting in the defeat of the Lord of the Nazgul by "piercing the sinew behind his mighty knee" (824) in a way comparable to (for example) an epic combatant "stab[bing] at the base of the leg ... / so that on the spearhead the sinew / was torn apart" (II. 16.314-316). The juxtaposition between the epic settings and type-scenes and the unconventional subject is this time not parodic, but instead creates an element of physical realism as epic conventions are guided to adapt to characters outside the generic norms.

Similarly, the depiction of Pippin in the service of Gondor simultaneously employs and modifies the conventional epic techniques seen elsewhere in the book. Like Merry, Pippin receives an arming scene, where he is outfitted with "strange garments, all of black and silver" (789) described in meticulous detail, and unlike Merry his new armour does fulfil its epic function, making him look "verily Ernil $i$ Pheriannath, the Prince of the Halflings, that folk had called him" (789). Pippin, however, finds his heroic role literally and metaphorically "uncomfortable" (789), and his fulfilment of epic conventions is balanced with his unheroic impressions of what such conventions entail:

"Now he was small soldier in a city preparing for a great assault, clad in the proud but sombre manner of the Tower of the Guard. In some other time and place Pippin might have been pleased with his new array, but he knew now that he was taking part in no play; he was in deadly earnest the servant of a grim master in the greatest peril. The hauburk was burdensome, and the helm weighed upon his head." (790)

Moreover, rather than immediately preceding an heroic aristeia, Pippin's arming scene occurs during a break in "kick[ing] [his] heels at the door of [Denethor's] chamber for many slow hours" while Denethor engages in the "debates with Gandalf and the Prince and other great persons" (790) that would be the focus of a conventional epic, and his time is spent waiting with his fellow soldier Beregond at the "sinister quiet of the front" that for C.S. Lewis evokes the "very quality of the war [Lewis'] generation knew" (Lewis 13). Even the "honour" (790) of service to a lord according to the heroic code Merry has easily adopted seems pointless to Pippin against the reality of such a war, as he asks Beregond, "But what is the good of such honour ... under this creeping shadow?" (790). Once again, conventions of the epic genre are merged with the hero of the folktale in a way that constitutes a form of emotional and physical realism.

This combination of these perspectives on combat reaches its climax by the final large-scale conflict of the book, the last stand outside the Black Gates. Rather than being even a possibility for "victory by arms" (862), the battle is merely a distraction to "keep [Sauron's] Eye from his true peril" (862), the unepic threat presented by Frodo and Sam. Moreover, though the scenes leading up to the conflict follow the major heroes, the battle itself is told from Pippin's perspective, once again allowing an epic scene to be seen through the lens of a folktale (or realist) hero. Pippin's thoughts before the battle commences are a mixture of epic sentiments filtered 
through hobbit language ("This [sword] was made for just such an hour ... If only I could smite that foul messenger with it, then almost I should draw level with old Merry" (874)) and pure realism ("I wish I could see cool sunlight and green grass again!" (874)), and the details of the battle that follows remain centred on Pippin and Beregond rather than the greater heroes, continuing the 'view from the trenches' motif established in Pippin's earlier scenes. At the same time, however, the scene contains the same profusion of Homeric-style similes, details of combat, and focus on the enemy's aberrant behaviour that signalled the epic combat of Aragorn and the other heroes at Helm's Deep and Pelennor, elevating rather negating the epic quality of the Black Gates battle. Even more interestingly, the scene utilises characteristics of epic that do not occur in the earlier, 'pure' epic battles such as Helm's Deep. Where the combat undergone by the more conventionally epic characters is usually described with similes that obscure the physical details of the fight - Theoden and Aragorn's climactic charge at Helm's Deep, for example, "drove through the hosts of Isengard as a wind among grass" (528) - Pippin's fight with the troll, like Merry's with the Nazgul, contains the anatomical detail common in Homer but not in Tolkien, as "the written blade of the Westernesse pierced through the hide and went deep into the vitals of the troll, and his black blood came gushing out" (874). Pippin also receives, albeit prematurely, a conventional epic death scene, the phrase "And his thought fled far away and his eyes saw no more" (874) echoing both the repeated Homeric refrain, "and a mist of darkness clouded both eyes" (II. 4.461 etc), and the Virgilian refrain, "his life, resentful, fled to Shades below" (Aen. 12.1271). As in the Middle-earth version of hospitality, different traditions, cultures, genres and viewpoints are presented in a way that do not negate one another, but instead sit comfortably within the same world and the same scene, unified by underlying principles of "duty" (862) and self-sacrifice.

\section{Conclusions}

Ultimately, the ritualised behaviour and the ritualised manner in which it is described contributes to the impression that the characters are walking in an epic world, with fictional cultures given the weight of the historical cultures of true oral epic. As with Homer and Virgil (and other epics such as Beowulf), the use of type-scenes provide us with a way of reading the characters, cultures and their interactions, with the willingness to behave in a correct manner a marker of order and civility in contrast to the disorder represented by the Orcs.

Interestingly, however, these scenes often illustrate not only correct social behaviour but correct moral behaviour, with cultural differences in the way characters interact in peace and in war ultimately irrelevant in the face of their common, near-identical principles. Unlike in classical epic, hospitality in Tolkien though ritualised is characterised primarily by good-will, while in battle stress is repeatedly laid upon not merely doing the right thing in terms of a hero's personal glory but in doing the "good" thing even to the detriment of both. 
This moral code underlying The Lord of the Rings' social and heroic code is in some ways unique to Tolkien but heavily influenced by Tolkien's Christian beliefs; Tolkien described the book himself as "a fundamentally religious and Catholic work" (Letters 172). As a result, The Lord of the Rings can perhaps be seen as aiming to provide a form of "normative epic" (Reichl 68) for England - or for the modern world - itself. Tolkien, in his refutation of the presence of allegory in the book, suggests that the book's "history" can instead be read as containing a "varied applicability to the thought and experience of the readers" (xvii), and the Christian moral standards in the pre-Christian world of Middle-earth suggest that the book's patterns of correct behaviour may be read as universal in much the same way. Aragorn summarises this idea neatly in response to Eomer's question of how a man should judge "what to do" in a time when "the world has all gone strange" (427): "As he has ever judged ... Good and ill have not changed since yesteryear; nor are they one thing among Elves and Dwarves and another among Men. It is a man's part to discern them, as much in the Golden Wood as in his own house" (428). Although the times of The Lord of the Rings were not Tolkien's and the Golden Wood not contemporary England, he may have on some level intended its moral and heroic codes to be applicable to both, conveyed in the form of epic myth that best expresses them. 


\section{CHAPTER FIVE: HOMECOMINGS}

As the title of its third part suggests, the conclusion of The Lord of the Rings is very much concerned with returns, homecomings and the establishment or re-establishment of kingdoms, and Aragorn's return to his ancestral throne in many ways perfectly echoes the motif of the returning king found in many ancient cultures. In classical epic, this figure is best exemplified by Odysseus, whose story forms the archetypal homecoming myth, and Aeneas, whose prophesised arrival in Latium forms the etiological myth of Rome. Though Aragorn's homecoming draws extensively from these predecessors, however, he also deviates from them in ways that create tension between classical heroism and Tolkien's own moral code. This tension is only made more explicit as the story progresses, and the hobbits undergo a homecoming of their own that both uses and supersedes the classical archetype.

Like both Odysseus and Aeneas, Aragorn arrives in his kingdom by ship, a detail not particularly significant to the classical heroes but unusual for Aragorn, who never has need or opportunity to travel by sea in any other section of the book. The method, manner and description of Aragorn's late arrival to the battle in fact most closely resembles Aeneas' return to the beseiged Trojan camp from Evander in the Aeneid. Both Aragorn and Aeneas are assisted by a supernatural agency, Aragorn accompanied by the Dead and Aeneas by the nymphs born from his ships, and both return to bring crucial reinforcements to their people. The return of both characters is also conveyed with similar images, with Aragorn unfurling a banner with stars that "flame in the sunlight" (829) and a crown "bright in the morning, for it was wrought of mithril and gold" (829) while Aeneas lifts a "glowing shield" (10.379) that "spouts tremendous flames, / just as... / the blazing Dog Star, bringer of diseases / and drought to tired mortals, when it rises / with light and menace, saddening the skies" (10.379384). Moreover, the reactions of the allies and enemies are paralleled in the two scenes. Aragorn's unexpected arrival to the battle causes Eomer to feel "wonder ... and a great joy; and he cast his sword up in the sunlight and sang as he caught it ... But the hosts of Mordor were seized with bewilderment, and a great wizardry it seemed to them that their own ships should be filled with their foes" (829). Meanwhile, Aeneas' beseiged men "raise high a starward shout up from the ramparts; / ... But this astounded / the chieftains of Ausonia and the prince / of the Rutulians, until they looked / backward and saw the sterns turned toward the shore / and all the waves alive with gliding ships" (10.367-376).

Interestingly, however, while Aeneas' arrival is overt, unnoticed at first by his enemies but not concealed, Aragorn arrives in the ships of the Corsairs with his banner hidden, causing the enemy to believe the ships "their own" (829). This Odyssean motif of disguise (here almost echoing the Trojan Horse deception) continues to surround Aragorn's homecoming, as he lands in Gondor only to refuse to enter it except by stealth. Although Gondor has not quite been usurped in the manner of Ithaca, it has fallen under the rule of the Stewards whom 
Aragorn correctly suspects will be unwilling to relinquish it; Denethor has already openly refused to "step down to be the dotard chamberlain of an upstart ... even were his claims proved to me" (836). As a result, Aragorn chooses to, like Odysseus, exercise caution in claiming his rightful inheritance, remaining outside the citadel in a way compared by Imrahil to "a beggar at the door" (843). When he does enter the Houses of Healing at Gandalf's behest, it is in the guise of a "cloaked man" (844) who is not identified until others explicitly wish for his presence, and even then not by name: when Imrahil asks whether Aragorn should be sent for, he replies "He is come" (844), much as Odysseus responds to Philoitius' wish for his king's return with "I am he" (Od. 21.207). Once again, Aragorn's evocations of Aeneas are balanced with references to Odysseus, exemplified perhaps best in the sign that Aragorn identifies as accompanying his return. As with Odysseus' return, Aragorn's arrival in his kingdom is heralded by a celestial omen, but while Odysseus' omen is "the sun... perished out of the sky" (Od. 20.357), hinting at disguise and concealment and heralding the suitors' doom, Aragorn's omen is "the Sun setting in a great fire" (843), akin to the "blazing Dog Star" (Aen. 10.382) with which Aeneas' arrival is compared, and heralds a more Virgilian "end and fall of many things, and a change in the tides of the world" (843).

This slightly paradoxical juxtaposition of Aragorn as both an Aeneas figure openly claiming his rightful kingdom and an Odysseus figure returning to his rightful kingdom in disguise is noticed by Eomer, who when Aragorn declares that he will not immediately challenge the rule of the Stewards points out that he has already "raised the banner of the Kings and displayed the token of Elendil's House" (843). However, Aragorn is doing upon his homecoming what he has been doing throughout the book, navigating aspects of both the Odysseus and Aeneas model of the wandering hero and adapting them to his own moral code. Though Aragorn employs Odyssean methods of concealment, he does so not from self-interest, but through wishing to avoid "doubt and debate... while this war is fought" (843). Moreover, he responds to Imrahil's objection to him remaining "like a beggar at the door" by claiming to be rather "a captain of the Rangers, who are unused to cities and houses of stone" (843), effectively negating the idea of disguise. Much like Gandalf when he reappears as Gandalf the White, Aragorn is not hiding his title but delaying taking it up in favour of another, just as accurate: in his own words, he is "for the present ... but the Captain of the Dunedain of Arnor" (844). ${ }^{15}$ Similarly, Odysseus' right to the kingdom is proven through a demonstration of a unique skill, drawing his bow and firing it through twelve battle axes, and Aeneas' is proven through divine heritage and fulfilment of a prophecy, with Evander being told that "strangers come / as sons-in-laws; their blood will raise our name / above the stars" (Aen. 7.123-125). Aragorn's, meanwhile, is established through a combination of both, with his unique ability to heal Eowyn,

15 This is reinforced in the final usage of the motif of disguise and recognition surrounding Aragorn, which becomes almost an inversion of Odysseus. Upon being introduced to the King of Gondor, the hobbits at first see only "a mail-clad man" before finally recognising "Strider", "changed as he was, so high and glad of face, kingly, lord of Men, dark-haired with eyes of grey" (932). Where Odysseus' friends and family do not recognise him because he looks like a beggar, Aragorn's do not recognise him because he looks like a king, suggesting a fluidity to Aragorn's identity that allows him to literally become different people in different company. 
Faramir and Merry simultaneously fulfilling the "old lore" that "the hands of a king are the hands of a healer. And so the rightful king could ever be known" (842). The fact that the skill and prophecy in question lies in healing, however, is a motif of medieval and Christian rather than classical tradition, and emphasises a very different aspect of Aragorn's heroism. Through Aragorn, Tolkien employs classical signifiers of heroism to glorify increasingly non-classical ideals of leadership, reflecting the different moral universe in which Aragorn operates.

This becomes more apparent as Aragorn's reclamation of Gondor progresses, and the emphasis on revenge and violence that characterises the Homeric homecoming is avoided in favour of a more peaceful resolution. It is notable that while Odysseus' concealment culminates in a bloody reclamation of his kingdom from the suitors, the similar "strife" (843) with Denethor that Aragorn anticipates in fact never eventuates, as the Steward kills himself before Aragorn even enters the city. His successor, Faramir, not only accepts him without reservation but does so precisely through recognition of a disguised Aragorn, a motif that in the Odyssey symbolises a character's acquiescence to Odysseus' claim to the kingship (Murnagham 23). This more peaceful reclamation of the throne operates on not only a plot level but a character level, as Aragorn passes judgement on Beregond for deserting his post to help Faramir. Odysseus also passes judgements on those accused of disloyalty immediately after claiming his throne, ordering the disgraced serving maids put to death, and Beregond's expectations are clearly of a similar fate. However, Aragorn instead rewards Beregond for his loyalty to Faramir, causing the soldier to recognise "the mercy and justice of the king" (948). The concept of mercy over revenge is not alien to Virgil, and although Aeneas crucially fails to employ it with regard to Turnus he is frequently shown treating his men "kindly" (Aen. 5.1014) despite being wronged by them. The scene where members of Aragorn's army are "unmanned" (868) by the sight of the "desolate" (868) Emyn Muil so that "they could neither walk or ride further north" (868) could almost be a direct reference to a similar scene in the Aeneid where the Trojan women, dismayed by the sight of "so wide a sea" (5.810), are inspired by Iris to revolt and refuse to go further. Just as Aeneas allows "all who are weak and fear new dangers" (5.945) to remain behind and build a lesser city, Aragorn allows the "faint-hearted" (1069) to remain behind and gives them "a task which [they] may attempt and so be not wholly shamed" (868), re-taking Cair Andros in a lesser battle. However, where Aeneas requires advice from Nautes and his dead father in order to decide how to deal with this rebellion, Aragorn does not hesitate, and unlike Aeneas his instinctive reaction is consistently toward "pity ... rather than wrath" (868). In this, as elsewhere, Aragorn is depicted as naturally embodying a form of heroism that Aeneas struggles with and that is alien to Odysseus, positioning him alongside them on a heroic continuum that reflects the changing values of the societies both within the stories and without.

In some ways, Aragorn's reclamation of his kingdom is as much a restoration and reaffirmation of the classical homecoming motif itself as it is of the Numorean blood-line within the context of the story, marked by traditional 
patterns and signifiers of heroism. Like Homer's Odysseus, Aragorn lives out his days in the kingdom that is his by right, and dies finally "worn out after an easy old age and surrounded by a prosperous people" (Od. 11.135-137; trans. Rieu). At the same time, however, Aragorn's rule is explicitly a "new age ... [and] though much has been saved, much must now pass away" (949). Ultimately, Aragorn's skill in negotiating elements of classical heroism by employing those aspects suited to his purpose and discarding those out of place in Middle-earth is symptomatic of his destiny and great strength as king: to "preserve what may be preserved" (949) of the old age while simultaneously allowing what has become superfluous to "fade or depart" (950).

These hints of tension between older, epic forms of heroism and Tolkien's more Christianity-based moral code become more explicit as Frodo and the other hobbits undergo a homecoming of their own. Despite being distinctly unepic in tone, in many ways the hobbits' return to the Shire parallels the archetypal homecoming of Odysseus even more clearly than did Aragorn's. Both journeys begin with the completion of a task - the defeat of Troy in the Odyssey, the defeat of Sauron in The Lord of the Rings - and involve a scene shortly before the homecoming in which the heroes hear their story told. Most significantly, where Aragorn's homecoming neatly manages to circumvent conflict, the hobbits find themselves having to forcibly reclaim both Bag End and the Shire from the dark forces that have usurped it in their absence when they return to discover the Shire under a form of totalitarian rule. The threat posed to the Shire by the usurpers at first seems to mimic The Hobbit in being (albeit on a grander scale) a parodic version of the Odyssey homecoming, with the "Shirriffs with staves in their hands and feathers in their caps, looking both important and rather scared" (978) a non-epic substitution for the suitors. Sam in particular seems to take the conventional Odysseus role in comic form, as he is first unrecognisable to Tom Cotton in his "gear" (984) from "foreign parts" (984) and subsequently returns to the faithful Penelope figure of Rosie Cotton. Like Bilbo and Odysseus, Sam is thought to have been killed, and Rosie's greeting upon his arrival beautifully parodies Odysseus' return to his Queen: "They told me you were dead, but I've been expecting you since spring. You haven't hurried, have you?" (985).

As the hobbits draw closer to their "own country" (980), however, it becomes more apparent that the "ruffians" are not a comic threat that will entail "legal bother" (The Hobbit 276), but an invasion by Isengard and the epic world it represents that will "certainly mean fighting" (983) to vanquish. Merry and Pippin respond to the threat in terms of the heroic cultures into which they have been assimilated, with Merry quickly demonstrating Odysseus-like skill in strategy and command and Pippin answering an insult to Frodo in a manner indistinguishable from that of an epic hero:

He cast back his cloak, flashed out his sword, and the silver and sable of Gondor gleamed on him as he rode forward. 'I am a messenger of the King,' he said. 'You are speaking to the King's friend, and one of the most renowned in all the lands of the West. You are a ruffian and a fool. Down on your knees in the road and ask pardon, or I will set this troll's bane in you!' (982) 
Frodo, however, recognises this form of heroism as inappropriate to both the non-epic surroundings and, more importantly, the ethos of "Pity, and Mercy" (58) that has throughout the book increasingly superseded the traditional epic emphasis on revenge and glory. Pippin's wish to "destroy" (983) Lotho for his role in events is countered by Frodo's pity for him and wish to rescue him from a situation that has left his control, and where Odysseus and even Aeneas have no qualms about slaying their enemies in anger even after they cast down their weapons, Frodo's self-appointed role in the later battle is to prevent other hobbits "in their wrath at their losses, from slaying those of the enemies that threw down their weapons" (993). While seemingly accepting Merry's argument that they "won't rescue Lotho, or the Shire, just by being shocked and sad about it" (983), he attempts to limit the violence to the 'epic' threat alone, instructing the others, "There is to be no slaying of hobbits ... No hobbit has ever killed another on purpose in the Shire, and it is not to begin now. And nobody is to be killed at all, if it can be helped." (893). For Frodo, saving the Shire does not only entail freeing it physically, but like Strider and the Rangers keeping it "free" (242) from the "care and fear" (242) the wider epic world entails.

Frodo's unwillingness to employ traditional heroic conventions is borne out as the conflict escalates, and classical heroism becomes depicted increasingly uneasily. At the exact point where in the Odyssey the theme of disguise reaches its climax, the same theme in The Lord of the Rings has been entirely appropriated by the villain: Saruman, as has been previously discussed, is the "beggar in the wilderness" (982), going by the false identity "Sharky" in order to usurp the hobbits' homes rather than to reclaim his own. With neither Aragorn nor Gandalf now concealing their identities (and Frodo having in Mordor cast aside his one disguise vowing to "be an orc no more... and... bear no weapon, fair or foul" (916)) there is a sense that even the positive aspects of Odyssean subterfuge have become redundant in the Fourth Age. Instead, the hobbits' arrival is an open show of strength, startling the ruffians with the appearance of "fearless hobbits with bright swords and grim faces" (982), and Merry immediately vetoes Sam's vaguely Odyssean suggestion of "getting undercover" (983) in favour of "doing something at once" (983). Even the less ambiguous form of classical heroism that Merry and Pippin employ instead, however, sits uneasily in the context of the Shire. Merry's valiant desire to "raise the Shire! ... Wake all our people!" (983) can be read as paralleling the ruffians' declaration that "this country wants waking up and setting to rights" (982), and the resulting scenes of hobbits in battle are a deliberately awkward mixture of would-be epic warfare with homely hobbit details and language: the hobbits ambush the ruffians with "a stout barrier of old farm-carts upturned" (992), and are "obliged to shoot many of [the ruffians] or hew them with axes" (992). At times Merry's army almost appear to be unconsciously mimicking epic behaviour, as when the motif of fire that surrounds not only Helm's Deep and the Seige of Gondor but the classical seiges of the Aeneid and the lliad is echoed by "some of the village-folk ... [lighting] a large fire, just to enliven things" (985). Merry and Pippin's quasi-epic battle and heroism is never condemned, and earns them glory not incompatible with classical ideas. The description of the battle itself, for example, ends with a hobbit version of 
the ritual conclusion to the Battle of Pelennor Fields, with a description of the burial of the dead and how they will be remembered:

"The dead ruffians were laden on waggons and hauled off to an old sand-pit nearby and there buried: in the Battle Pit, as it was afterwards called. The fallen hobbits were laid together in a grave on the hillside ... So ended the Battle of Bywater, 1419, the last battle fought in the Shire ... [l]t has a chapter to itself in the Red Book, and the names of all who took part were made into a Roll, and learned by heart by the Shire-historians ... [A]t the top of the Roll in all accounts stand the names of Captains Meriadoc and Pippin." (992)

While the sentiments derive from epic, however, the language is resolutely realist, with the references to dates, history books and rolls of honour signifying a form of record-keeping very different from the mythologising oral culture of epic. Unlike the earlier battles featuring hobbits, in which epic and realism are merged comfortably, "the last battle fought in the Shire" (and also in the book) is taking place in a world that has already passed beyond epic.

Moreover, the "final stroke" (997) of the battle comes after this traditional conclusion, and echoes the climax of not the Odyssey but the Aeneid in its preoccupation with mercy to a fallen enemy as Frodo encounters Saruman at Bag End. Unlike the conclusion of the Aeneid, however, there is no combat between the two main players that would glorify Saruman's conduct as the Aeneid does Turnus' (Saruman and Frodo have not, until this point, even been direct rivals). Moreover, Saruman does not ask for his life to be spared, but seems instead determined to provoke his own death, taunting the hobbits to "kill him, if you think there are enough of you" (995) and attempting to treacherously stab Frodo. As a result, unlike Aeneas faced with Turnus at the close of the Aeneid, Frodo is unquestionably within his rights to allow Saruman's death according to any classical code of conduct. Nonetheless, like Sam when confronted with Gollum on the slopes of Mount Doom, Frodo chooses to "pity" (995) Saruman rather than kill him or allow him to be killed, justifying his decision with the Christian reasoning, "He is fallen, and his cure is beyond us; but I would still spare him, in the hope that he may find it" (996). Where Aeneas' failure to spare Turnus is left morally ambiguous by Virgil, Frodo's mercy is acknowledged as a moral victory by Saruman himself, who frames it as an act of revenge of a different kind that earns his "mingled wonder and respect and hatred" (996): "You have grown, Halfling ... You have robbed my revenge of its sweetness, and now I must go hence in bitterness, in debt to you and your mercy" (996). Interestingly, The Lord of the Rings never depicts an evil character who is spared actually finding redemption. Instead, Wormtongue, Gollum and Saruman all survive only to be killed by other means (in the case of Gollum and Wormtongue becoming instruments of grace in the process), and Frodo's further mercy to Wormtongue indirectly sparks a furious attack on Saruman that leads to both their deaths. Ultimately, the purest form of heroism in Middle-earth is one characterised not by classical victory in combat but by refusing to engage in combat, and thus allowing evil to destroy itself. 
Perhaps most importantly, the end to Frodo's homecoming emphasises what has already been hinted at in Aragorn's: that if The Lord of the Rings is, like the Aeneid, an epic of the birth of a new age, it is also like the Aeneid an epic about the passing of the old world that preceded it. Although arrived at by very different means, Saruman's death faintly hints at the death of Turnus in that all three are depicted in terms of a departure of spirits: "a grey mist" (996-7) arises from Saruman's body and hovers until "out of the West came a cold wind, and it bent away, and with a sigh dissolved into nothing" (997), while Turnus' "limbs fell slack with chill, and with a moan/ his life, resentful, fled to Shades below" (12.1270-1). These lines not only echo Turnus' destruction, but also the defeat of the Amazon warrior Camilla (11.1102), uniting the three characters as relics of the old world that must be displaced to make way for the new social order. Saruman's death, like that of Turnus, is "a nasty end" (997), but it simultaneously signifies "the very last end of the War" (997), allowing the hobbits like the Trojans to begin rebuilding that which they have lost. For Virgil, the loss of these doomed figures is simultaneously necessary yet regretted, with Turnus like Camilla glorified for his "handsome youth and form, / ... royal ancestors, and ... / those bright deeds that his right hand has done" (7.625-627). In Tolkien, however, for whom there is very little admirable about enemy figures such as Sauron, Saruman and Gollum, this takes a slightly different form, where the birth of a new age "more fair" (947) than any that have come before it requires the inevitable sacrifice of not only that which is unambiguously evil, but also that which is unambiguously good yet whose time is now past. As a result, the end of the book also sees the departure of the elves and Gandalf over the seas, "for the Third Age was over, and the Days of the Rings were passed, and an end was come of the story and song of those times" (1006).

Moreover, as in the Aeneid the new world is not only forged at the expense of the old, but at the willing expense of the hero who brings it about. Like Aeneas, who surrenders his potential future happiness in Carthage so that his "own heir" (4.68) Ascanius will have the "realm of Italy and the land of Rome" (4.369), Frodo finds he must "lose [the Shire] so others may keep it" (1006) and departs with the ship into the West after naming Sam his heir and leaving him "all that [he] had and might have had" (1006). In a condensed version of the parade of descendants Aeneas sees in the Underworld, Frodo predicts for Sam a future populated with "Rose, and Elanor, and Frodo-lad will come, and Rosie-lass, and Merry, and Goldilocks, and Pippin; and perhaps more that I cannot see ... You will be Mayor, of course, as long as you want to be, and the most famous gardener in history" (1006). Frodo, however, cannot be part of this new world because he has been "too deeply hurt" (1006) by the old, and instead chooses what is essentially a different version of the spiritual departure of Turnus and Saruman as he passes away to "white shores and beyond them a far green country under a swift sunrise" (1007). The idea of war leaving physical and emotional wounds that "never really heal" (1002) is non-classical, likely owing to Tolkien's war experience and echoing the difficulty in adjusting to peace after prolonged exposure to battle experienced by returning soldiers of the two World Wars. 
The idea of personal sacrifice for the good of others, however, is essential to both Virgilian and Christian heroism, and is embodied by Frodo's departure from the Shire he has saved at the cost of his own ability to enjoy it. In his wake, Middle-earth passes into the "Dominion of Men" (950), and by implication the beginning of our own modern, non-epic world. 


\section{CONCLUSION}

It is undeniable that Tolkien's primary influences were Northern rather than classical, drawing extensively on Anglo-Saxon, Norse and Celtic traditions to create an entirely new mythology. The contents of what Tolkien referred to as the "soup" of the story (On Fairy-Stories 120) are however far more varied than this, and The Lord of the Rings can be read a celebration of classical epic just as it is a celebration of folk tale, fairy story and heroic myth. Its heroes and heroines draw at least in part on the iconography and motifs associated with specific and general classical figures, in ways that are almost certainly expected to be recognised as markers of heroism by the readers. Its world is one that operates at least in part according to classical rules of peace and war, with the ritualised manner in which hospitality and battle are treated by both Tolkien and the characters themselves providing signifiers of correct social behaviour. Most importantly, its treatment of the defeat of Sauron and Aragorn's restoration to his prophesised throne is one that glorifies heroes and heroic deeds, and despite its fictional setting shares with classical epic a belief that "the real life of men is of that mythic and heroic quality" (Lewis 14).

The Lord of the Rings' relationship to epic is far more complex than this, however, not only employing these heroic and epic conventions but also subverting or superseding them as Tolkien engages with the problems of classical motifs within a very different universe. While The Hobbit moves from folk tale to epic and back again, The Lord of the Rings moves from folk-tale to epic to somewhere "beyond the epic" (Flieger 145), and as the book draws to its elegiac conclusion pure classical values become increasingly supplanted by the book's own heroic code, influenced by many heroic traditions and overwhelmingly by Tolkien's Catholic beliefs. Though the Homeric and Virgilian aspects of Aragorn's heroism remain, they are tempered with the medieval and Christian attributes of healing and mercy that characterise his homecoming, while other characters such as Eowyn cast aside the classical connotations of their personality entirely as Middle-earth enters the Fourth Age. In the end, the book's final model of heroism is not that provided by Aragorn, who like Homer's Odysseus is rewarded for his courage by gaining the status his birth affords him and the stable household he deserves, but the Christian model of self-sacrifice provided by Frodo. While Frodo's deeds are sung of in Gondor, he does not receive the glory traditionally sought by classical epic heroes once within the Shire (Sam is "pained to notice how little honour [Frodo] had in his own country" (1002)), and his reward is not a return to his rightful place but the opportunity to see those he loves installed in their rightful places before embarking upon another voyage to symbolic death. This ending, however, is not a rejection of classical heroism anymore than it is a rejection of folk tale or chivalric heroism. Instead, Gondor under Aragorn becomes a city that "after the ending of the Third Age of the world into the new age ... preserved the memory and the glory of the years that were gone" (947), reflecting an ideal balance not only between past and present but between the different cultural and generic influences on the book. Pure epic inevitably passes (as does pure folk tale), but what can be kept is kept, and 
what cannot be is remembered.

In this, Tolkien echoes not Homer so much as Virgil, whose epic also gradually moves away from traditional values to a new heroic code not dissimilar to Christian virtues. Reckford argues that the similarity between, and the strength of, Virgil and Tolkien is that both balance the glorification of "virtues and achievements against the 'tears of things,' the accumulated loss and sadness of men and women who live, suffer, and die upon this middle-earth" ("Review" 176), and indeed both the Aeneid and The Lord of the Rings are ultimately stories of the birth of a new world from the heroism and sacrifice of the old. The attitudes of both authors, however, are subtly different. For Virgil, there is horror and regret in what must be sacrificed for a new age even as he is writing to glorify this new age, and the foundation of the Roman Empire is haunted by images of Troy in ruins, "the walls of Carthage glow[ing]/ with sad Elissa's flames" (4.4-5), and the lives of Camilla and Turnus "resentful, fl[ying] to Shades below" (12.1270). In The Lord of the Rings, however, the regret for what has been lost is equally keen but without such resentment: while the evil of the old world is defeated, the good passes away naturally and voluntarily with the "tide of Time" (356), leaving those remaining with "a sadness that was yet blessed and without bitterness" (1006). If both Virgil and Tolkien are largely concerned with "tears for passing things" (Aen. 1.655), in The Lord of the Rings "not all tears are an evil" (1007). It is notable that while the lliad and Beowulf end with the funerals of their heroes, and the Aeneid, for all its talk of a new age, ends ambiguously with Aeneas reverting to his old heroic code and killing Turnus, Tolkien moves past the departure of Frodo and ends with Sam's return home to very non-epic domestic peace, in which he can "keep alive the memory of the age that is gone, so that people will remember the Great Danger and so love their beloved land all the more" (1006). For Tolkien, the present is made more, not less, "beloved" (1006) by what has been sacrificed to bring it about.

Ultimately, if The Lord of the Rings is an epic, it is an epic about the passing of epic. "The deeds and destinies of great heroes" (Griffin 13) both classical and otherwise are remembered and glorified as in Homer and Virgil, and their sacrifice enables the world to move into an age that, while not our own, is nonetheless very recognisable to us. In this, it can be seen as providing a form of Virgilian etiological myth for a society that no longer believes in etiological myths, and thus a heroic code for an age that is not itself heroic. According to Tillyard, one of the main qualifications for an epic writer is the ability to "express the feelings of a large group of people living in or near his own time" (12), and the enduring popularity of The Lord of the Rings seems to supplement W.H. Auden's claim that "If there is any Quest Tale which ... manages to do more justice to our experience of social-historical realities than The Lord of the Rings, I should be glad to hear of it" (51). 


\section{Bibliography}

All translations from the Aeneid are Allen Mandelbaum's, and from the lliad and the Odyssey are Richmond Lattimore's, unless otherwise stated.

Auden, W.H. "The Quest Hero." Understanding the Lord of the Rings: The Best of Tolkien Criticism. Eds. Rose A. Zimbardo and Neil D. Isaacs. Boston: Houghton Mifflin. 2004. pp 31-51. Print.

Beowulf: A Student Edition. Ed. George Jack. Oxford: Oxford University Press. 1994. Print.

Bradley, Marion Zimmer. "Men, Halflings and Hero Worship." Understanding the Lord of the Rings: The Best of Tolkien Criticism. Eds. Rose A. Zimbardo and Neil D. Isaacs. Boston: Houghton Mifflin. 2004. pp 76-92. Print.

Burns, Marjorie. Perilous Realms: Celtic and Norse in Tolkien's Middle-earth. Toronto: University of Toronto Press. 2005. Print.

Chance, Jane. "The Lord of the Rings: Tolkien's Epic." Understanding the Lord of the Rings: The Best of Tolkien Criticism. Eds. Rose A. Zimbardo and Neil D. Isaacs. Boston: Houghton Mifflin. 2004. pp 195-232. Print.

Duriez, Colin. J.R.R. Tolkien and C.S. Lewis: The Story of their Friendship. UK: Sutton Publishing. 2003. Print.

Eliot, T.S. "Vergil and the Christian World." The Sewanee Review, Vol. 61, No. 1 (1953). pp. 1-14. Online.

Fenik, Bernard. Typical Battle Scenes in the lliad. Germany: F. Steiner, Weisbaden. 1968. Print.

Flieger, Verlyn. "Frodo and Aragorn: The Concept of a Hero." Understanding the Lord of the Rings: The Best of Tolkien Criticism. Eds. Rose A. Zimbardo and Neil D. Isaacs. Boston: Houghton Mifflin. 2004. pp 122-145. Print.

Frye, Northrop. Anatomy of Criticism. UK: Penguin Books Ltd. 1990. Print.

Fuller, Edmund. "The Lord of the Hobbits: J.R.R. Tolkien." Understanding the Lord of the Rings: The Best of Tolkien Criticism. Eds. Rose A. Zimbardo and Neil D. Isaacs. Boston: Houghton Mifflin. 2004. pp 16-30. Print. 
Griffin, Jasper. "Greek Epic." The Cambridge Companion to Epic. Ed. Catherine Bates, Cambridge University Press. 2010. Print.

Isaacs, Neil D. "On the Pleasures of (Reading and Writing) Tolkien Criticism." Understanding the Lord of the Rings: The Best of Tolkien Criticism. Eds. Rose A. Zimbardo and Neil D. Isaacs. Boston: Houghton Mifflin, 2004. pp 1-10. Print.

Hershkowitz, Debra. The Madness of Epic: Reading Insanity from Homer to Statius. Oxford: Clarendon Press; New York: Oxford University Press. 1998. Print.

Homer. The lliad of Homer. Trans. Richmond Lattimore. Chicago: University of Chicago Press. 1951. Print.

Homer. The Odyssey of Homer. Trans. Richmond Lattimore. Perennial Classics. 1999. Print.

Homer. The Odyssey. Trans. E.V. Rieu. Norwich: Book Club Associates. 1973. Print.

Jackson, W.T.H. The Hero and the King: An Epic Theme. New York: Columbia University Press. 1982. Print.

Jenkyns, Richard. Homer and Virgil. London: Bristol Classical Press. 1992. Print.

Kocher, Paul. "Middle-earth: An Imaginary World?" Understanding the Lord of the Rings: The Best of Tolkien Criticism. Eds. Rose A. Zimbardo and Neil D. Isaacs. Boston: Houghton Mifflin. 2004. Print.

Libran-Moreno, Miryam. "Greek and Latin Amatory Motifs in Eowyn's Portrayal." Tolkien Studies, Vol. 4. (2007). pp 73-97. Online.

Lewis, C.S. "The Dethronement of Power." Understanding the Lord of the Rings: The Best of Tolkien Criticism. Eds. Rose A. Zimbardo and Neil D. Isaacs. Boston: Houghton Mifflin. 2004. pp 11-15. Print.

Martin, Richard P. "Epic as Genre." A Companion to Ancient Epic. Ed. John Miles Foley, Blackwell Publishing. 2005. Print.

Merchant, Paul. The Epic. London: Methuen and Co. Ltd. 1971. Print.

Morse, Robert E. Evocation of Virgil in Tolkien's Art: Geritol for the Classics. Illinois: Bolchazy-Carducci 
Publishers, 1986. Print.

Murnaghan, Sheila. Disguise and Recognition in the Odyssey. New Jersey: Princeton University Press. 1987. Print.

Neville, Jennifer. "Women." Reading The Lord of the Rings: New Writings on Tolkien's Classic. Ed. Robert Eaglestone. London, New York: Continuum. 2005. pp 101-110. Print.

Obertino, James. "Moria and Hades: Underworld Journeys in Tolkien and Virgil." Comparative Literature Studies, Vol. 30, No. 2 (1993), pp. 153-169. Online.

Peretti, Daniel. "The Ogre Blinded and The Lord of the Rings." Mythlore. Volume 25, Issue 97 (Spring 2007). pp 133-145. Online.

Purtill, Richard L. J.R.R. Tolkien: Myth, Morality, and Religion. San Fransisco: Harper and Row. 1984. Print.

Rateliff, John D. The History of The Hobbit Part Two: Return to Bag End. London: HarperCollins. 2008. Print.

Reckford, Kenneth J. Review of Evocations of Virgil in Tolkien's Art: Geritol for the Classics by Robert E. Morse. The Classical Journal, Vol. 84, No. 2. (Dec. 1988 - Jan. 1989). pp. 174-176. Online.

Reckford, Kenneth J. "Some Trees in Virgil and Tolkien." Perspectives of Roman Poetry: A Classics Symposium. Texas: University of Texas Press. 1974. Print.

Reece, Steve. The Stranger's Welcome: Oral Theory and the Aesthetics of the Hospitality Scene. University of Michigan Press. 1993. Print.

Reichl, Karl. "Heroic Epic Poetry in the Middle Ages." The Cambridge Companion to Epic. Ed. Catherine Bates, Cambridge University Press 2010. Print.

Reilly, R.J. "Tolkien and the Fairy Story." Understanding the Lord of the Rings: The Best of Tolkien Criticism. Eds. Rose A. Zimbardo and Neil D. Isaacs. Boston: Houghton Mifflin, 2004. pp 93-105. Print.

Rosebury, Brian. Tolkien: A Cultural Phenomenon. New York: Palgrave Macmillan. 2003. Print. 
Stanford, W.B. The Ulysses Theme. Oxford: Basil Blackwell and Mott Ltd 1963. Print.

Stewart, Douglas J. The Disguised Guest: Rank, Role and Identity in the Odyssey. Lewisburg: Bucknell University Press, 1976. Print.

Tillyard, E.M.W. The English Epic and Its Background. London: Chatto and Windus Ltd. 1954. Print.

Tolkien, J.R.R. "Beowulf: The Monsters and the Critics." The Monsters and the Critics and Other Essays. Ed. Christopher Tolkien. London: George Allen \& Unwin Ltd. 1983. Print.

Tolkien, J.R.R. "On Fairy-Stories." The Monsters and the Critics and Other Essays. Ed. Christopher Tolkien. London: George Allen \& Unwin Ltd. 1983. pp 109-161. Print.

Tolkien, J.R.R. The Hobbit. London: George Allen \& Unwin Ltd. 1966. Print.

Tolkien, J.R.R. The Letters of J.R.R. Tolkien. London, Boston: Allen \& Unwin. 1981. Print.

Tolkien, J.R.R. The Lord of the Rings. HarperCollins. 1995. Print.

Toohey, Peter. "Roman Epic." The Cambridge Companion to Epic. Ed. Catherine Bates, Cambridge University Press 2010. Print.

Virgil. The Aeneid of Virgil. Trans. Allen Mandelbaum. University of California Press. 2007. Print.

Virgil. Virgil's Aeneid. Trans. John Dryden. Ed. Frederick M. Keener. Penguin Classics 1997. Print.

Zimbardo, Rose A. "Moral Vision in The Lord of the Rings." Understanding the Lord of the Rings: The Best of Tolkien Criticism. Eds. Rose A. Zimbardo and Neil D. Isaacs. Boston: Houghton Mifflin, 2004. pp 68-75. Print. 